\title{
MODELLING WORKLOAD TO QUALITY USING SYSTEM DYNAMICS IN MANUFACTURING AND HEALTHCARE
}

\author{
By \\ Mashal Farid \\ B. Eng., Ryerson University, Canada, 2014
}

\begin{abstract}
A thesis
presented to Ryerson University

in partial fulfillment of the

requirements for the degree of

Master of Applied Science

in the program of

Mechanical and Industrial Engineering
\end{abstract}

Toronto, Ontario, Canada, 2017

(C) Mashal Farid, 2017 


\section{AUTHOR'S DECLARATION FOR ELECTRONIC SUBMISSION OF A THESIS}

I hereby declare that I am the sole author of this thesis. This is a true copy of the thesis, including any required final revisions, as accepted by my examiners.

I authorize Ryerson University to lend this thesis to other institutions or individuals for the purpose of scholarly research.

I further authorize Ryerson University to reproduce this thesis by photocopying or by other means, in total or in part, at the request of other institutions or individuals for the purpose of scholarly research.

I understand that my thesis may be made electronically available to the public. 


\begin{abstract}
MODELLING WORKLOAD TO QUALITY USING SYSTEM DYNAMICS IN MANUFACTURING AND HEALTHCARE
\end{abstract}

\author{
Mashal Farid \\ Master of Applied Science \\ 2017 \\ Mechanical and Industrial Engineering \\ Ryerson University
}

This paper presents an approach using System Dynamics (SD) to model long-run effects of given workload levels on employee health and quality of the system output. The models integrate scientific evidence on injury and burnout risk factors, error making probabilities, and presenteeism phenomena to create two SD models - one for a manufacturing assembly line and the other for a hospital nursing unit - that can help users explore the ergonomics-system performance relationship. The manufacturing model results show an increase in injury rates and a decrease in yield as the operators are exposed to higher spinal loads. The nursing model results show an increase in nurse burnout and medical errors as nursing workload is increased. This demonstration reveals the feasibility of SD modeling to help managers and engineers explore the long-run consequences of the human factors in their operations system design and inform policy decisions in terms of both human health and system performance outcomes. 


\section{ACKNOWLEDGEMENTS}

I would like to thank Dr. Patrick Neumann for his continuous support throughout this journey, for being available to answer any question, curiosity or doubt I had, and for helping me grow in my research, and as a person. I would not have been able to come this far without your encouragement and guidance.

I would also like to thank Dr. Nancy Purdy for her help and support through a major part of my research. Thank you for welcoming my questions and lending your time and expertise to this research.

A special thank members of the HFE lab, those I was fortunate enough to meet in the past and work with at present. Your stories brought color to my days and your kind words lent me the support I needed to keep moving when times were tough.

Thank you to Dr. Salustri, and Dr. Searcy for supporting and guiding me at the start of my research.

And lastly and perhaps most importantly, a huge thanks to my family, without whose support and encouragement at every step, I would not be where I am today. 


\section{Table of Contents}

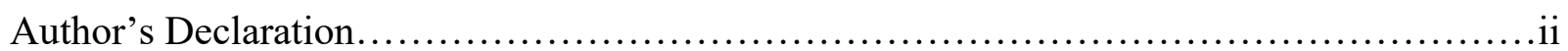

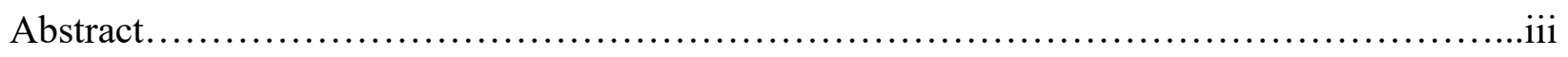

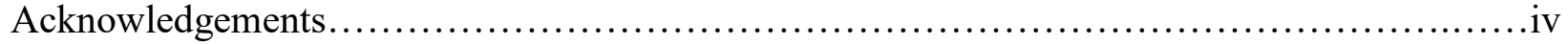

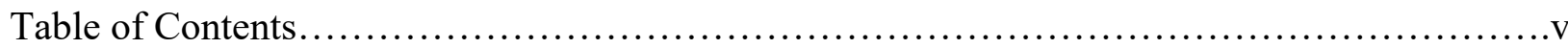

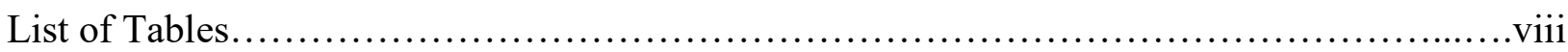

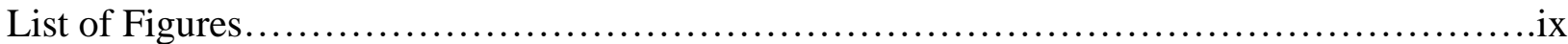

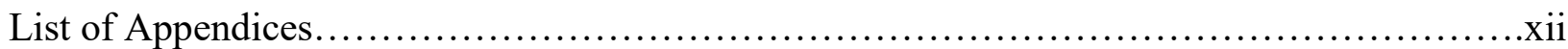

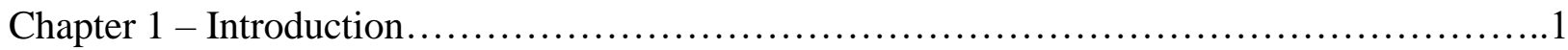

1.1 Burden of WIH and MSDs......................................................

1.2 Need for SD Models in HF....................................................

1.3 System Dynamics (SD) Modeling ..............................................

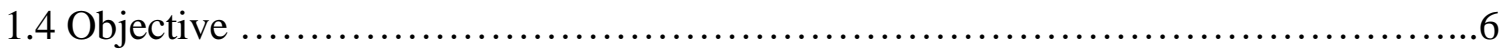

1.5 Organization of the Thesis......................................................... 6

Chapter 2 - A SD Model Linking HF Risk Factors to Health and Performance in

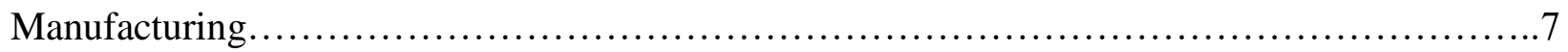

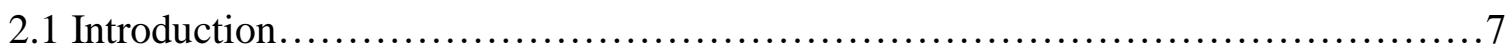

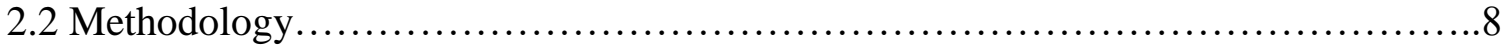

2.2.1 Model Assumptions.............................................. 9

2.2.2 Model Framework........................................................ 9

2.2.3 Causal Loop Diagram (CLD) .....................................10

2.2.4 Simulation Model......................................................12

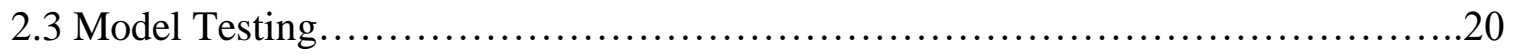

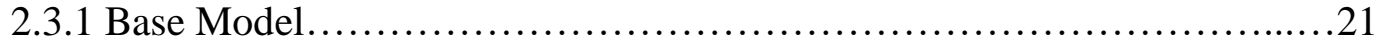

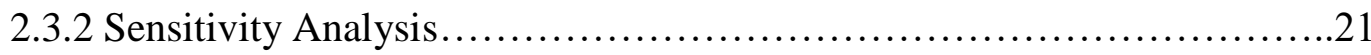

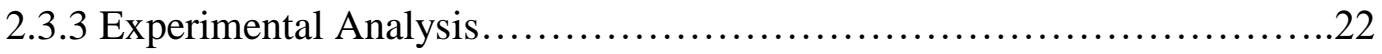

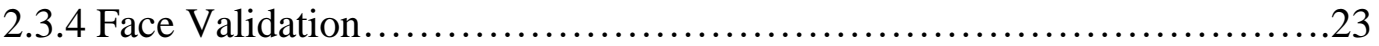

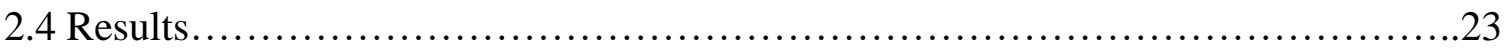




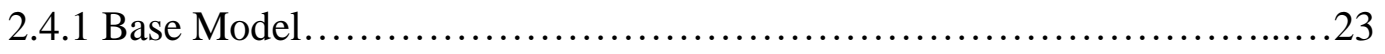

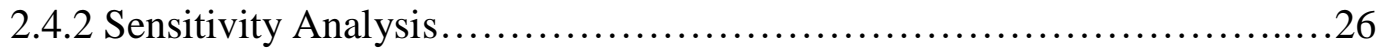

2.4.3 Experimental Analysis............................................. 31

2.4.4 Face Validation..................................................... 37

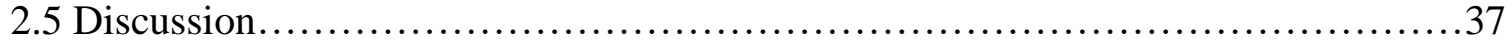

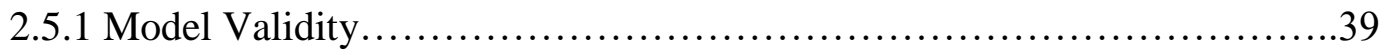

2.5.2 Mangers' Perspectives...............................................40

2.5.3 Future Work......................................................

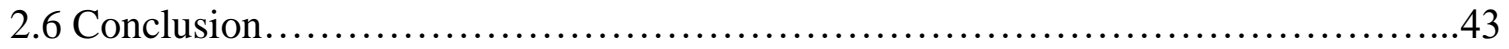

Chapter 3 - A SD Model Linking HF Risk Factors to Health and Performance in

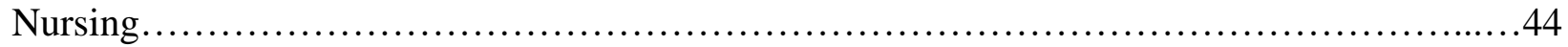

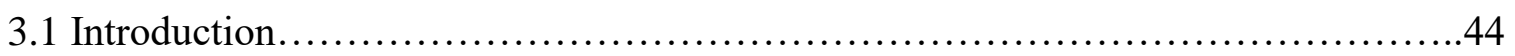

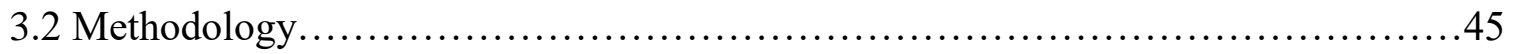

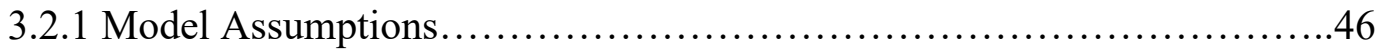

3.2.2 Model Framework...................................................46

3.2.3 Causal Loop Diagram (CLD) …...................................4

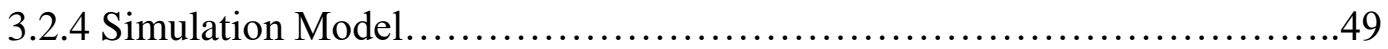

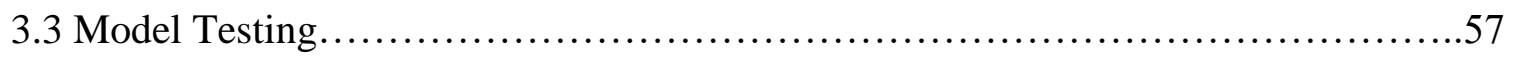

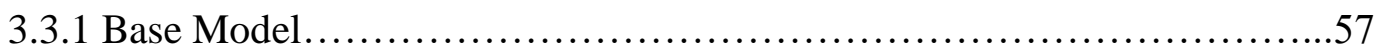

3.3.2 Sensitivity Analysis.................................................5

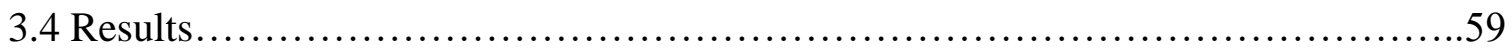

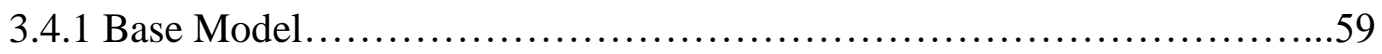

3.4.2 Sensitivity Analysis..................................................61

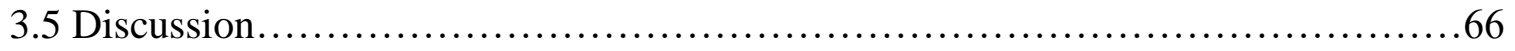

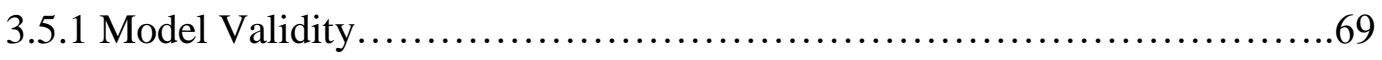

3.5.2 Modeling Challenges............................................. 71

3.5.3 Future Work........................................................ 71

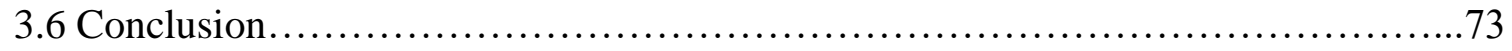

Chapter 4 - General Discussion..................................................... 74 


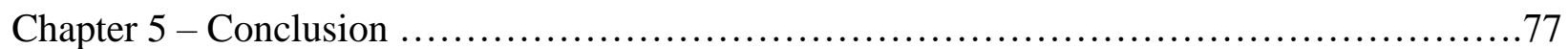

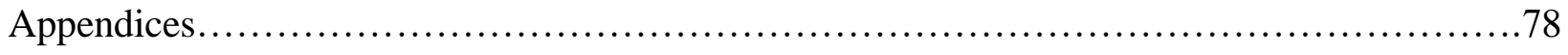

References.................................................................... 100 


\section{List of Tables}

Table 1. Manufacturing Model Parameters and their definitions........................... 19

Table 2. Parameter Values Used in Base Manufacturing Model.............................21

Table 3. Manufacturing Model Parameter Values Used in Sensitivity Analysis (Values in bold

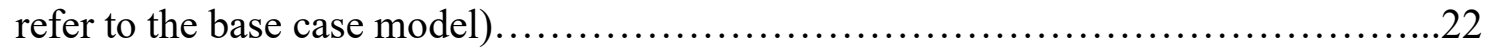

Table 4. Definitions for Healthcare Model Parameters......................................56

Table 5. Model parameter values for the Base Healthcare Model............................57

Table 6. Healthcare Model Parameter Values Used in Sensitivity Analysis (Values in bold refer

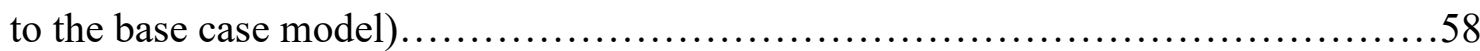




\section{List of Figures}

Figure 1. The Modeling Building Process followed in this thesis $\ldots \ldots \ldots \ldots \ldots \ldots \ldots \ldots \ldots \ldots \ldots$

Figure 2. Model framework showing the underlying model logic......................... 10

Figure 3. Causal Loop Diagram showing the linkages between various factors within a

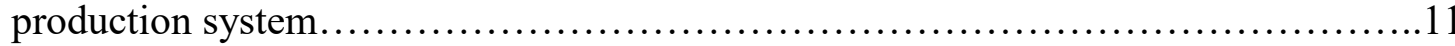

Figure 4. Simulation model divided into risk factors, human effects and system effects........12

Figure 5. Risk Factors section of the model illustrating the link between risk factors and the odds

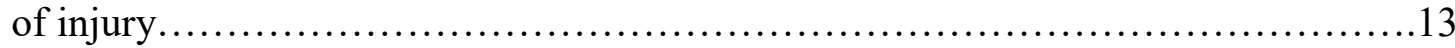

Figure 6. Human Effects section of the model illustrating the link between the odds of injury and

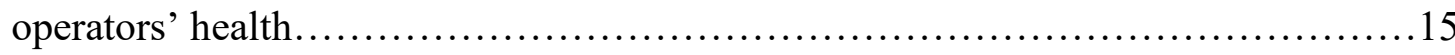

Figure 7. System Effects section of the model illustrating the link between the odds of injury, health of operators, and the system output.................................... 17

Figure 8. Time-series graphs for Fraction Reporting Pain (fRP) and Human Error Probability (HEP) for base model.................................................. 24

Figure 9. Time-series graphs for Fraction Reporting Pain (fRP) and Production Rate for base model.

Figure 10. Time-series graphs for Fraction Reporting Pain (fRP) and Rework Rate for base case

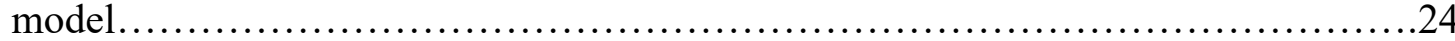

Figure 11. Time-series graph showing changes in Fraction Reporting Pain over one week......25

Figure 12. Fraction Reporting Pain (fRP) and Yield Rate at the end of Year 1 for Varying Machine Time.

Figure 13. Fraction Reporting Pain (fRP) and Yield Rate at the end of Year 1 for Varying Peak Hand Load. .27

Figure 14. Fraction Reporting Pain (fRP) and Yield Rate at the end of Year 1 for Varying Shift Length....

Figure 15. Fraction Reporting Pain (fRP) and Yield Rate at the end of Year 1 for Varying Spinal Load (Working) .28

Figure 16. Fraction Reporting Pain (fRP) and Yield Rate at the end of Year 1 for Varying Takt Time. .28

Figure 17. Fraction Reporting Pain (fRP) at the end of Year 1 for Varying Risk Factor exposures 
Figure 18. Human Error Probability (HEP) at the end of Year 1 for Varying Risk Factor

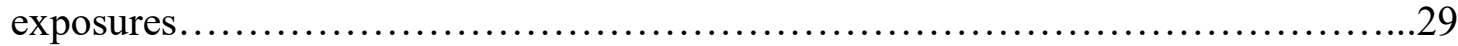

Figure 19. Production Rate at the end of Year 1 for Varying Risk Factor exposures............29

Figure 20. Rework Rate at the end of Year 1 for Varying Risk Factor exposures...............30

Figure 21. Time-series graph with varying Peak Hand Loads for (A) Fraction Reporting Pain (fRP); (B) Human Error Probability (HEP); (C) Production Rate; and, (D) Rework

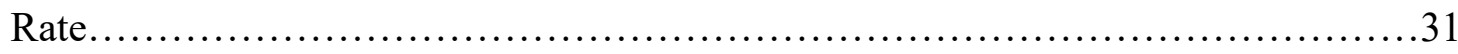

Figure 22. 1-D graphs of the experimental analysis, showing Fraction Reporting Pain (fRP) for varying shift length, spinal load, and peak hand load. ...

Figure 23. 1-D graphs of the experimental analysis, showing Human Error Probability (HEP) for varying shift length, spinal load, and peak hand load 32

Figure 24. 1-D graphs of the experimental analysis, showing Production Rate for varying shift length, spinal load, and peak hand load 32

Figure 25. 1-D graphs of the experimental analysis, showing Rework Rate for varying shift length, spinal load, and peak hand load .33

Figure 26. 3-D graphs of the experimental analysis, showing Fraction Reporting Pain for varying (A) shift length and peak hand load; (B) spinal load and peak hand load; and (C) shift length and spinal load .34

Figure 27. Fraction Reporting Pain (fRP) plotted against Shift Length, Spinal Load, and Peak

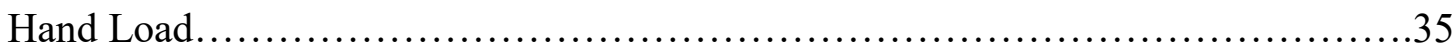

Figure 28. Human Error Probability (HEP) plotted against Shift Length, Spinal Load, and Peak Hand Load.

Figure 29. Production Rate plotted against Shift Length, Spinal Load, and Peak Hand Load. .36

Figure 30. Rework Rate (right hand bar) plotted against Shift Length, Spinal Load, and Peak Hand Load.......................................................... 36

Figure 31. Model Framework showing the logic used to build the model.

Figure 32. Causal Loop Diagram showing the links between HF and quality of care in nursing. 
Figure 33. Healthcare simulation model, divided into risk factors, human effects and system effects.

Figure 34. Risk factors section of the model illustrating the link between risk factors and workload.

Figure 35. Health Effect section of the model illustrating the link between workload and burnout. ...

Figure 36. System Effects section of the model illustrating the link between burnout and medical errors. .55

Figure 37. Time-series graph showing changes in Fatigue level over one week .59

Figure 38. Fatigue with the Percentage of Total Nurses who are Burnt-Out and Absent for the 4week simulation period.

Figure 39. The number of Medical Errors with Burnout for the 4-week simulation period.

Figure 40. Peak values for Fatigue, Percentage Burnout, Percentage Absent and Medical Errors (A); and Peak Fatigue and Residual Fatigue (B) as NPR Limited by Budget is varied

Figure 41. Peak values for Fatigue, Percentage Burnout, Percentage Absent and Medical Errors

(A); and Peak Fatigue and Residual Fatigue (B) as Shift Length is varied... .63

Figure 42. Peak values for Fatigue, Percentage Burnout, Percentage Absent and Medical Errors (A); and Peak Fatigue and Residual Fatigue (B) as Number of Working Days Per Week is varied .64

Figure 43. Peak values for Fatigue, Percentage Burnout, Percentage Absent and Medical Errors as the Fractional Rate of Absence is varied (A); Time-series graph with varying Fractional Rate of Absence for Medical Errors (B) .65

Figure 44. Peak values for Fatigue, Percentage Burnout, Percentage Absent and Medical Errors as the Time Off Work is varied (A); Time-series graph with varying Fractional Rate of Absence for Medical Errors (B) .66 


\section{List of Appendices}

Appendix A: Calculation of the Constant $\alpha_{0}$ for the Regression Model in the Manufacturing

Model........................................................... 78

Appendix B: Manufacturing Model Documentation.................................... 79

Appendix C: Results of Sensitivity Analysis for the Manufacturing Model...................84

Appendix D: Results of Experimental Analysis for the Manufacturing Model................89

Appendix E: Healthcare Model Documentation....................................93

Appendix F: Results of Sensitivity Analysis for the Healthcare Model......................97 


\section{Chapter 1 - Introduction}

In today's world of global marketing, companies face intense competitive pressure, making it essential to differentiate one's product or service from others. One of the top strategies used to compete on the market is through higher quality and lower cost products and services. The last few decades have therefore seen changes in the product and process design, with strategies and interventions such as total quality management and lean being applied at large to create efficient systems that provide higher quality outputs (Tan, Kannan, Handfield, \& Ghosh, 2000). While in most industries, the need for higher quality is driven by the demand of the end-user, others, like healthcare, inherently demand high quality. In healthcare, a low quality, inefficient system does not only mean an unsatisfied customer, but rather it directly affects the quality of life and mortality of its patients. Regardless of the industry, quality acts as one of the main strategic goals of a company. This thesis contains an exploration of a modeling technique to highlight the Human Factors aspects that influence the quality of a product within a manufacturing company, and quality of patient care within a healthcare unit.

Human Factors (HF) is an important contributor to a company's quality. The International Ergonomics Association defines ergonomics (or Human Factors) as (IEA, 2016):

"the scientific discipline concerned with the understanding of interactions among humans and other elements of a system, ... in order to optimize human well-being and overall system performance."

Hence, HF includes all factors that can affect an individual, their health, and their ability to perform their job. The literature includes numerous case studies that show HF interventions resulting in improved quality. On the other hand, lack of HF design results in poor work environments and degraded quality (Neumann \& Dul, 2010). Kolus et. al (2014) reviewed studies associated with quality risk factors, and found that low work performance and human errors were the main reasons for poor quality. Zare et. al (2016) performed a similar review study with a focus on the automotive industry, showing a direct impact of injury risk factors on the quality outcomes. Various healthcare and nursing studies also directly link HF to medical errors and patient safety (Carayon et al., 2014; Holden et al., 2007). Some of the above studies look at 
the direct link between injury risk factors and the resulting quality effects (Neumann, Kolus, \& Wells, 2016); others propose fatigue and employee health as a mediator between the two (Zare et al., 2016). Whichever pathway one chooses to accept, research supports that HF affects quality outcomes. The current study will use simulation modeling to explore how HF influences quality in both a product-based manufacturing industry and a service-based healthcare industry.

Despite research showing the effect of HF on these strategic goals, HF is given little consideration by managers and often ignored during the design stage (Neumann \& Village, 2012). Managers are often unaware of the importance of HF in achieving their strategic goals. As a result, most $\mathrm{HF}$ related issues and concerns are not considered during design, but raised through problems and complaints regarding the working environment (Jensen, 2002). At this stage, changes are often expensive and difficult, while being less effective (Taylor, Hignett, \& Joseph, 2014). The late application of HF makes it appear time consuming and costly, and reinforces the manager's misconception of $\mathrm{HF}$ as a health and safety (H\&S) tool that has minimal influence on organization effectiveness (Dul \& Neumann, 2009). Thus, it becomes necessary to find ways that can dispel this misconception regarding HF for managers, designers and others involved in the design of work systems. This thesis will introduce a modeling technique called System Dynamics (SD) as a tool that can help understand the true potential of including $\mathrm{HF}$ in design.

HF needs top management support for it to be included in the design of products, processes and work systems (Ingelgård \& Norrgren, 2001). One of main barriers preventing managers from recognizing the true potential of HF is the separation of HF and operations management. The literature related to $\mathrm{HF}$ content is neither readily available to operations managers, nor read by them often (Neumann \& Dul, 2010). If we can clearly show HF's contribution to the company's quality goals in a language managers understand, managers are likely to be more receptive and support HF integration in the organization, helping it reach its full potential (Dul et al., 2012). Thus, there is a need for tools that can clearly show the contribution of HF to a company's strategic goals. The current study explores SD modeling technique as a tool that can highlight the links between HF and quality in a way that helps managers understand the true nature of HF contributions to their company's quality goals. 


\subsection{Burden of WIH and MSDs}

While integrating HF into design improves quality, excluding HF from the design of work systems can lead to health and financial burdens not only for the company, but also for society at large. One of the direct impacts of poor work environments is work-related ill health (WIH) and injuries among workers. In 2013, 16\% of Canadians between the ages of 15 and 74 sustained injuries, of which $14.5 \%$ reported their most serious injury taking place at work (Statistics Canada, 2015). Statistics from AWCBC show that in 2014, there were 239,643 cases of lost time injuries with 919 fatalities at work (AWCBC, 2014). Of these injuries, OHSCO describes musculoskeletal disorders (MSDs) as the most reported lost-time claim (OHSCO, 2006). A 2011 survey study conducted in Québec by Vézina et al. (2011) estimated that 1 in every 5 workers have work-related MSD injury. Manufacturing and healthcare industries are among the employment industries that require the most WSIB coverage (WSIB, 2015). Data from the U.S. Bureau of Labor Statistics shows the rate of overexertion injuries to be 37.7/10,000 full-time workers for manufacturing and 48.7/10,000 full-time workers for healthcare and social assistance in 2014 (Bureau of Labor Statistics, 2014). Risk factors in the work environment of a company can pose health risks for its employees and workers (National Research Council, 2001).

MSDs not only cause pain and injury for the worker but also lead to costs of million of dollars to Ontario workplaces due to worker absences and loss of productivity (OHSCO, 2006). The combined direct and indirect costs for MSDs from 1996-2006 are conservatively estimated to be \$19 billion (Infrastructure Health and Safety Organization, n.d.), with cost estimates for 2007 showing that the cost of MSD injuries is at the same level as all cancers combined (Leigh, 2011). Work-related injuries not only result in direct costs, such as sick-leave wages and insurance cost, which can be easily calculated; but also the indirect costs that are difficult to account for (Rose, Orrenius, \& Neumann, 2013). Employees suffering from WIH or injuries perform below their optimal level (McDonald, DiBonaventura, \& Ullman, 2011). This results in quality and productivity losses that lead to indirect costs. Factors that contribute to WIH indirect costs include presenteeism (employees working with reduced capacity due to illness or injury; (Johns, 2010)), and employee turnover, resulting in recruitment and training of new employees. Research shows that direct costs form only a small part of the total costs related to WIH and poor work environments, while the majority of the costs result from the above-described indirect costs 
(Rose et al., 2013). These indirect costs are often difficult to measure and are excluded from most calculations of MSD costs. Modeling may provide a way to bring these hidden costs to light. This thesis will use simulation modeling to link both the health effects and the system outputs to the HF-related risk factors in order to show a more comprehensive picture of the effect of HF on the quality and productivity within an organization.

\subsection{Need for SD Models in HF}

Modeling tools have previously been used to highlight and address specific aspects of HF related to injury and performance. Modeling tools that integrate HF provide cost-effective solutions as they can show the effects of design factors without the need to test them in a physical system. An example would be the studies by Neumann and Medbo $(2009 ; 2016)$ that integrated HF into discrete-event simulation (DES) and used the model to study different production strategies. Perez et. al also used DES to predict workload exposures for an entire shift (Perez, de Looze, Bosch, \& Neumann, 2014). Other examples include math models that show the effects of job rotation on quality of product (Michalos, Makris, \& Chryssolouris, 2013); the effect of fatigue, learning and other factors on human error in a manufacturing assembly line (Di Pasquale, Miranda, Iannone, \& Riemma, 2015; Givi, Jaber, \& Neumann, 2015; Sobhani, 2014); effect of learning on order picking at a warehouse (Grosse \& Glock, 2015; Grosse, Glock, \& Jaber, 2013); and human behavior in a manufacturing system (Elkosantini \& Gien, 2009).

This study explores the use of a modeling technique called System Dynamics to highlight the relationship between HF-related risk factors, worker health and system outputs. System Dynamics (SD) has previously been used to solve problems at the organizational level in many different areas and industries, with a focus on problems related to policy decisions (Sterman, 2000). Examples of SD modeling include its use in understanding capacity problems with increasing work pressure (Repenning \& Sterman, 2002), decrease in quality that results from cutting corners (Oliva \& Sterman, 2001), and factors affecting quality improvement interventions (Sterman, Repenning, \& Kofman, 1997); exploring the effects of intangible factors such as stress and anxiety (Chapman, 1998; Morris, Ross, \& Ulieru, 2010; Rudolph \& Repenning, 2002); and as a hybrid with DES to create a model of the manufacturing system (Pastrana, Marin, Helal, \& Mendizabal, 2010). SD modeling has also been used to solve HF 
related issues; however, these HF-related SD models focus mainly on accident prevention and safety (Ajimotokan, 2011; Han, Saba, Lee, Mohamed, \& Peña-Mora, 2014; Shin, Lee, Park, Moon, \& Han, 2014). No SD models could be found that examined the effect of HF on quality and productivity. The current study explores a novel application of SD by using it to study the effect of HF-related risk factors on both the health of the employee and the quality performance of the system.

\subsection{System Dynamics (SD) Modeling}

SD modeling is based on systems thinking, the idea that a system cannot be understood entirely by studying it in parts (Vicente, 2004). Rather, to fully understand a system and its behavior, a system must be studied as a whole with its various feedbacks and delays (Sterman, 2000). The ability to model these feedbacks and time delays is what makes SD unique. Since no system is truly a one-directional process (start to finish), it is more realistic to allow feedbacks that can change the system based on its outcome. SD modeling also allows for non-linear time responses and time delays. When interacting with simple systems, the cause of a problem is often close in time and space to the problem itself. However, real-world interactions often consist of complex systems in which the cause of a problem is distant in time and space from its effect(s). An example of this would be the injury risk factors that do not result in immediate MSD injuries; rather, MSDs develop over time as the individual is repeatedly exposed to these risk factors (Kumar, 2001). As a result, it becomes essential to account for time delays between a process or a decision, and its resulting effects to identify and understand the actual causes to real-world problems. SD is able to model these feedbacks and time delays.

SD modeling consists of two types of conceptual mapping tools that can be converted into computer simulations (Sterman, 2000): causal loop diagrams (CLDs) and stock and flow maps. Causal loop diagrams, or CLDs, can be used at earlier stages of the modeling to create conceptual mind maps representations of individuals working closely with the system. These mind maps show the feedback dependency between factors within the system. The CLDs can then be converted into stock-and-flow maps, which are more structured representations of the system and closer to the layout of the simulation model. In SD terminology, a stock refers to an item that can accumulate over time, while a flow is the rate at which the stock/item accumulates. 
Once the stock-and-flow map is developed, the model can be built and simulated in a SD simulation software after adding quantitative factors and equations to model. In this thesis, a SD model will be developed that links design-related injury risk factors with workers' health and system performance using Vensim simulation software ("Vensim PLE Plus," n.d.).

\subsection{Objective}

The objective of this research study is to explore the use of System Dynamics (SD) modeling as a possible tool that can help understand the contribution of HF to the quality of a product within a manufacturing company and quality of care within a healthcare unit.

\subsection{Organization of the Thesis}

The next two chapters provide a description of the building and testing of a SD model to address the above objective in a product-based manufacturing industry (Chapter 2), and in a servicebased healthcare industry (Chapter 3). A modeling framework will be developed in each chapter that shows the underlying logic of the model; a conceptual CLD that describes the elements within the system and their inter-linkages; and a simulation model that shows the time-dependent behavior of the system in response to different model inputs. The simulation model will also be tested will various inputs to determine the effect of each model parameter on the behavior of the system. Chapter 4 will discuss the main lessons derived from such modeling, its limitations and future directions. Chapter 5 will summarize the main findings of this thesis study. 


\section{Chapter 2 - A SD Model Linking Risk Factors to Health and Quality in Manufacturing}

\subsection{Introduction}

The manufacturing industry has one of the highest number of lost time claims (AWCBC, 2014), with the majority of these claims resulting from musculoskeletal injuries. One of the main reasons for such workplace injuries is lack of HF in design (Neumann, Ekman, \& Winkel, 2009), which in itself is a result of the gap between Operations Management (OM) and HF (Neumann \& Dul, 2010). System Dynamics (SD) modeling is introduced as a tool that can span this gap and help managers, and others within the industry, understand the need for HF in the design of its products and processes in order to better achieve its strategic goals. SD modeling has previously been used to model problems related to human behavior, performance, and safety (Han et al., 2014; Shin et al., 2014). However, the novelty of this study lies not only in studying the combined effects of HF on health and performance using SD, but also in the application of this modeling technique as a tool that can facilitate managers' understanding of this issue. The development and testing of a SD model linking HF to the long-term productivity and quality performance within a production system is presented in this chapter.

Aim: The aim of this chapter is to explore the use of SD to show the effect of Low Back Pain (LBP) risk factors on operators' health, and long-term productivity and quality performance of a production system.

The study will also address the following specific research questions:

1. For the model based on average (base) values, what time-based trends are displayed by the model output?

2. How does each model parameter independently affect the model output?

3. How does the model output respond to an interaction of the risk factors? 
The rest of Chapter 2 is organized as follows: the model building process is described in Section 2.2 while the steps followed for model testing are described in section 2.3. The results of model testing are presented in Section 2.4, and discussed in Section 2.5.

\subsection{Methodology}

The modeling process used to build the current model has been previously used by other SD model projects (Sterman, 2000), where a problem to be explored by the model is defined, model boundaries are set, and factors to be included in the model are determined. For the current model, LBP injuries were chosen as the main focus of the model as these are one of the most common injuries seen among operators in a manufacturing environment (Garg et al., 2014). The development of the SD model involved multiple stages. First, a modeling framework was developed to outline the main logic of the model. Then, a conceptual causal-loop diagram (CLD) was built that showed the cause-and-effect links between various factors within the system, as well as the direction of causality. The CLD was developed by finding keywords in the literature related to the problem as well as the cause-and-effect links between these keywords (Eklund, 1997; Mateo, 2008; Neumann, Greig, Village, \& Wells, 2013; Rose et al., 2013). The next step was to translate the conceptual CLD into a simulation model. The variables within the CLD were operationalized either based on their definitions used previously in research studies, or based on structure and output of the production system (yield, rework, scrap etc.). For each of the links in the CLD, literature was searched to find quantitative relationships or empirical data; where data was unavailable or difficult to find, estimates by the research team and industrial mangers had to be used instead. For the manufacturing model, we met with two managers in a production plant,

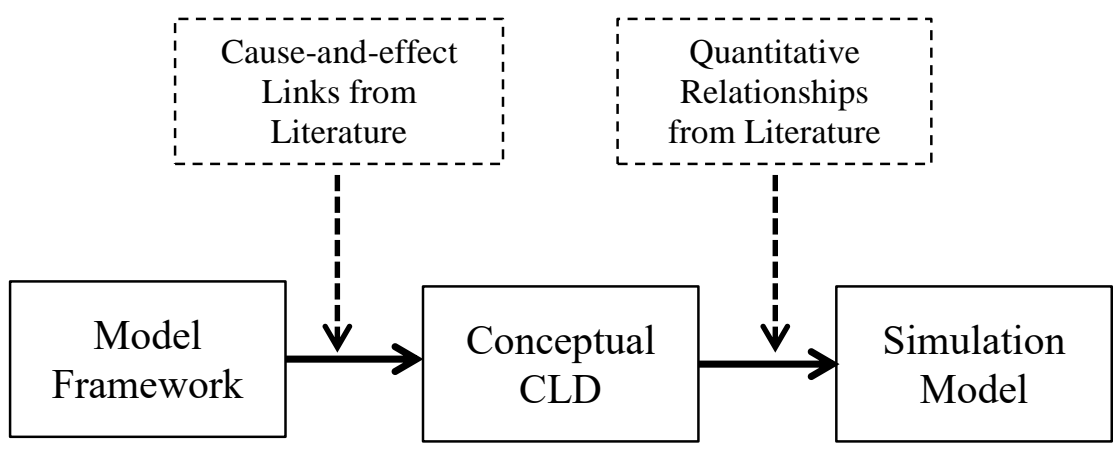

Figure 1. The Modeling Building Process followed in this thesis 
showed them the model based on literature, and asked them for their estimates regarding key variables within the model. These quantitative relationships were then used to build the simulation model in a System Dynamics software called Vensim ("Vensim PLE Plus," n.d.). The model building process described above is summarized in Figure 1.

\subsubsection{Model Assumptions}

The automotive sector was chosen as the context for the current model as this sector has been widely studied in the literature (Falck, Örtengren, \& Högberg, 2010; Kerr, 1998; Norman et al., 1998). The model logic and relationships were based on research studies available in the automotive manufacturing literature as well as those provided by industrial managers. The model represents a hypothetical assembly line with a 100 stations, each station requiring one operator. The assembly line is mostly manual and requires the operators to move midrange to heavy weights. To keep the model simple, it is assumed that the pool of operators remains the same, with no operator leaving their job and no new operators being hired. Full-time operators do not cover for absent operators; rather, if an operator is absent, a temporary operator is assumed to take their place. The model deals with most variables at the group level. The operators are classified into groups of healthy, injured/in-pain, and absent workers based on their health status. All operators are assumed healthy at the start of the simulation, while some of them become injured as they are exposed to risk factors during their working hours. The assembly line itself is also simplified, and only the rate of end products is modeled. It is assumed that the assembly line runs 24-hours a day; however, the model only captures one of the shifts to show the changes in the exposure of risk factors during work and rest, and their resulting effects.

The next sections will describe the underlying framework and logic of the model; the conceptual causal loop diagram developed using the literature; and, the simulation model based on empirical relationships found in the literature.

\subsubsection{Model Framework}

Figure 2 shows the framework used to build the model. The current study focuses on the injury risk factors that increase the likelihood for low-back pain (LBP) musculoskeletal disorders, as 


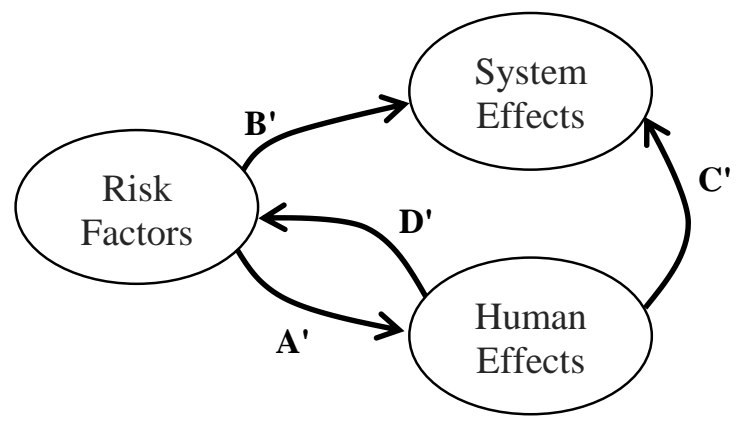

Figure 2. Model framework showing the underlying model logic

these are the most common of occupational injuries (Garg et al., 2014). The LBP risk factors at workplace affect both the health of human operators in a production system (Link $\mathbf{A}^{\prime}$ ) as well as the output of the production system itself (Link B') (Neumann \& Dul, 2010). These health effects may include fatigue, discomfort and pain, and LBP injuries that result from exposure to risk factors (Kerr, 1998; Norman et al., 1998). A unique aspect of these MSD-related injuries is that they reoccur often (Marras, Ferguson, Burr, Schabo, \& Maronitis, 2007). Once an individual develops a LBP injury, they are at a greater risk of a subsequent injury than someone without a history of LBP. Therefore, LBP injuries increase the impact of the original risk factor that caused the injury, creating the feedback link $\mathbf{D}^{\prime}$ ' shown in Figure 2. Link $\mathbf{B}$ ' and link $\mathbf{C}^{\prime}$ show that both the risk factors themselves, and the resulting human effects, may affect the output of the production system, such as productivity and quality (Eklund, 1997; Neumann et al., 2013). Similar frameworks that link the design factors with the human and system effects have also been studied previously in the literature (Neumann \& Dul, 2010; Neumann et al., 2016; Rose et al., 2013).

\subsubsection{Causal Loop Diagram (CLD)}

The conceptual CLD in Figure 3 was developed based on the risk factors, human effects, system effects, and their cause-and-effect links studied in occupational health, ergonomics, manufacturing and production journals. The letters in Figure 3 (A-L) refer to the links between each pair of variables and follow their alphabetical order in the text. The CLD models the main HF-related factors at play as operators work in a mid-heavy assembly of products. Injury risk factors, such as high physical loads, can influence the operators' health and quality of system performance (Kolus et al., 2014). Operators repeatedly exposed to these risk factors will experience discomfort and pain (Link A; Figure 3), and over time develop MSD-related injuries 


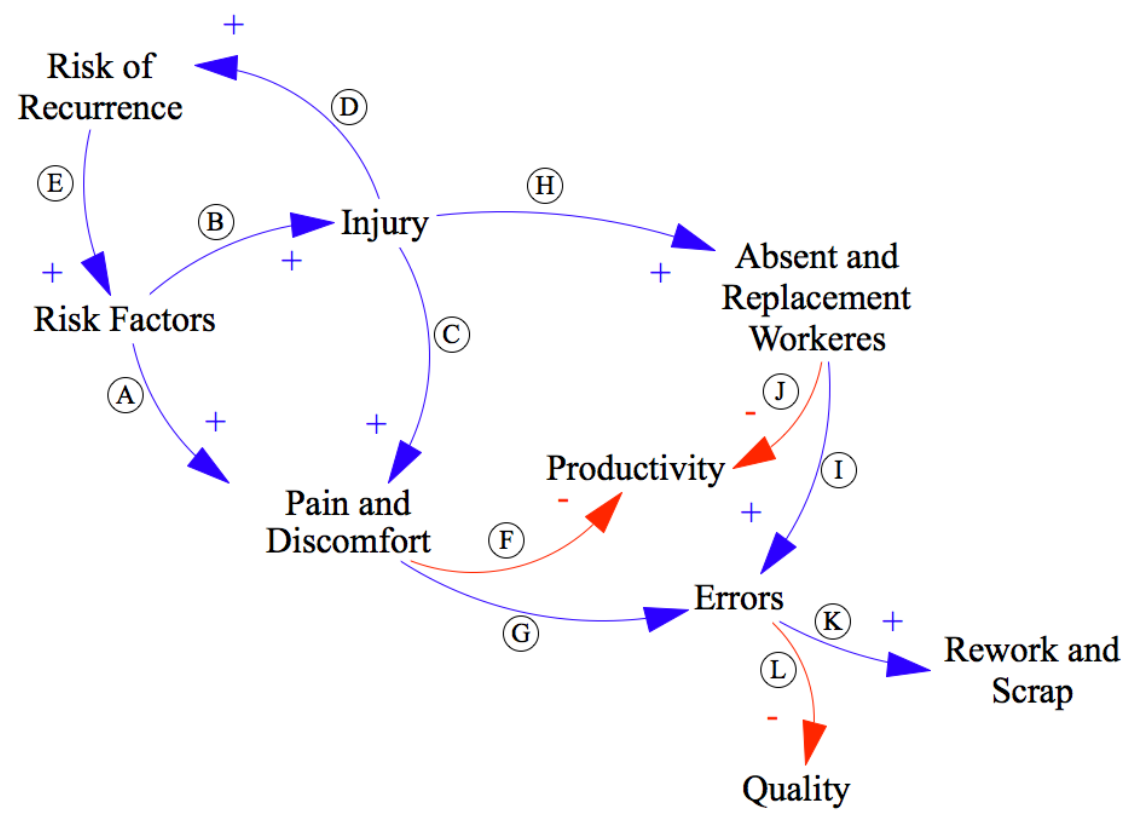

Figure 3. Causal Loop Diagram showing the linkages between various factors within a production system

(Links B \& C) (Eklund, 1995; Kerr, 1998; Norman et al., 1998). MSD injuries reoccur often, and with each episode of MSD-related pain, the likelihood of a risk factor causing a subsequent injury episode increases (Links D \& E) (Marras et al., 2007). This pain and discomfort affects the quality of work and the resulting product in two ways. First, it reduces the performance of the operators, who not only have lower productivity (Link F) and make more errors (Link G) (Falck et al., 2010; Rose et al., 2013), but are also less likely to correct their work (Eklund, 1995). On the other hand, as more operators develop MSD injuries, the number of absent and replacement operators increases (Link H) (Rose et al., 2013). These replacement operators may lack the level of skill and experience of the full-time operators. Depending on the production system, the replacement operators will either make more errors (Link I), or reduce system productivity as they take more time to perform the same tasks (Link J) (Blumenfeld \& Inman, 2009; Khan, Jaber, \& Ahmad, 2014; Mateo, 2008). A high fraction of defective products would increase the need for rework and scrapping (Link K), and may lower the quality of the resulting products (Link L) (Falck et al., 2010; Rose et al., 2013). This conceptual diagram in Figure 3 was used to build the simulation model in the next section. 


\subsubsection{Simulation Model}

The structural overview of the simulation model is shown in Figure 4. The model is divided into the same three sections shown earlier in the model framework in Figure 2 - risk factors, human effects and system effects. The logic structure of these three sections of the model will be described in detail and any empirical relationships used in the model will be explained in the

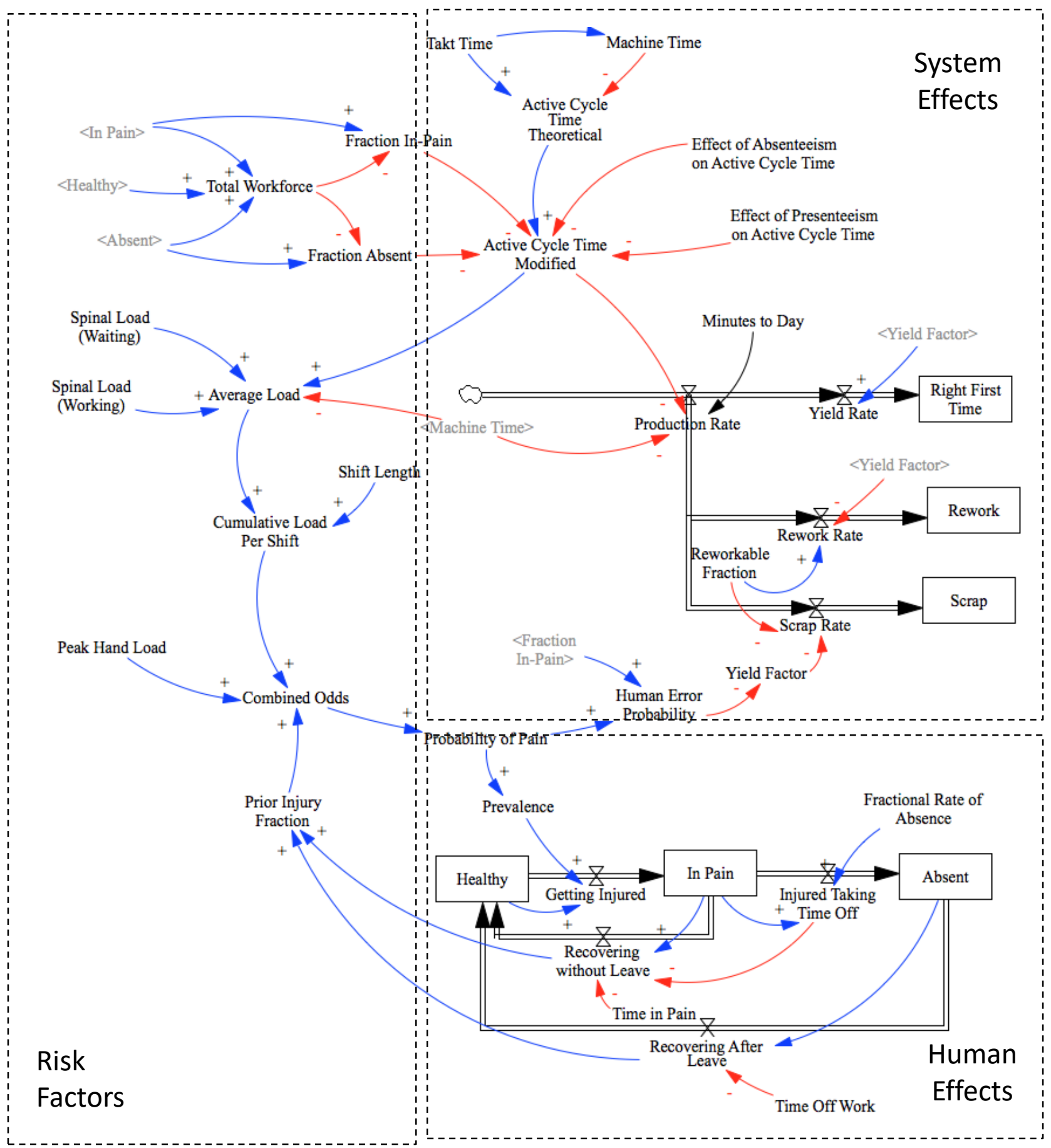

Figure 4. Simulation model divided into risk factors, human effects and system effects 
subsections below. The variables in the model description below are numbered in the sequence that they appear in the text, and correspond to the numbers in Figure (5-7).

\section{$\underline{\text { Risk Factors }}$}

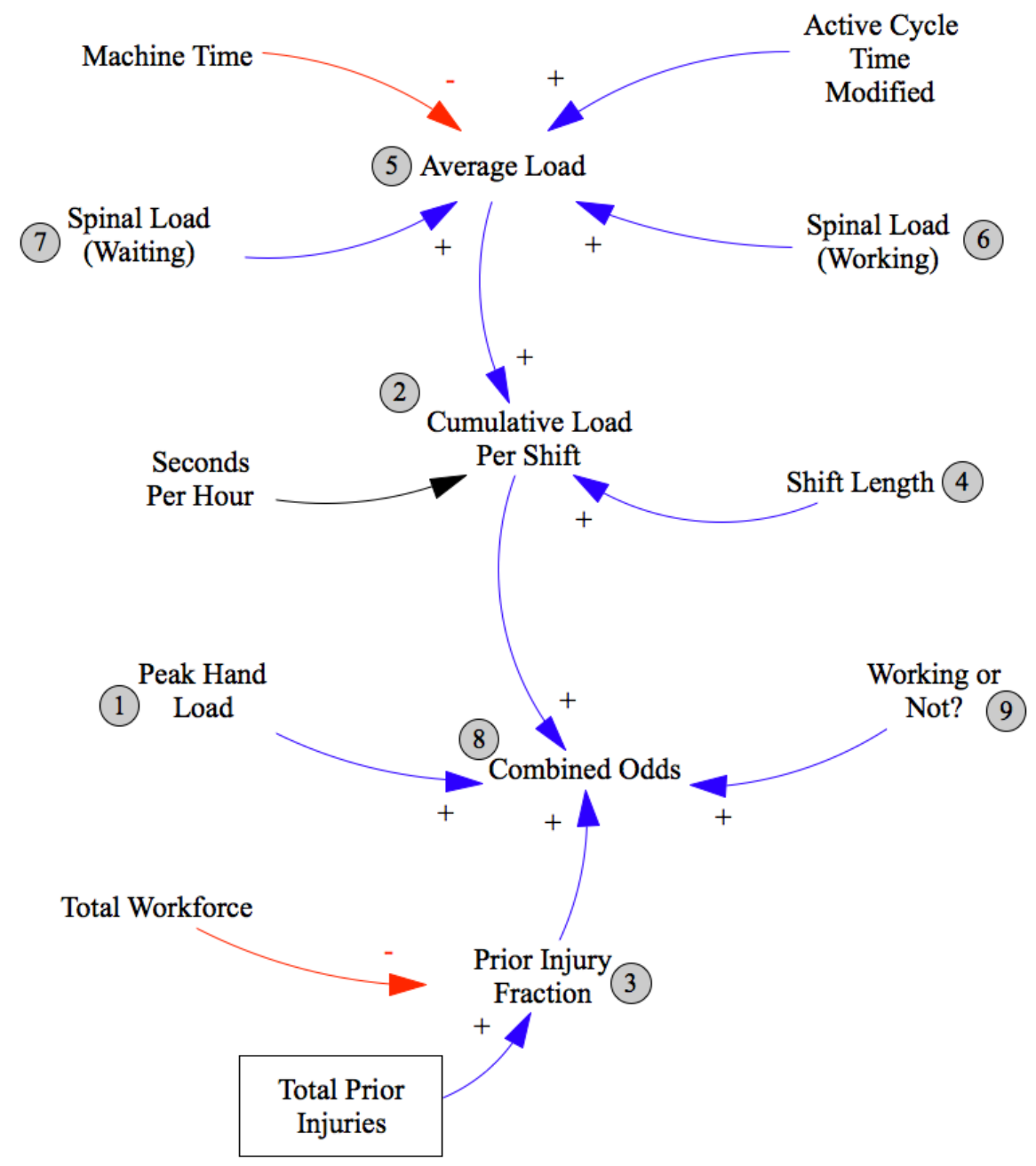

Figure 5. The 'Risk Factors' section of the full-simulation model in Figure 4, isolated to illustrate the link between risk factors and the odds of injury

The 'Risk Factors' section of the model is shown in Figure 5. The risk factors for this study were selected based on the LBP risk factors previously studied by Kerr (1998). These risk factors are the peak hand load (1), cumulative spinal load (2), and the prior history of LBP injuries (3). 
The cumulative spinal load (2) was calculated as the product of shift length (4) and the average load (5), where the average load was the weighted-mean of the spinal load of operators when performing the task (6), and the spinal load when waiting for the next product to arrive (7).

Prior LBP injuries (3) act as a risk factor because the incidence of a LBP injury can increase the chances for a subsequent episode. The prior injury fraction (3) was calculated as follows

$$
\text { Prior Injury Fraction }=\frac{\left(\frac{\text { Total Prior Injuries }}{\text { Total Workforce }}\right)}{\left(\frac{\text { Total Prior Injuries }}{\text { Total } \text { Workforce }}\right)+1}
$$

The construction in Eq. (1) was developed as it limits the value for the risk factor between 0 and 1, as proposed by Kerr (1998) in their regression model.

The combined odds (8) (Figure 5) represent the odds of developing a LBP injury given the level of exposure to the three risk factors. The model calculates the combined odds (8) for LBP injuries based on an earlier regression model ("final regression model excluding controls with acute unreported LBP") provided by Kerr (1998). The combined odds (8) for LBP injury were calculated using the following equation (cf. Sobhani, 2014):

$$
\text { Combined Odds }=\exp \left[\sum_{i=1}^{n} \beta_{i} X_{i}+\alpha_{0}\right]
$$

where $X_{i}$ is value for the $i$ th risk factor, $\beta_{i}$ is its corresponding coefficient and $\alpha_{0}$ is the constant of Logistic regression model. $\beta_{i}$ is a function of the odds ratio (OR) and the interquartile range (IQR) (cf. Sobhani, 2014):

$$
\beta_{i}=\frac{\ln \left(O R_{i}\right)}{I Q R}
$$

where the IQR represents "the average difference of a given risk factor measured between the cases and the controls" (Sobhani, 2014). As Kerr's regression model contains additional risk factors, which are not included in the current model, these were set to their control values in Eq. (2) to minimize their effect.

The combined odds (8) of injury was multiplied with "Working or Not?" (9), a binary variable that assumes the value 1 during working hours, and 0 otherwise. Since the operators are only 
exposed to the specified risk factors during work, it was necessary to limit the exposure to their working hours. The combined odds (8) of LBP injury are the main input to the 'Human Effects' section of the model described in the next subsection.

\section{$\underline{\text { Human Effects }}$}

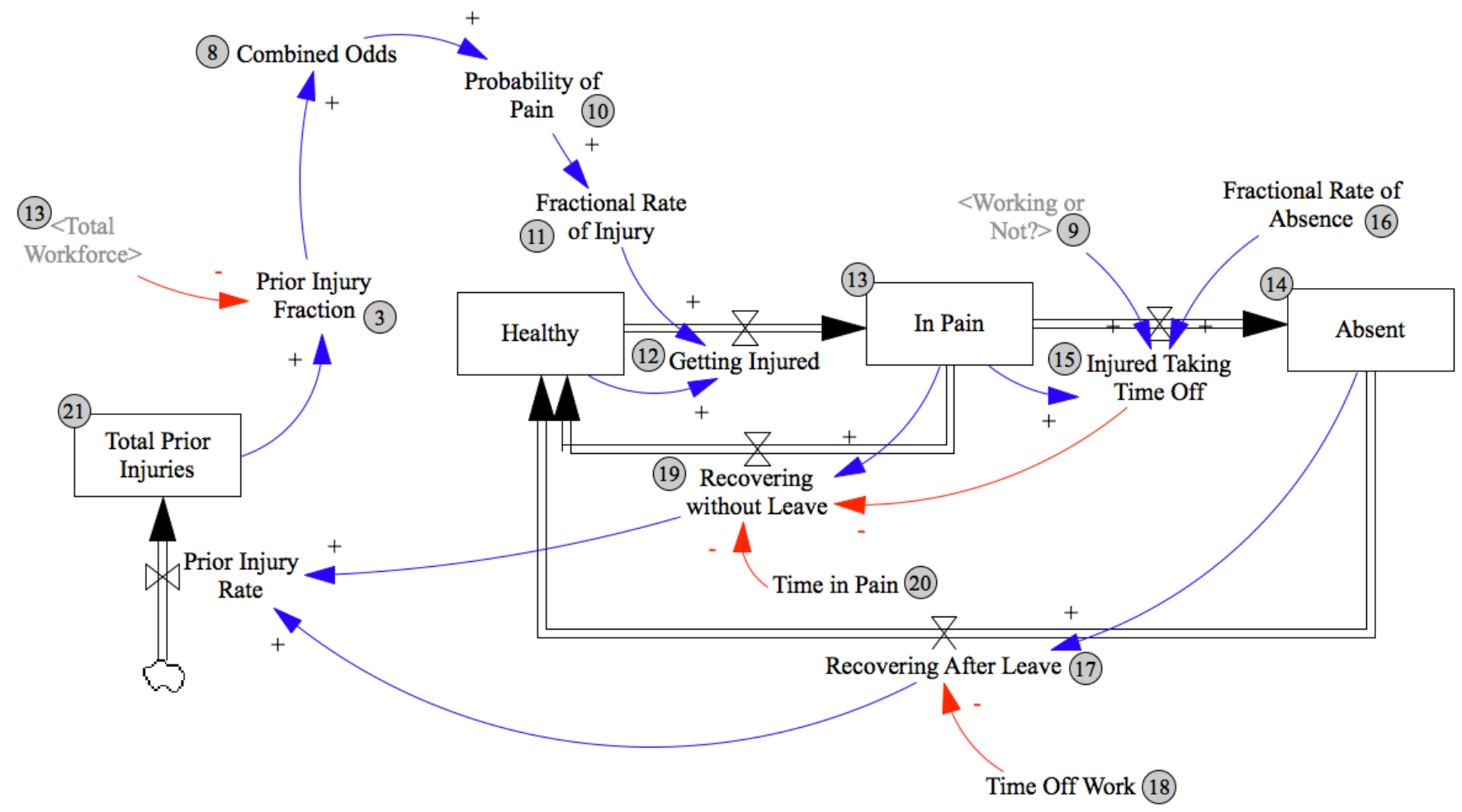

Figure 6. The 'Human Effects' section of the full-simulation model in Figure 4, isolated to illustrate the link between the odds of injury and operators' health

The 'Human Effects' section of the model is shown in Figure 6. The risk factors and the resulting combined odds (8) determine the occurrence of pain and injury among the operators. The combined odds $(\mathbf{8})$ are converted into a probability $(\mathbf{1 0})$ and used to calculate the fractional rate of LBP injury (11) among the operators (cf. Sobhani, 2014)

$$
\text { Fractional Rate of LBP Injury }=\ln \left(\frac{1}{1-P_{\text {Pain }}}\right)
$$

The fractional rate of LBP injury (11) determines the rate at which the operators get injured (12) or develop pain. These in-pain or injured operators (13) follow the definition for a 'case' used by Kerr (1998) and only include those individuals that report their pain or injury to the occupational health services. Some of the operators reporting pain (13) may require a leave of absence (14) 
from work to recover. The rate of injured operators taking time off (15) is governed by the fractional rate of absence (16) and the number of operators reporting pain (RP) (13):

$$
\begin{aligned}
& \text { Injured Taking Time off } \\
& \qquad=\text { "Working or Not?" } \times \text { Fractional Rate of Absence } \times R P
\end{aligned}
$$

Since the operators can only be "absent" from work during working hours, "Working or Not" (9) is multiplied to limit operator absences to the working hours. It is assumed that when the operators return to work, they are fully recovered. Hence, the rate of recovery and return to work (17) is governed by length of time away from work (18).

The remaining operators reporting pain (13) may not take time off and would gradually recover over time while at work. The rate of recovery without leave (19) is then given as a function of the remaining operators reporting pain and the time it takes for the pain to resolve by itself (20):

$$
\text { Recovering without Leave }=\frac{R P}{\text { Time in Pain }}-\text { Injured Taking Time off }
$$

Instead of tracking individual operators for their injuries, the model looks at the total injuries among operators and uses it to calculate the effect of MSD recurrence, where each prior episode of MSD pain or injury increases the likelihood or odds (8) of a subsequent episode. Since prior injuries are episodes that the operators have already recovered from, the two recovery rates (17, 19) are integrated over time to obtain the total prior injuries (21) among the operators.

\section{$\underline{\text { System Effects }}$}

The 'System Effects' section of the model is shown in Figure 7. The risk factors and operators' health from the previous two sections affect the system performance in two ways - first, the fraction of operators that report pain (fRP) or are absent (fA) affects the production rate; second, both the risk factors and injury affect the probability of error and the resulting product quality.

The production rate (22) is calculated as the inverse of the total cycle time:

$$
\text { Production rate }=\frac{1}{(\text { ACT Modified }+ \text { Machine Time })}
$$


where active cycle time (ACT) (23) is the part of the cycle that the operators perform their task, while machine time (24) is the portion of CT when the operators are waiting for the next part or product to arrive. When the operators are in pain or injured, or they are replacing absent full-time

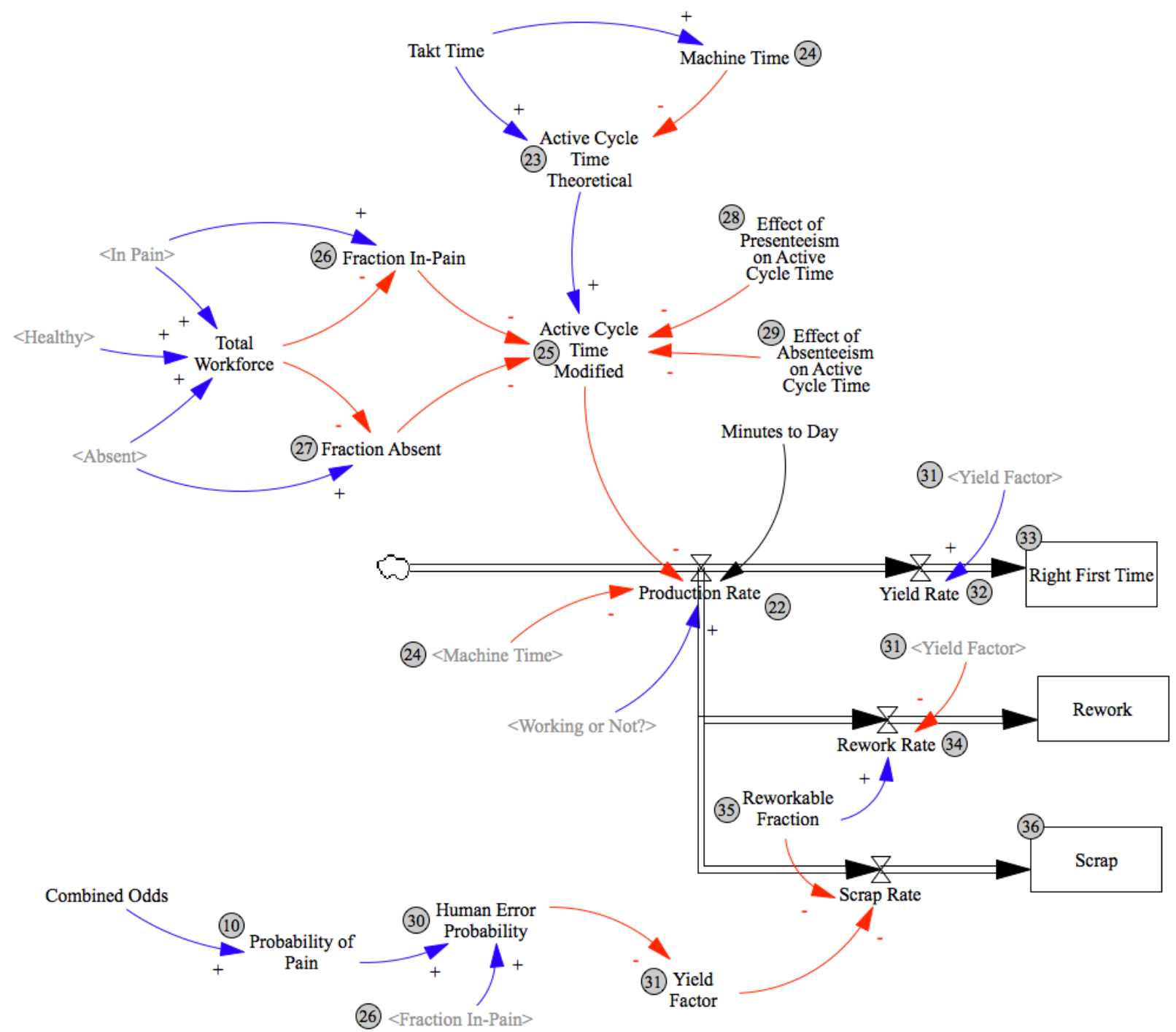

Figure 7. The 'System Effects' section of the full-simulation model in Figure 4, isolated to illustrate the link between the odds of injury, health of operators, and the system output

operators, they may not be able to perform at the expected pace (Rose et al., 2013). The modified ACT (25) shows the effect of injury or absence on ACT, and is a function of fRP (26), fA (27), and the corresponding weight of each $(\mathbf{2 8 ,} 29$ respectively):

$$
\begin{aligned}
& \text { ACT Modified } \\
& \qquad \begin{aligned}
=\text { ACT Theorical } \times(1+(f R P \times E f f e c t \text { of Presenteeism }) \\
+(f A \times E f f e c t \text { of Absenteeism }))
\end{aligned}
\end{aligned}
$$


where the Effect of Presenteeism (28) and Absenteeism (29) represent the weight or size of effect of each on ACT, scaled between 0 (no effect) and 1 (greatest effect). The modified ACT is then used to calculate the production rate in Eq. (7) above.

The Human Error Probability (HEP) (30) quantifies the quality loss in the model, and determines the rework and scrap rate for the assembly line. For the current model, it is a function of the risk factors and operators' injuries (Givi et al., 2015; Sobhani, 2014). However, a general HEP model that would determine the probability of human error based on risk factors and injuries could not be found in the literature. As a result, the author developed a custom HEP function based on the maximum and minimum HEP values found in the literature. An exponential function was fitted to the nominal HEP ranging from $0.1 \%$ to $5 \%$ (Falck \& Rosenqvist, 2014):

$$
H E P_{\text {nominal }}=0.001 \cdot \exp (3.912 \cdot \text { Probability of Pain })
$$

where the probability of pain (10) acts as an indicator of the risk factors. The above equation was modified to include the additional errors resulting from operators in pain (29), giving the contextual HEP (30) as (cf. Di Pasquale et al., 2015):

$$
H E P=\left(H E P_{\text {nominal }} \times(1-f R P)\right)+\left(\left(\frac{P S F \cdot H E P_{\text {nominal }}}{\left((P S F-1) \cdot H E P_{\text {nominal }}\right)+1}\right) \times f R P\right)
$$

where the performance shaping factor (PSF) corresponding to "degraded fitness" for duty (PSF=5) (Di Pasquale et al., 2015) was used in the equation above.

The yield factor (31) represents the fraction of Right First Time (RFT) (33) products and is the complement of the above-calculated HEP (30). The yield rate (32) is the product of the net production rate (22) and the yield factor (31). The rework rate (34) is the rate of reworkable defective products:

$$
\begin{aligned}
\text { Rework rate } & =\text { Production rate } \times(1-\text { Yield Factor }) \\
& \times \text { Reworkable Fraction }
\end{aligned}
$$

where the reworkable fraction (35) is the fraction of defective products that can be corrected. The remaining defective products are scrapped (36).

The definitions for each of the model parameters are listed in Table 1. The model building process above shows structurally how injury risk factors can affect both the health of the 
operators as well as the productivity and quality within a production system. The next section will test the model for trends between these risk factors and human and system outputs.

Table 1. Manufacturing Model Parameters and their definitions

\begin{tabular}{|c|c|c|}
\hline Parameter & Units & Definition \\
\hline Absent & Operators & $\begin{array}{l}\text { The number of operators that are absent because of a LBP } \\
\text { injury at any given time }\end{array}$ \\
\hline $\begin{array}{l}\text { Active Cycle Time } \\
\text { (ACT) Modified }\end{array}$ & Minutes/Product & $\begin{array}{l}\text { ACT Theoretical adjusted for the effect of pain and } \\
\text { absenteeism }\end{array}$ \\
\hline $\begin{array}{l}\text { Active Cycle Time } \\
\text { (ACT) Theoretical }\end{array}$ & Minutes/Product & $\begin{array}{l}\text { The time an it takes an operator to perform all the tasks } \\
\text { required for one product }\end{array}$ \\
\hline Average Load & Newtons & $\begin{array}{l}\text { The average spinal load the operators experience in any } \\
\text { given work cycle }\end{array}$ \\
\hline Combined Odds & Dimensionless & $\begin{array}{l}\text { The odds of LBP injury given the operators are exposed to } \\
\text { the specified risk factors }\end{array}$ \\
\hline $\begin{array}{l}\text { Cumulative Load Per } \\
\text { Shift }\end{array}$ & $\begin{array}{l}\text { Newtons*Second/ } \\
\text { Shift }\end{array}$ & $\begin{array}{l}\text { The total spinal load that an operator is exposed to over a } \\
\text { shift }\end{array}$ \\
\hline Effect of Absenteeism & Dimensionless & $\begin{array}{l}\text { The effect of absenteeism on ACT, scaled between } 0 \text { (no } \\
\text { effect) and } 1 \text { (greatest effect) }\end{array}$ \\
\hline Effect of Presenteeism & Dimensionless & $\begin{array}{l}\text { The effect of presenteeism on ACT, scaled between } 0 \text { (no } \\
\text { effect) and } 1 \text { (greatest effect) }\end{array}$ \\
\hline Fraction Absent & $\begin{array}{l}\text { Operators/ } \\
\text { Operator }\end{array}$ & $\begin{array}{l}\text { The fraction of total operators that are absent because of } \\
\text { LBP injury }\end{array}$ \\
\hline $\begin{array}{l}\text { Fraction Reporting } \\
\text { Pain }\end{array}$ & $\begin{array}{l}\text { Operators/ } \\
\text { Operator }\end{array}$ & $\begin{array}{l}\text { The fraction of total operators that report a LBP injury to } \\
\text { the occupational health services at the plant (Kerr, 1998) }\end{array}$ \\
\hline $\begin{array}{l}\text { Fractional Rate of } \\
\text { Absence }\end{array}$ & 1/Day & $\begin{array}{l}\text { The fraction of injured operators per day that take time off } \\
\text { to recover }\end{array}$ \\
\hline $\begin{array}{l}\text { Fractional Rate of } \\
\text { Injury }\end{array}$ & 1/Day & $\begin{array}{l}\text { The fraction of healthy operators per day that develop and } \\
\text { report a LBP injury }\end{array}$ \\
\hline Getting Injured & Operators/Day & $\begin{array}{l}\text { The number of healthy operators per day that develop and } \\
\text { report a LBP injury to the occupational health services at } \\
\text { the plant (Kerr, 1998) }\end{array}$ \\
\hline Healthy & Operators & $\begin{array}{l}\text { The number of operators that are healthy (at work with no } \\
\text { LBP) }\end{array}$ \\
\hline $\begin{array}{l}\text { Human Error } \\
\text { Probability }\end{array}$ & Dimensionless & $\begin{array}{l}\text { The probability that a product will contain an error that } \\
\text { requires rework or scrap }\end{array}$ \\
\hline $\begin{array}{l}\text { Injured Taking Time } \\
\text { Off }\end{array}$ & Operators/Day & $\begin{array}{l}\text { The number of injured operators per day that take time off } \\
\text { to recover from a LBP injury }\end{array}$ \\
\hline Machine Time & Minutes/Product & The time it takes for the next part or product to arrive \\
\hline Peak Hand Load & Kilograms & $\begin{array}{l}\text { The peak hand load that an operator is exposed to during a } \\
\text { shift }\end{array}$ \\
\hline Prior Injury Fraction & Dimensionless & $\begin{array}{l}\text { Total prior injuries among the operators given as a } \\
\text { fraction of the total operators }\end{array}$ \\
\hline Prior Injury Rate & People/Day & $\begin{array}{l}\text { The number of injuries per day that the operators recover } \\
\text { from }\end{array}$ \\
\hline Probability of Pain & Dimensionless & $\begin{array}{l}\text { The probability of developing a LBP injury given the } \\
\text { operators are exposed to the specified risk factors }\end{array}$ \\
\hline
\end{tabular}




\begin{tabular}{|c|c|c|}
\hline Parameter & Units & Definition \\
\hline Production Rate & Products/Day & $\begin{array}{l}\text { The total number of products (defective and defect-free) } \\
\text { produced per hour }\end{array}$ \\
\hline $\begin{array}{l}\text { Recovering After } \\
\text { Leave }\end{array}$ & Operators/Day & $\begin{array}{l}\text { The number of absent operators per day that return to } \\
\text { work after a LBP-related absence }\end{array}$ \\
\hline $\begin{array}{l}\text { Recovering without } \\
\text { Leave }\end{array}$ & Operators/Day & $\begin{array}{l}\text { The number of injured operators per day that recovery } \\
\text { fully without taking any absence after a LBP injury }\end{array}$ \\
\hline Reporting Pain & Operators & $\begin{array}{l}\text { The number of operators that report a LBP injury to the } \\
\text { occupational health services at the plant (Kerr, 1998) }\end{array}$ \\
\hline Rework & Products & $\begin{array}{l}\text { The total number of defective products that can be } \\
\text { reworked }\end{array}$ \\
\hline Rework Rate & Products/Day & $\begin{array}{l}\text { The number of defective products produced per hour that } \\
\text { can be reworked }\end{array}$ \\
\hline Reworkable Fraction & Products/Product & $\begin{array}{l}\text { The fraction of defective products that can be reworked to } \\
\text { produce a finished product }\end{array}$ \\
\hline Right First Time & Products & $\begin{array}{l}\text { The total number of finished products that did not require } \\
\text { any rework }\end{array}$ \\
\hline Scrap & Products & $\begin{array}{l}\text { The total number of products have been scrapped because } \\
\text { of irrecoverable error/defect }\end{array}$ \\
\hline Scrap Rate & Products/Day & The number of defective products scrapped per hour \\
\hline Shift Length & Hours & $\begin{array}{l}\text { The total number of working hours, including breaks, in a } \\
\text { day }\end{array}$ \\
\hline Spinal Load (Waiting) & Newtons & $\begin{array}{l}\text { The spinal load experienced by the operator while waiting } \\
\text { for the next part or product }\end{array}$ \\
\hline Spinal Load (Working) & Newtons & $\begin{array}{l}\text { The spinal load experienced by the operator while } \\
\text { performing their task }\end{array}$ \\
\hline Takt Time & Minutes/Product & The required cycle time, as set by the operations manager \\
\hline Time in Pain & Days & $\begin{array}{l}\text { The average time it takes for the operators to recover from } \\
\text { injury while at work }\end{array}$ \\
\hline Time Off Work & Days & $\begin{array}{l}\text { The average time the operators on leave spend away from } \\
\text { work }\end{array}$ \\
\hline Total Prior Injuries & Operators & The total number of prior pain and injury episodes \\
\hline Total Workforce & Operators & $\begin{array}{l}\text { Total number of operators, including healthy, in pain and } \\
\text { replacement (or absent) }\end{array}$ \\
\hline Working or Not? & Dimensionless & $\begin{array}{l}\text { Binary variable that shows if the operators are on shift } \\
(=1) \text { or not }(=0)\end{array}$ \\
\hline Yield Factor & Products/Product & The fraction of total products that are defect-free \\
\hline Yield Rate & Products/Day & The number of defect-free products produced per day \\
\hline
\end{tabular}

\subsection{Model Testing}

Three stages of model simulation were performed: (1) a base case model; (2) one-factor-at-atime (OFAT) (Daniel, 1994) sensitivity analysis; and (3) a multivariate experimental analysis. Each of these is described in detail in the sections below. Face validation was also performed with two managers from an assembly plant. Statistical tests were not required for the model since the model is deterministic, with no stochastic elements. Data analysis was performed for all 
output variables in the model. However, because of space limitations, only four main ones will be detailed in the results below: Fraction Reporting Pain (fRP), Human Error Probability (HEP), Production Rate and Rework Rate. For each run, the model was simulated for a 5-year period, long enough for the model to reach a steady state or trend. Unless stated otherwise, all graphs in the results exclude the data during non-work hours to enable better visualization of the trends.

\subsubsection{Base Model}

The base case model was run for 5 years, with the model parameters listed in Table 2. A base value was determined for each of the parameters within the model using the data (usually the mean) determined by the referenced study. Where multiple studies were available, the one closest to the context of the current model was chosen. For the risk factors, the base values correspond to the control group in the study by Kerr (1998). No reference could be found for machine time; hence, an estimate by an assembly plant quality manager was used instead.

Table 2. Parameter Values Used in Base Manufacturing Model

\begin{tabular}{|l|c|l|}
\hline \multicolumn{1}{|c|}{ Variable } & Value & \multicolumn{1}{c|}{ Reference/Reason } \\
\hline $\begin{array}{l}\text { Effect of Absenteeism on } \\
\text { Active Cycle Time }\end{array}$ & $10 \%$ & (Sobhani, 2014) \\
\hline $\begin{array}{l}\text { Effect of Presenteeism on } \\
\text { Active Cycle Time }\end{array}$ & $16 \%$ & (Sobhani, 2014) \\
\hline Fractional Rate of Absence & $15.5 \% /$ year & (Wynne-Jones et al., 2014) \\
\hline Machine Time & 3 seconds & $\begin{array}{l}\text { Assumed 5\% of takt time; Manager } \\
\text { Estimate }\end{array}$ \\
\hline Peak Hand Load & $14.3 \mathrm{~kg}$ & (Kerr, 1998) \\
\hline Reworkable Fraction & $90 \%$ & (Chiu, Chen, Cheng, \& Wu, 2010) \\
\hline Shift Length & 8 hours & (Givi et al., 2015) \\
\hline Spinal Load (Waiting) & $406 \mathrm{~N}$ & (Neumann et al., 2001) \\
\hline Spinal Load (Working) & $826 \mathrm{~N}$ & (Kerr, 1998) \\
\hline Takt Time & 1 minute & Manager Estimate \\
\hline Time in Pain & 42 days & (Hoy, Brooks, Blyth, \& Buchbinder, 2010) \\
\hline Time Off Work & 34 days & (Lötters, Meerding, \& Burdorf, 2005) \\
\hline
\end{tabular}

\subsubsection{Sensitivity Analysis}

An OFAT (Daniel, 1994) sensitivity analysis was run using the values listed in Table 3 for the model parameters. Seven values were tested for each input parameter. These values were determined by estimating the broadest realistic operational range using the literature or 
researcher judgment, and dividing that range into seven data points. The range was selected such that the base value was the central or median value; however, in some cases this was not possible (negative values; odds ratios below 1 etc.) or not realistic, and the base case value became the $3^{\text {rd }}$ value within the testing range. Each variable was then varied through the seven data points while the other variables were held at their base case value. The model was simulated each time for a 5-year period; however, since the model showed a steady increase/decrease for the output variables after the first year, the results at the end of Year 1 are shown for a single time-point analysis.

Table 3. Manufacturing Model Parameter Values Used in Sensitivity Analysis (Values in bold refer to the base case model)

\begin{tabular}{|c|c|c|c|c|c|c|c|c|}
\hline \multirow[t]{2}{*}{ Variable } & \multicolumn{7}{|c|}{ Values } & \multirow[t]{2}{*}{ Reference/Reason } \\
\hline & $1^{\text {st }}$ & $2^{\text {nd }}$ & $3^{\text {rd }}$ & $4^{\text {th }}$ & $5^{\text {th }}$ & $6^{\text {th }}$ & $7^{\text {th }}$ & \\
\hline $\begin{array}{l}\text { Cumulative Disk } \\
\text { Compression OR }\end{array}$ & 1.0 & 1.3 & 1.6 & 2.0 & 2.3 & 2.7 & 3.0 & (Kerr, 1998) \\
\hline $\begin{array}{l}\text { Effect of Absenteeism } \\
\text { on ACT }(\%)\end{array}$ & 0.0 & 5.0 & 10.0 & 15.0 & 20.0 & 25.0 & 35.0 & (Sobhani, 2014) \\
\hline $\begin{array}{l}\text { Effect of Presenteeism } \\
\text { on ACT }(\%)\end{array}$ & 0.0 & 5.0 & 10.0 & 16.6 & 20.0 & 25.0 & 35.0 & (Sobhani, 2014) \\
\hline $\begin{array}{l}\text { Fractional Rate of } \\
\text { Absence (\%/year) }\end{array}$ & 5.5 & 8.8 & 12.2 & 15.5 & 18.8 & 22.2 & 25.5 & $\begin{array}{l}\text { (Wynne-Jones et al., } \\
\text { 2014) }\end{array}$ \\
\hline $\begin{array}{l}\text { Machine Time } \\
\text { (\% of Takt time) }\end{array}$ & 1.0 & 2.5 & 4.0 & 5.0 & 6.5 & 8.0 & 10.0 & Estimated by researcher \\
\hline Peak Hand Load (kg) & 0.0 & 10.0 & 14.3 & 20.0 & 30.0 & 40.0 & 51.5 & (Kerr, 1998) \\
\hline Peak Hand Load OR & 1.0 & 1.7 & 2.4 & 3.0 & 3.7 & 4.3 & 5.0 & (Kerr, 1998) \\
\hline $\begin{array}{l}\text { Prevalence Rate } \\
\text { (\%/year) }\end{array}$ & 0.0 & 15.0 & 30.0 & 38.0 & 50.0 & 65.0 & 85.0 & (Hoy et al., 2010) \\
\hline Prior LBP OR & 1.0 & 2.5 & 3.7 & 5.5 & 7.0 & 8.5 & 10.0 & (Kerr, 1998) \\
\hline $\begin{array}{l}\text { Reworkable Fraction } \\
(\%)\end{array}$ & 80.0 & 83.3 & 86.6 & 90.0 & 93.3 & 96.6 & 100.0 & Estimated by researcher \\
\hline Shift Length (Hrs) & 4.0 & 5.3 & 6.7 & 8.0 & 9.3 & 10.7 & 12.0 & Estimated by researcher \\
\hline $\begin{array}{l}\text { Spinal Load (Waiting) } \\
\text { (N) }\end{array}$ & 61.0 & 176.0 & 291.0 & 406.0 & 521.0 & 636.0 & 751.0 & (Neumann et al., 2001) \\
\hline $\begin{array}{l}\text { Spinal Load (Working) } \\
\text { (N) }\end{array}$ & 351.0 & 510.0 & 668.0 & 826.0 & 985.0 & 1143.0 & 1301.0 & (Kerr, 1998) \\
\hline Takt Time (min.) & 0.5 & 0.7 & 0.8 & 1.0 & 1.2 & 1.3 & 1.5 & Estimated by researcher \\
\hline Time in Pain (Days) & 1.0 & 20.0 & 42.0 & 60.0 & 80.0 & 100.0 & 120.0 & $\begin{array}{l}\text { (Garg et al., 2014; Hoy } \\
\text { et al., 2010) }\end{array}$ \\
\hline Time Off Work (Days) & 8.0 & 19.0 & 34.0 & 42.0 & 53.0 & 64.0 & 76.0 & (WorkSafeBC, 2001) \\
\hline
\end{tabular}

\subsubsection{Experimental Analysis}

A multifactorial experimental analysis was also performed to examine the interaction effects for some of the risk factors on the model output. The three design variables that had the largest effect on the output in the sensitivity analysis above - Shift Length, Spinal Load (Working) and 
Peak Hand Load - were chosen as independent variables for the experiment. These three input variables were each varied through 3 levels (low, medium, high), resulting in a set of 27 experiments. The levels were chosen to cover most of the operational range for each risk factor. Shift Length was varied between 8 hrs, 10 hrs, and 12 hrs; Spinal Load was varied between 500 N, $750 \mathrm{~N}$, and $1000 \mathrm{~N}$; and Peak Hand Load was varied between $5 \mathrm{~kg}, 15 \mathrm{~kg}$, and $25 \mathrm{~kg}$ for the experimental analysis.

The experimental analysis produced data for each output variable as a function of the three risk factors, resulting in 4-dimensional graphs. To simplify understanding these graphs, the results first show 2-dimensional analysis of the results; then produce 3-dimensional graphs with the output plotted against two of the three risk factors; and finally show the 4-dimensional graphs of the experimental analysis. Eight time points were chosen to analyze the data so that the analysis captured any time-dependent changes in the trend: 1 week, 1 month, 6 months, 1 year, 2 year, 3 year, 4 year, and 5 year. Only the results at the end of Year 1 are displayed in the results, as the trends for each output variable were similar for the other time points. Complete results can be found in Tables A6-A9 in the Appendix.

\subsubsection{Face Validation}

Face validation of the model was performed with a small sample of two managers - a quality manager and a health and safety (H\&S) manager - at a heavy assembly manufacturing plant. We met with each manager individually, and each one was walked through a step-by-step development of the model structure in a presentation. Their comments and suggestions regarding the model were recorded and are presented with the results in the next section.

\subsection{Results}

The results below present the model output for the three sets of inputs described - base case, sensitivity analysis, and experimental analysis.

\subsubsection{Base Model}

The base case model results answer the following research question: For the model based on average (base) values, what time-based trends are displayed by the model output? 


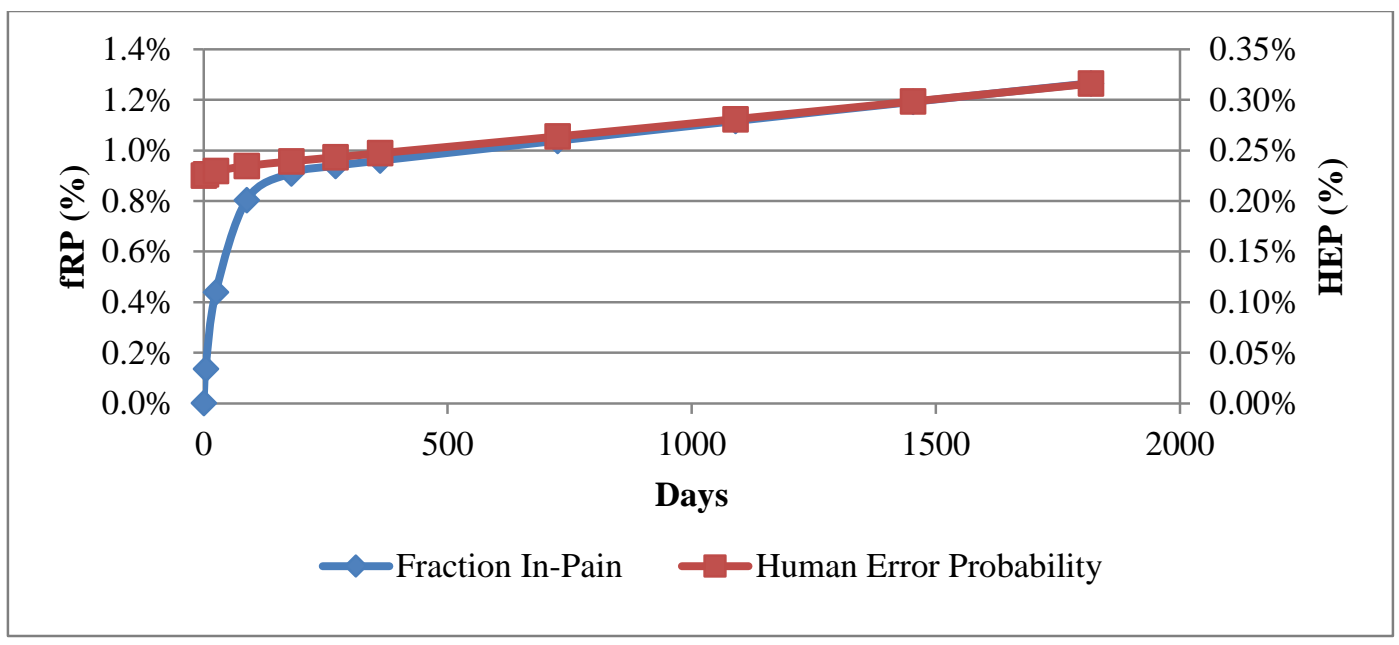

Figure 8. Time-series graphs for Fraction Reporting Pain (fRP) (Left axis) and Human Error Probability (HEP) (Right axis) for base model

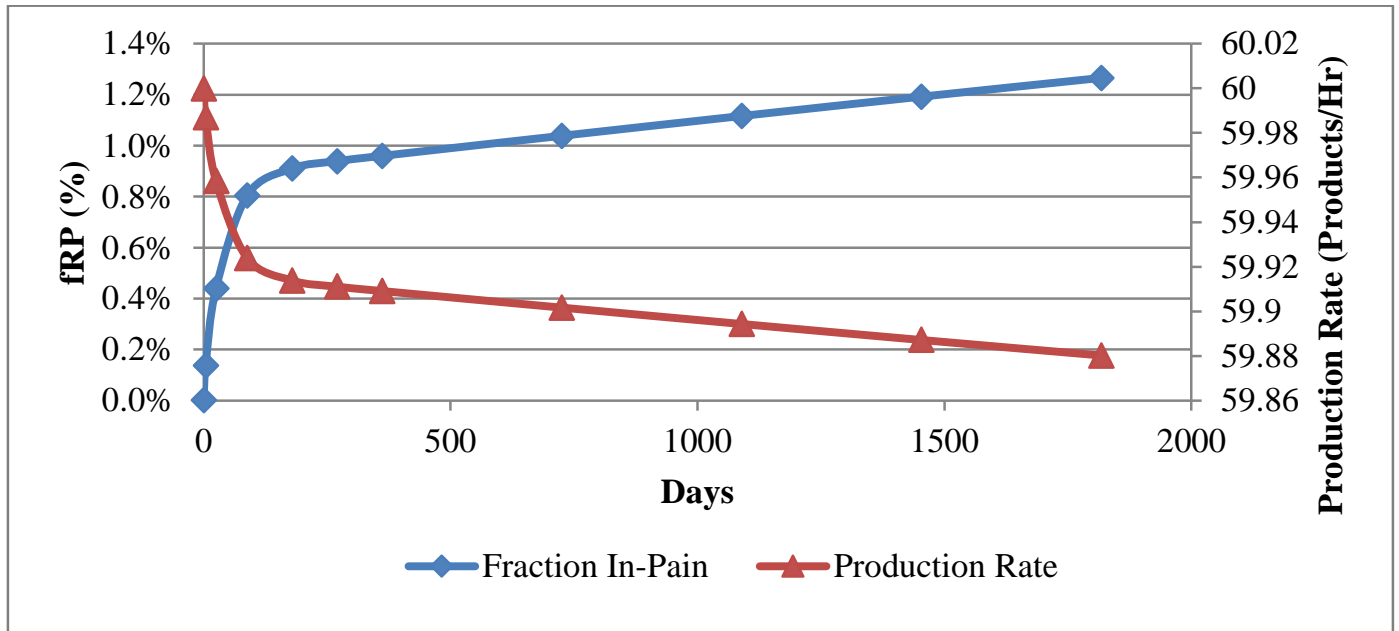

Figure 9. Time-series graphs for Fraction Reporting Pain (fRP) (Left axis) and Production Rate (Right axis) for base model

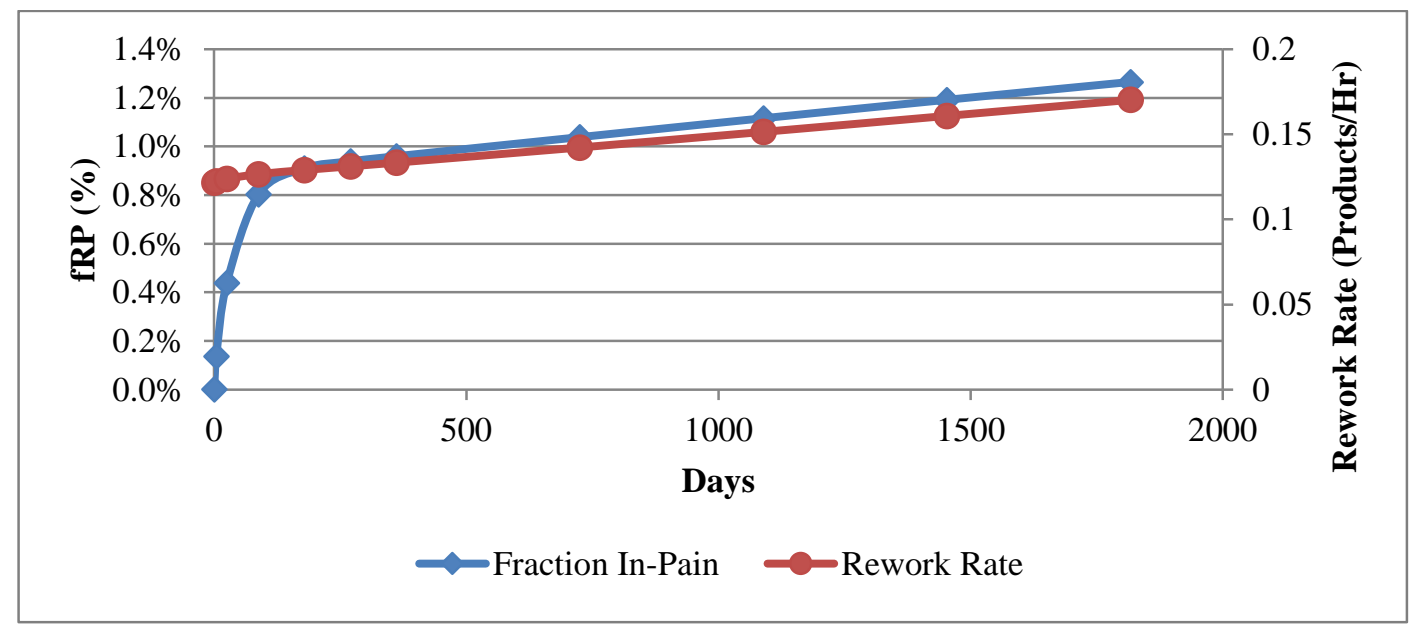

Figure 10. Time-series graphs for Fraction Reporting Pain (fRP) (Left axis) and Rework Rate (Right axis) for base case model 
The time-series results for the base model are presented in Figures 8-10. The Human Error Probability (HEP), production rate and rework rate are each graphed with the Fraction Reporting Pain (fRP) to make the comparison between trends easier. fRP (Figures 8-10), HEP (Figure 8), and rework rate (Figure 10) show an increasing trend with time while the production rate (Figure 9) decreases as time passes. The curve for fRP (Figures 8-10) shows that as the operators are exposed to risk factors at their job, they will start to develop pain and injuries. The injuries rise with time, with the fraction of injured operators (fRP) increasing from $\sim 0 \%$ to $1.3 \%$, and the probability of making error (HEP) increasing from $0.2 \%$ to $0.3 \%$ over the 5 -year simulation period. These errors, over time, cause a drop in the production rate from 60 Products/Hr to 59.9 Products/Hr (Figure 9), and an increase in the rework rate from 0.12 Products/Hr to 0.17 Products/Hr (Figure 10). Figures 8-10 highlight the link between fRP, HEP, production rate and rework rate. As injuries rise over time, HEP and the rework rate rise as well, while the production rate drops. Since all operators are assumed healthy at the start of the simulation, with no previous history of LBP injuries, this causes the steep initial rise seen in the fRP and the corresponding initial drop in production rate in Figures 8-10.

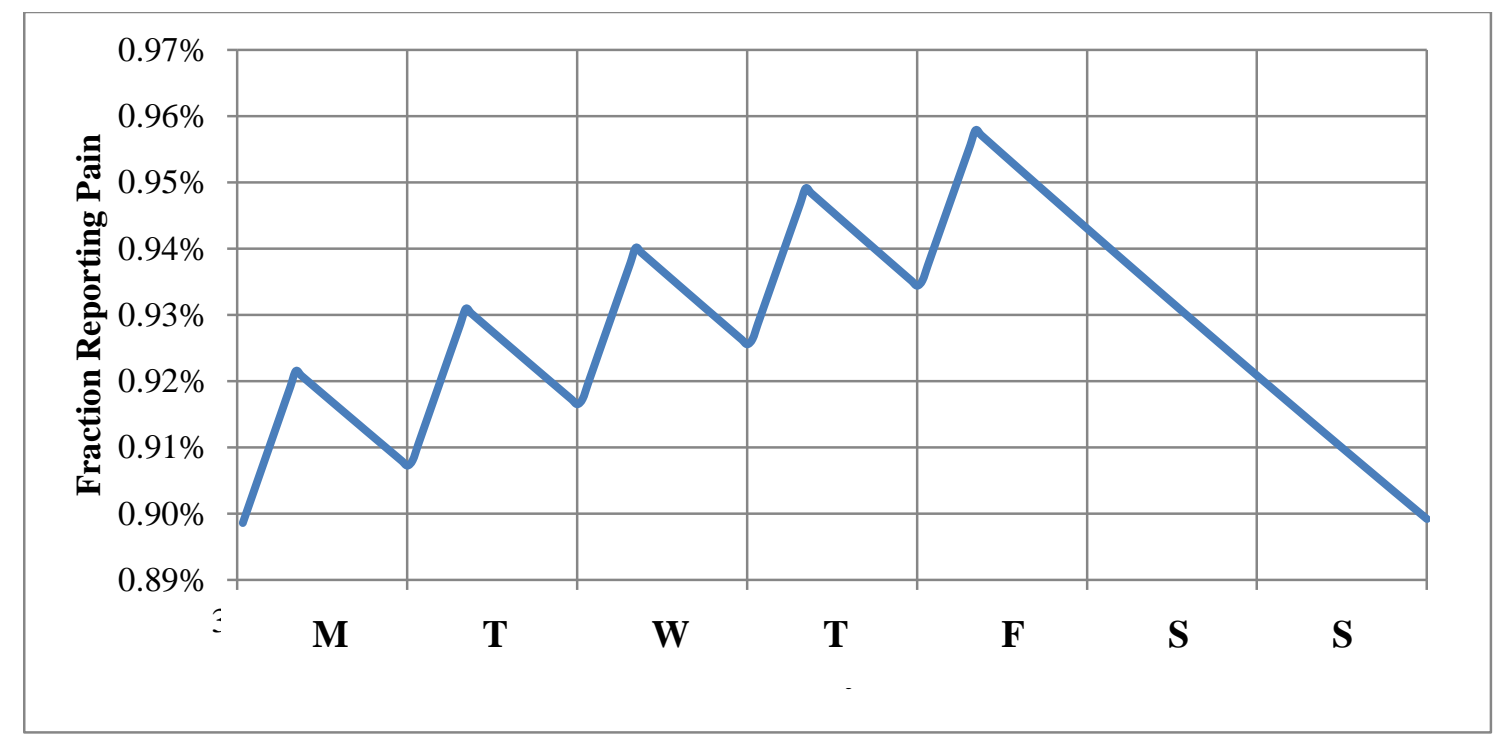

Figure 11. Time-series graph showing changes in Fraction Reporting Pain over one week

Figure 11 shows a magnified view of the fRP curve from Figure 8 for one week, and includes data from non-work hours. The week chosen is the first week of the second year, as this time interval is past the initial steep rise in fRP. The figure shows that fRP increases during the shift 
and decreases during non-work hours. fRP also shows a net increase during the week, rising from $0.92 \%$ to $0.96 \%$, and drops to the value at the start previous week by the end of the weekend. Figure 11 shows that the number of operators in pain and discomfort increases during the shift, and decreases during off-work hours as the operators recover. However, operators do not recover completely by the start of their next shift and the overall pain and discomfort rises throughout the week until the weekend, when the operators receive enough rest and recovery for their pain and discomfort to drop to approximately the levels seen at the start of the previous week.

\subsubsection{Sensitivity Analysis}

The results of sensitivity analysis answer the following research question: How does each model parameter independently affect the model output?

Sensitivity analysis was performed for all input variables listed in Table 2. However, due to space limitations, only the design variables that could be influenced by the operations managers were included. These design variables are Machine Time, Peak Hand Load, Shift Length, Spinal Load (Working) and Takt Time.

The fRP and yield rate at the end of Year 1 are shown in Figures 12-16, plotted against the level of exposure (given as a percentage of base case values) for these five risk factors. The yield rate is the rate of Right First Time (RFT) products after the defective products have been removed, and captures the effect of any productivity losses as well as quality errors. Figures 12-15 show that injury and yield rate have an inverse relationship, where as the fRP increases, the yield rate drops and vice versa. In Figure 12, as the machine time increases, fRP decreases while yield rate increases. This is because as machine time or wait time is increased, the operators' exposure to risk factors decreases while more time is available for recovery. On the other hand, for Peak Hand Load, Shift Length and Spinal Load, as the level of exposure to these risk factors are increased, the injury and the resulting fRP increases while the yield rate drops (Figures 13-15). Figure 16 showing the effects of Takt time on the output variables is different from the other risk factors in that as Takt time is increased, the injury remains constant but the yield rate drops. 


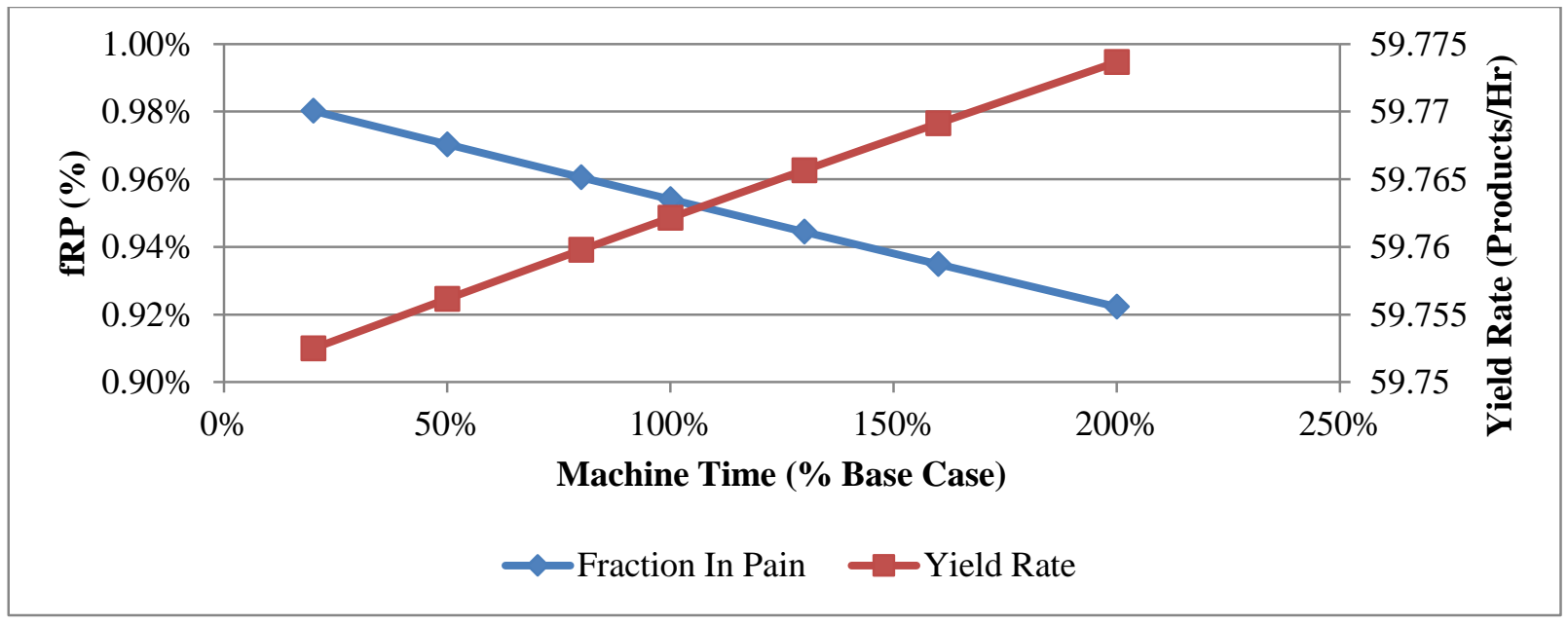

Figure 12. Fraction Reporting Pain (fRP) (Left axis) and Yield Rate (Right axis) at the end of Year 1 for Varying Machine Time

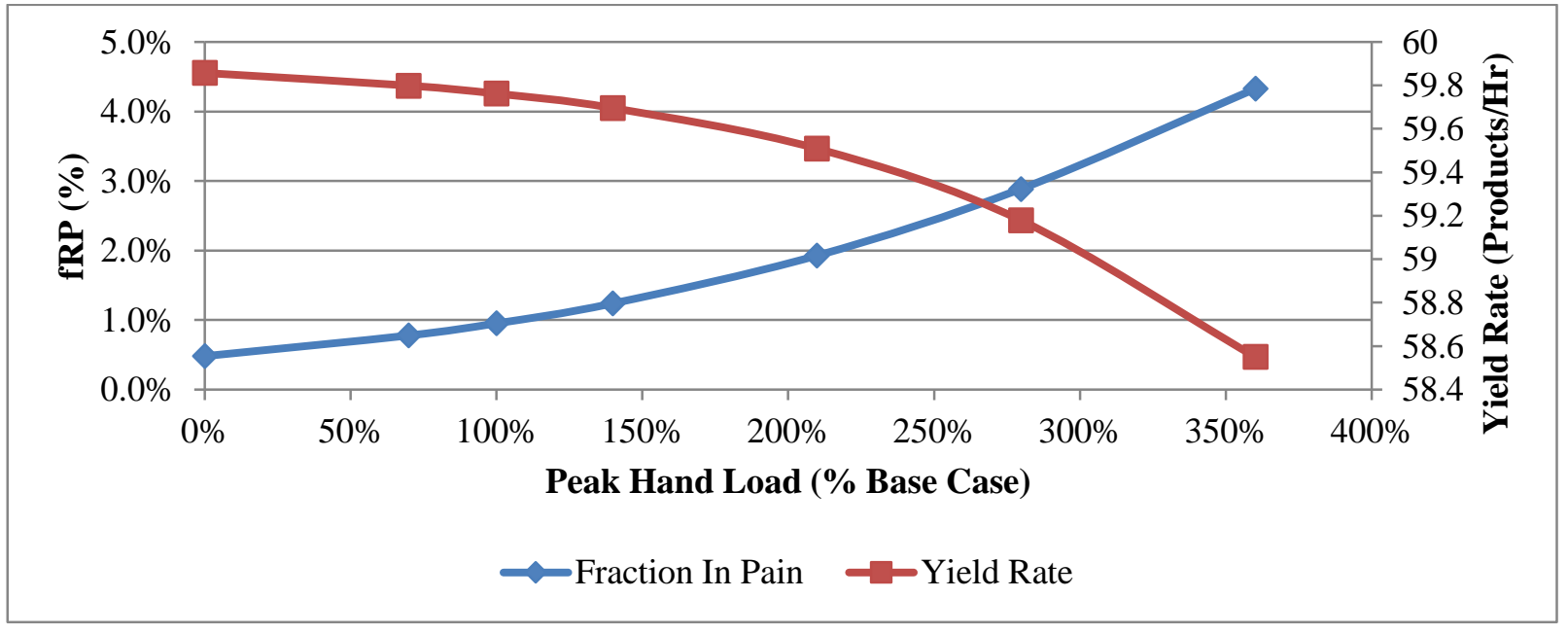

Figure 13. Fraction Reporting Pain (fRP) (Left axis) and Yield Rate (Right axis) at the end of Year 1 for Varying Peak Hand Load

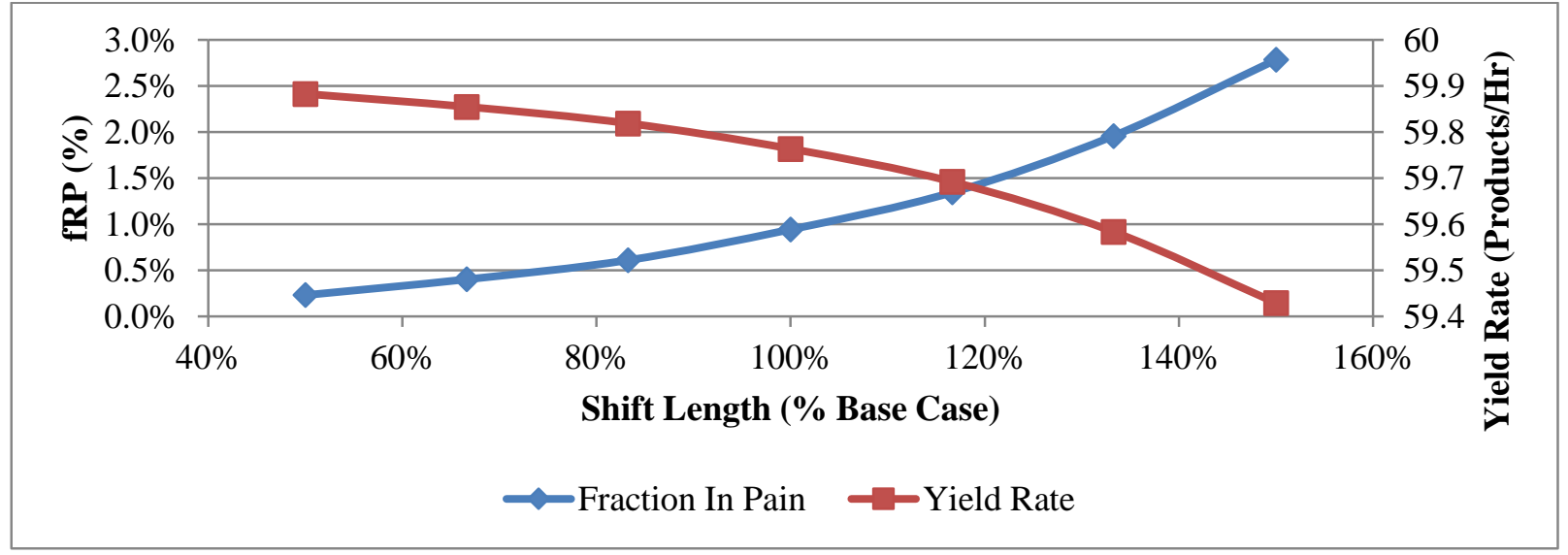

Figure 14. Fraction Reporting Pain (fRP) (Left axis) and Yield Rate (Right axis) at the end of Year 1 for Varying Shift Length 


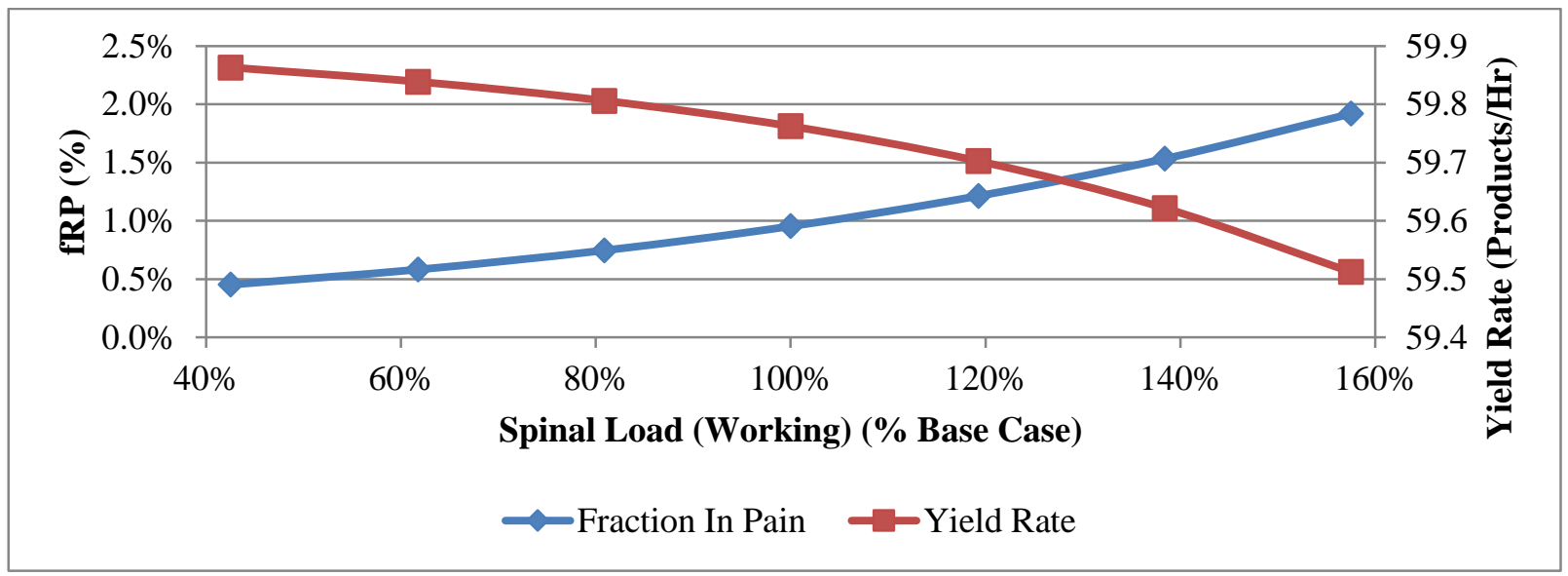

Figure 15. Fraction Reporting Pain (fRP) (Left axis) and Yield Rate (Right axis) at the end of Year 1 for Varying Spinal Load (Working)

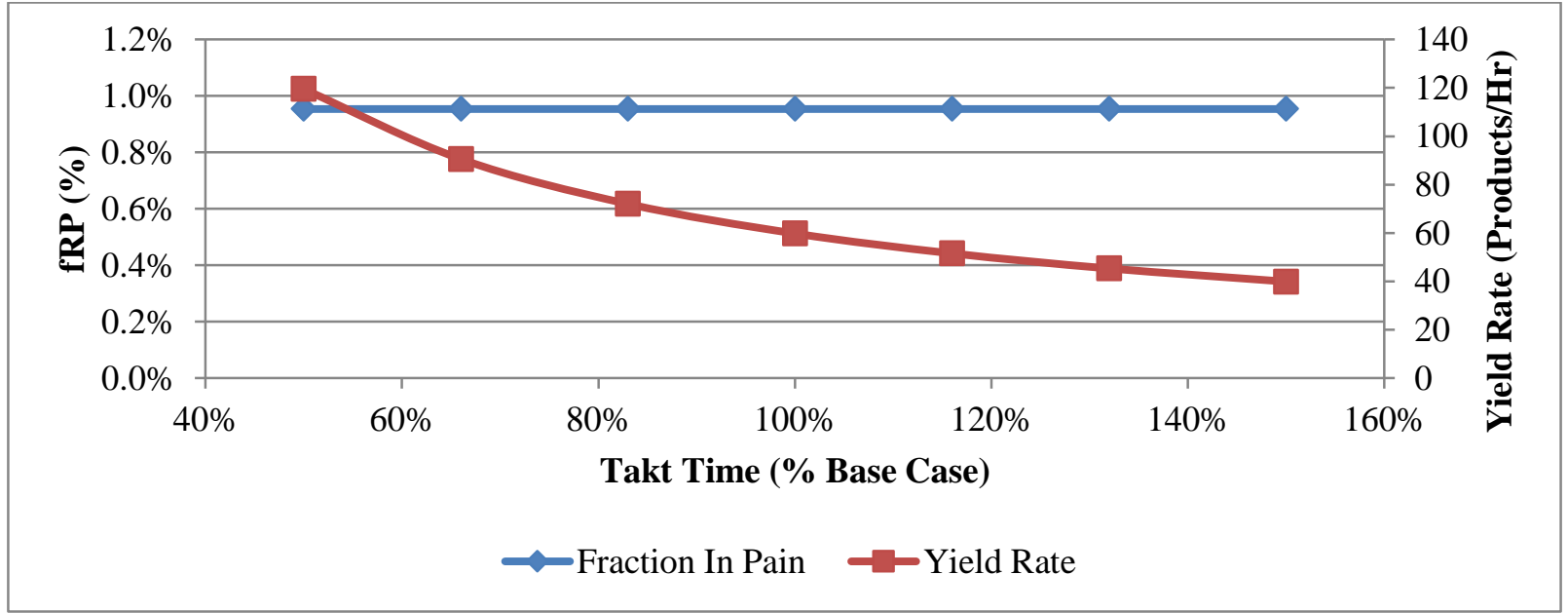

Figure 16. Fraction Reporting Pain (fRP) (Left axis) and Yield Rate (Right axis) at the end of Year 1 for Varying Takt Time

The main model output variables are shown in Figures 17-20, at the end of Year 1, plotted against the exposure level (percentage of base case values) for the five main risk factors within the model. For Peak Hand Load, Shift Length and Spinal Load, as their level of exposure is increased, the fRP (Figure 17), HEP (Figures 18), and rework rate (Figures 20) also increase, while the production rate drops (Figure 19). Machine Time shows an opposite trend, where an increase in machine time or wait time results in decreasing fRP, HEP and rework, while the production rate rises. Takt time shows a different trend than the other risk factors. To enable better visualization of data, Takt time is excluded from Figure 20. 


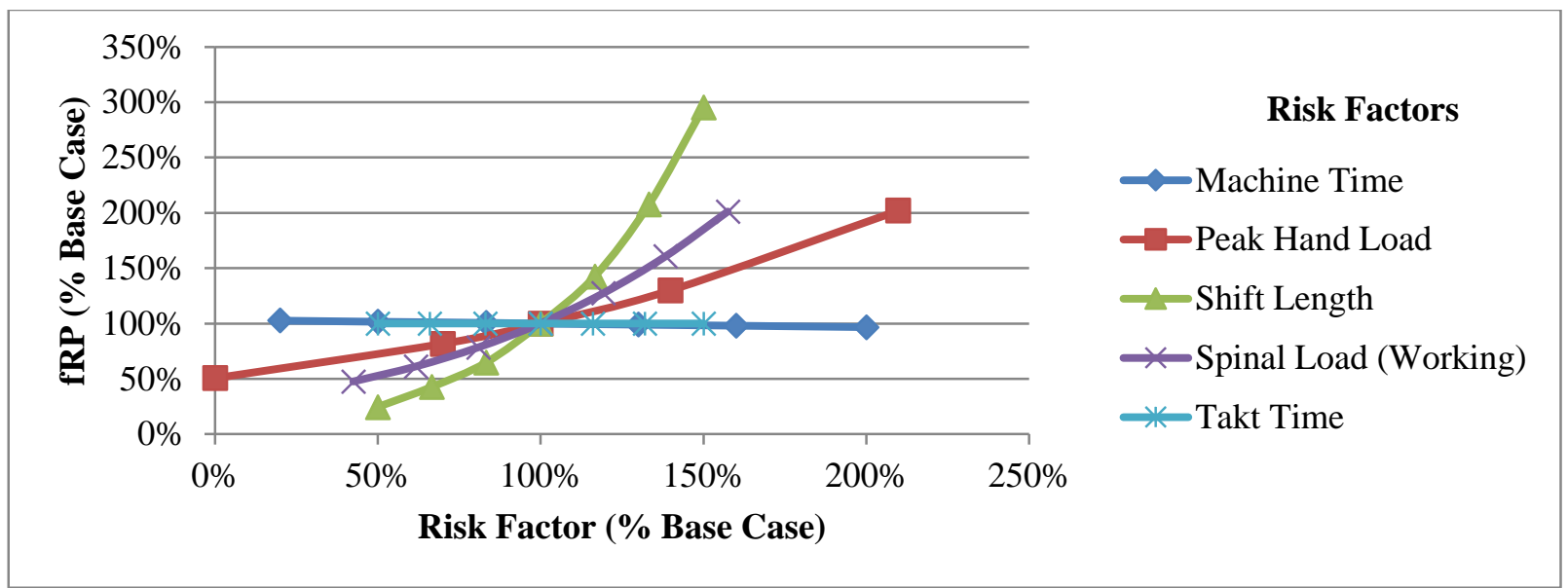

Figure 17. Fraction Reporting Pain (fRP) at the end of Year 1 for Varying Risk Factor exposures

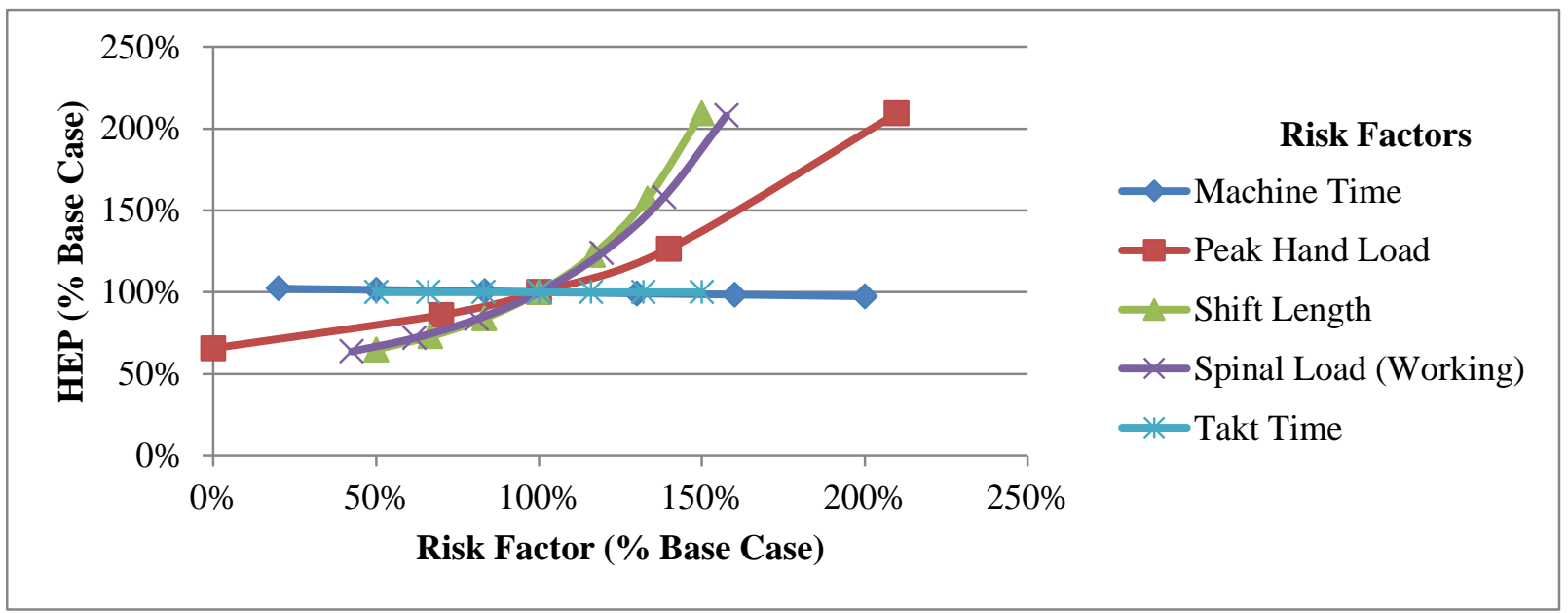

Figure 18. Human Error Probability (HEP) at the end of Year 1 for Varying Risk Factor exposures

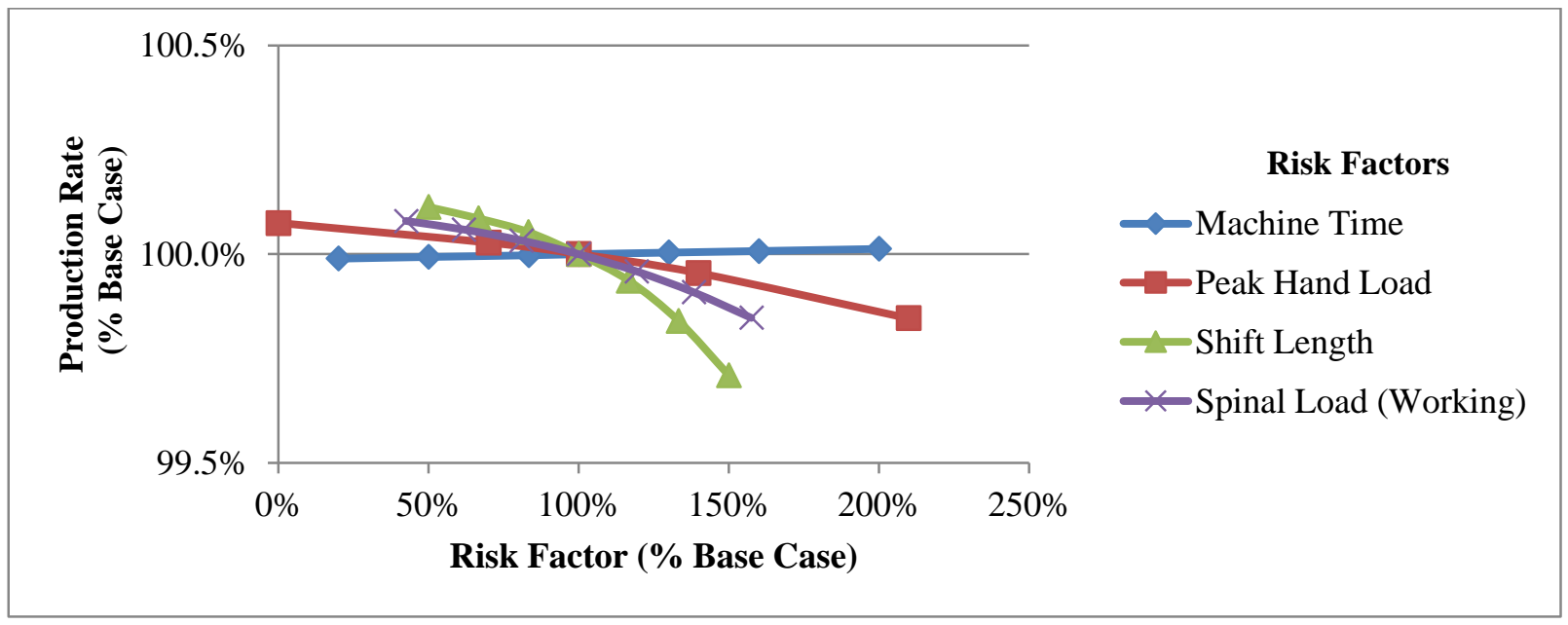

Figure 19. Production Rate at the end of Year 1 for Varying Risk Factor exposures 


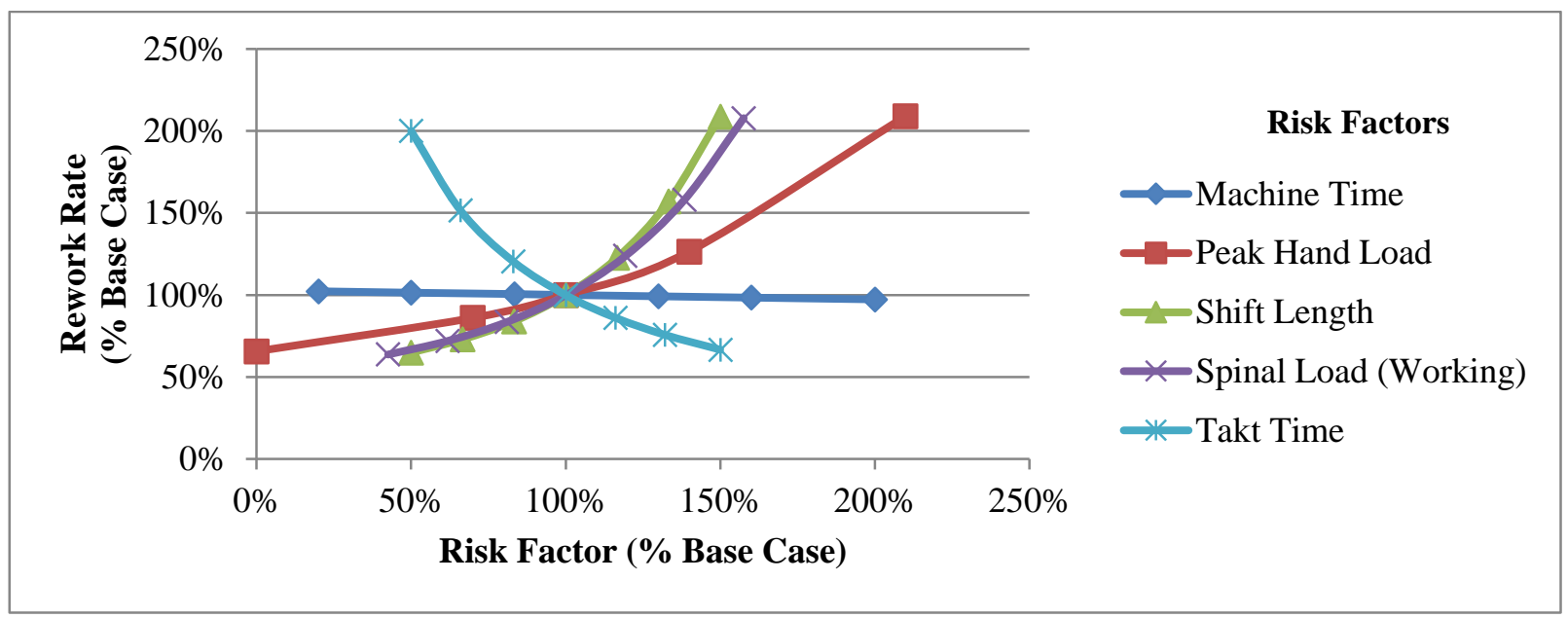

Figure 20. Rework Rate at the end of Year 1 for Varying Risk Factor exposures

Figures 17-20 also show different slopes for each of the five risk factors. Excluding Takt time, Shift Length has the largest slope, with fRP increasing at $0.31 \% / \mathrm{Hr}$ and HEP increasing at $0.04 \% / \mathrm{Hr}\left(\mathrm{R}^{2}=0.9\right)$ for Shift Length. Spinal Load has the next largest slope followed by Peak Hand Load, with Machine Time showing the smallest slope.

The four main model output variables are shown in Figure 21, plotted against the 5-year simulation period, as the exposure to one of the risk factors, Peak Hand Load, is varied. The results only show one of the design variables as the other design variables produce similar trends, with different effect sizes. These effect sizes are listed in Tables A1-A5 in the Appendix.

The fRP in Figure 21(A) increases with both the passage of time and the level risk factor exposure. fRP remains small for low load levels, ranging between 0\%-1\%, and grows larger as the peak hand load is increased, ranging from 1\%-6\%. For smaller values of peak hand load, the changes in the slopes are small, with a slope of $\sim 0 \% /$ day for $0 \mathrm{Kg}$ hand load; however, the larger the load becomes, the larger the slope as well, with $51.5 \mathrm{Kg}$ hand load showing an increase in fRP at $0.001 \% / d a y$. Similar changes can be seen for HEP and rework rate in Figures 21(B), and (D), respectively, where heavier loads lead to a greater and faster increase in HEP and rework rate. The curves for production rate in Figure 21(C) show inverted trends, where an increase in the peak hand load results in a sharper drop in production rate compared to lower hand load levels. The graphs show that the greater the exposure to risk factors, the larger the effect on 
operator health and system performance, with fRP increasing by up to 10 times and HEP and rework rate increasing by up to 15 times as the exposure is increased; however, these effects amplify with time, resulting in even larger growth in injury and decline in performance.

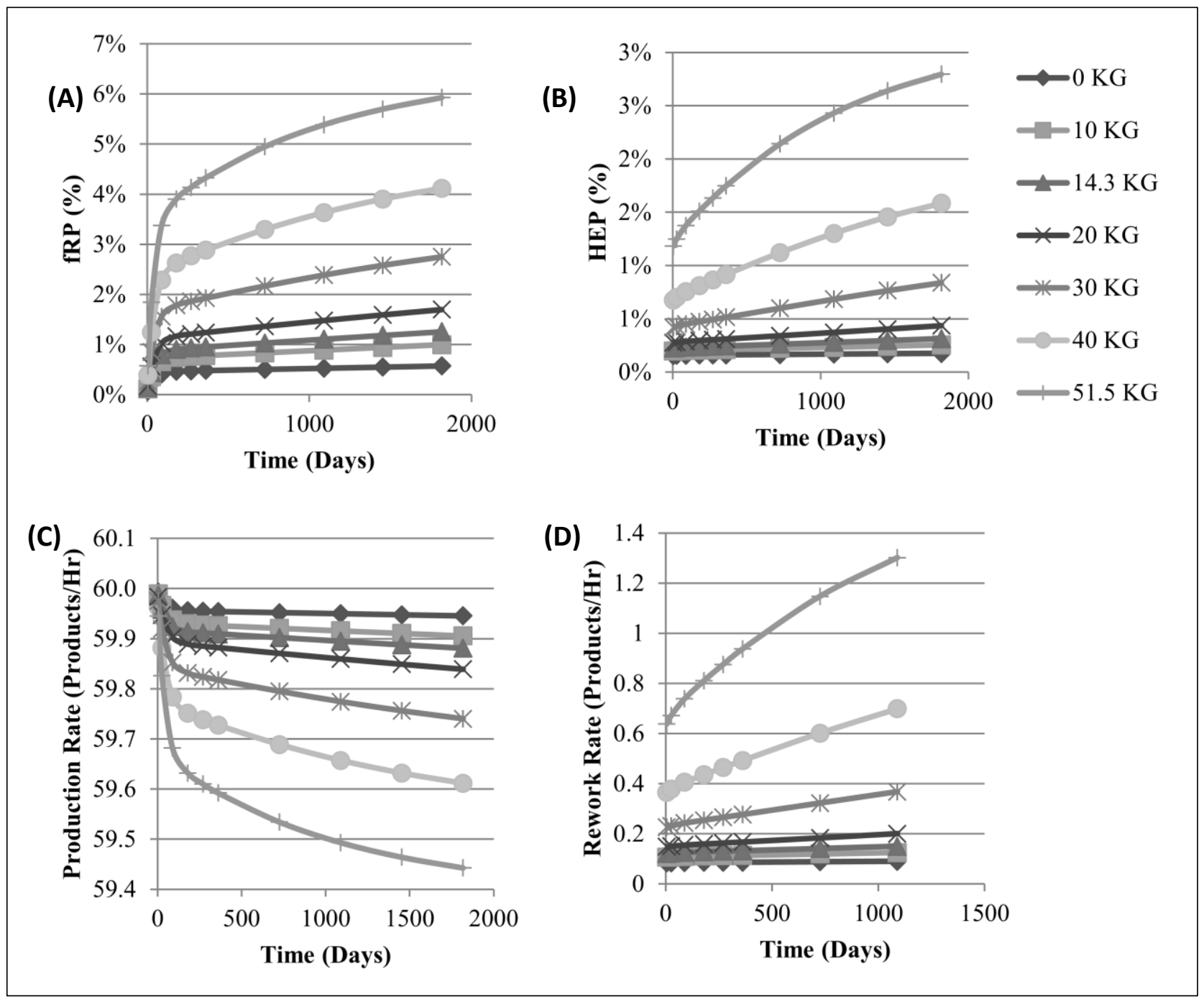

Figure 21. Time-series graph with varying Peak Hand Loads for (A) Fraction Reporting Pain (fRP); (B) Human Error Probability (HEP); (C) Production Rate; and, (D) Rework Rate

\subsubsection{Experimental Analysis}

The results of the experimental analysis answer the following research question: How does the model output respond to an interaction of the risk factors? 

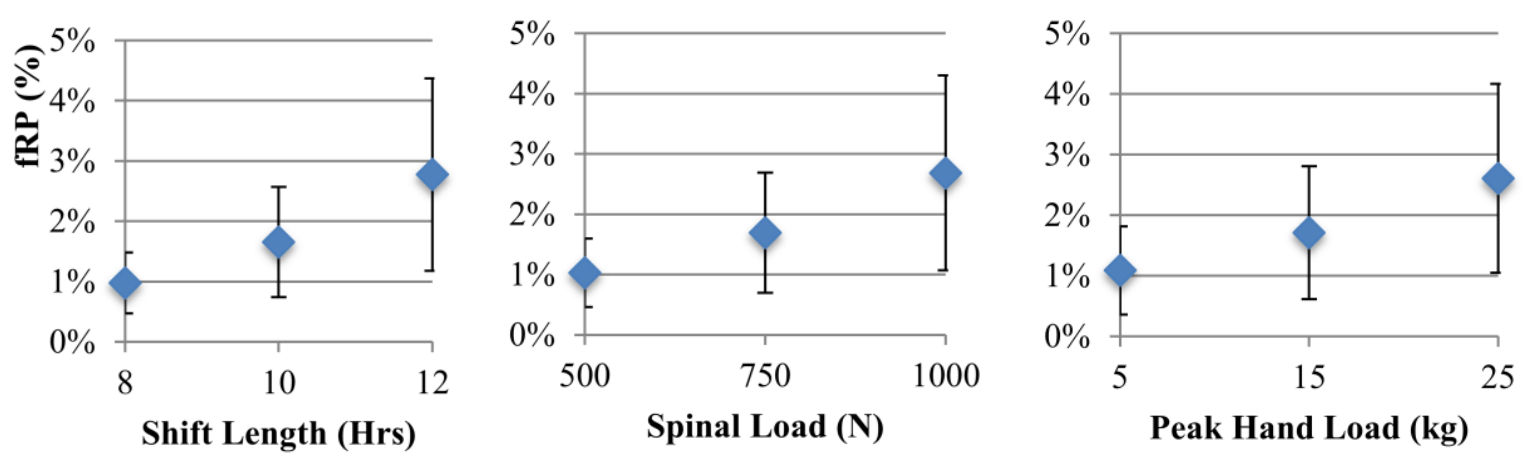

Figure 22. 2-D graphs of the experimental analysis, showing Fraction Reporting Pain (fRP) for varying shift length (left), spinal load (center), and peak hand load (right)
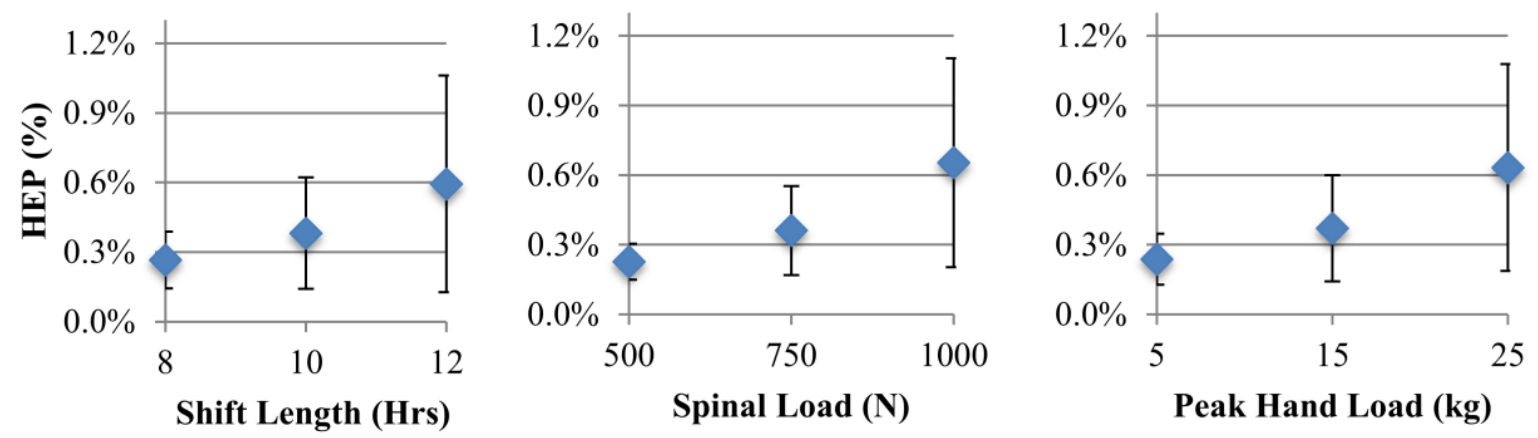

Figure 23. 2-D graphs of the experimental analysis, showing Human Error Probability (HEP) for varying shift length (left), spinal load (center), and peak hand load (right)
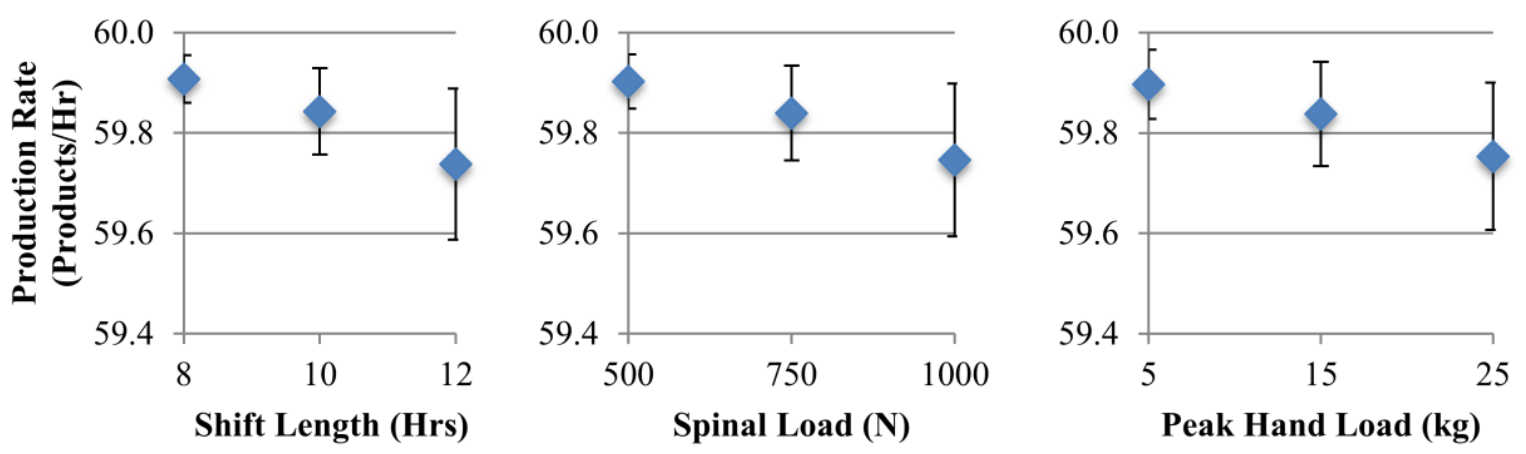

Figure 24. 2-D graphs of the experimental analysis, showing Production Rate for varying shift length (left), spinal load (center), and peak hand load (right) 

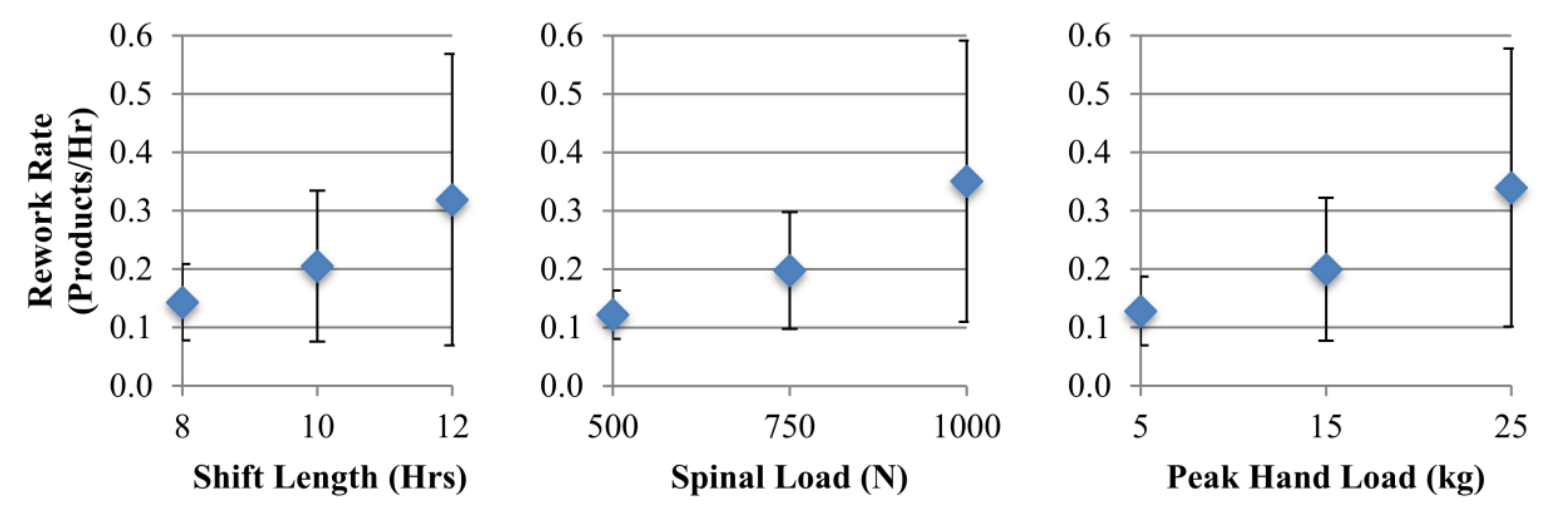

Figure 25. 2-D graphs of the experimental analysis, showing Rework Rate for varying shift length (left), spinal load (center), and peak hand load (right)

The 2-dimensional graphs for each out of the output variables are shown in Figures 22-25, plotted against the three risk factors. The graphs isolate the effect of each of the risk factors on the output. Each data point on the graph is the mean of the output variable values for the given risk factor level, while the error bars represent the standard deviation of the output variable for the given risk factor level. For the selected testing range of risk factor values, each model output shows a very similar trend across all three risk factors. Mean fRP increases from $\sim 1 \%$ to $\sim 3 \%$ of total operators (Figures 22), mean HEP increases from $\sim 0.3 \%$ to $\sim 0.6 \%$ (Figures 23 ), mean production rate drops from $\sim 59.9$ Products/Hr to $\sim 59.7$ Products/Hr (Figure 24) and mean rework rate rises from $\sim 0.1$ Products/Hr to $\sim 0.3$ Products/Hr (Figures 25) for increase from lowest to highest level of either of the three risk factors.

The combined effect of each pair of risk factors - shift length and peak hand load (Figure 26(A)); spinal load and peak hand load (Figure 26(B)); and, shift length and spinal load (Figure $26(C))$ - on the fRP are shown in Figure 26. For each of the graphs, the fRP is smallest, at $1 \%$ of total operators, when both the risk factors are at the lowest level, and largest, at $4 \%$ of total operators, when both the risk factors are at their highest levels. Similar results were seen for HEP and rework rate while the production rate showed inverted trends. 


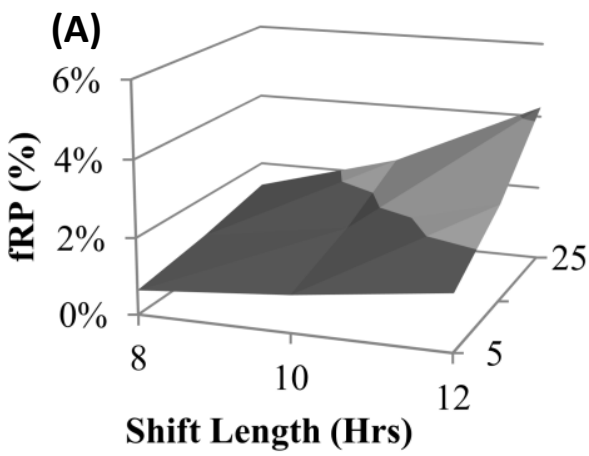

Shift Length (Hrs)

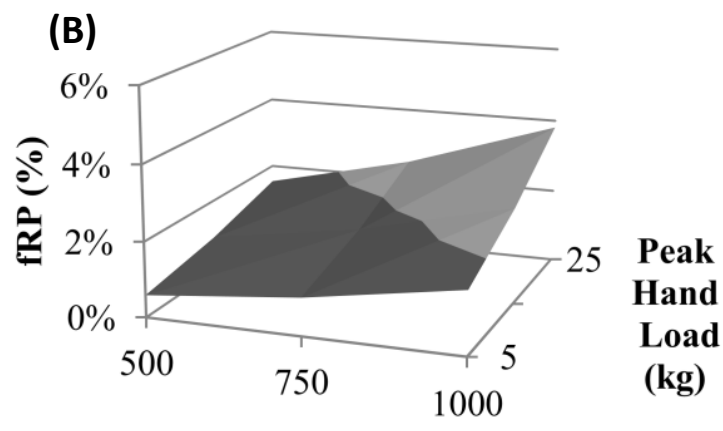

Spinal Load (N)

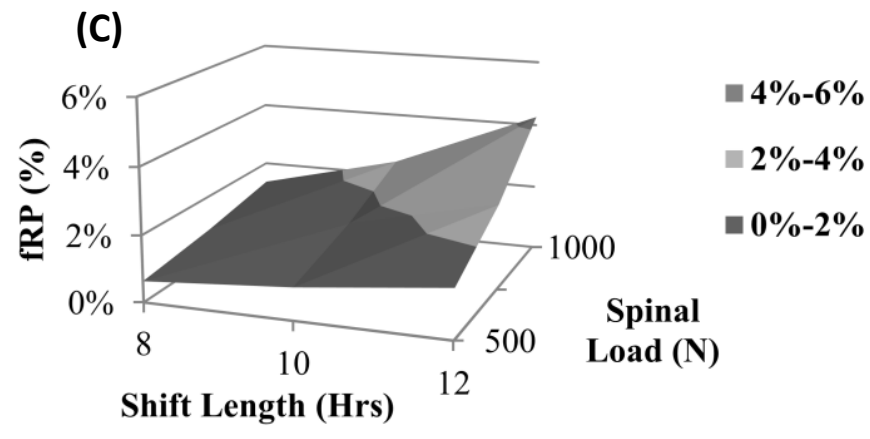

Figure 26. 3-D graphs of the experimental analysis, showing Fraction Reporting Pain for varying (A) shift length and peak hand load; (B) spinal load and peak hand load; and (C) shift length and spinal load

The combined effect of shift length, spinal load (working) and peak hand load on the main output variables is shown in Figures 27-30. For each of these figures, the $x_{-}^{-}, y_{-}$, and z-axis are used to plot the three risk factors. The marker shading and size, on the other hand, are used to represent the value for the output variables. The shade bar on the right side of each figure shows the actual value that corresponds to the marker shade, while relative marker sizes are used to show the direction of effect size (i.e. smallest to largest value) for the output variables.

When all three risk factors are set to their lowest level in Figure 27, the fRP is also the smallest at $0.4 \%$ of total operators (smallest, darkest sphere), while the highest level for the three variables produces the largest fRP at $6 \%$ of total operators (largest, lightest sphere). Therefore, when operators are exposed to multiple risk factors simultaneously, more of them are likely to get injured than if they were being exposed to only one of the risk factors. Similar trends are seen 


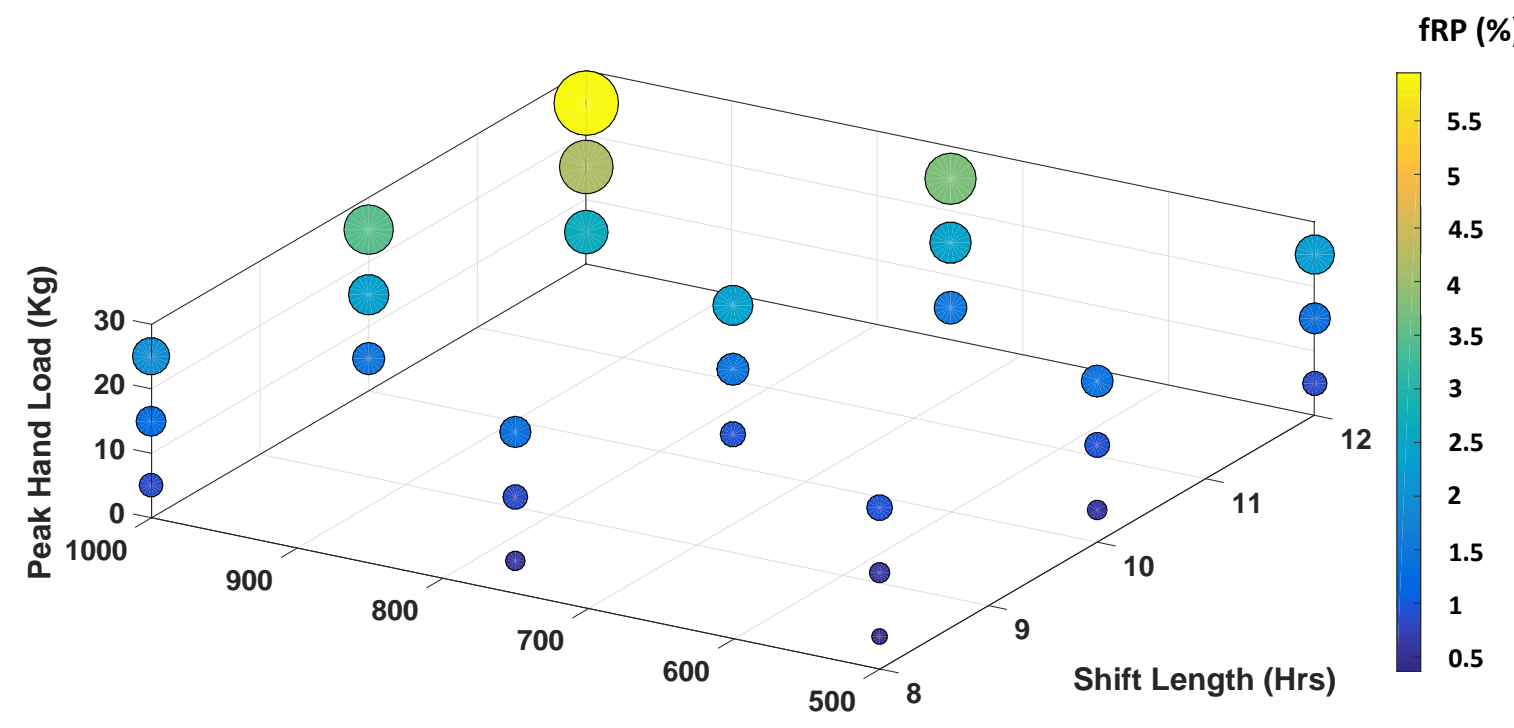

Spinal Load (Working) (N)

Figure 27. Fraction Reporting Pain (fRP) (right hand bar) plotted against Shift Length, Spinal Load, and Peak Hand Load

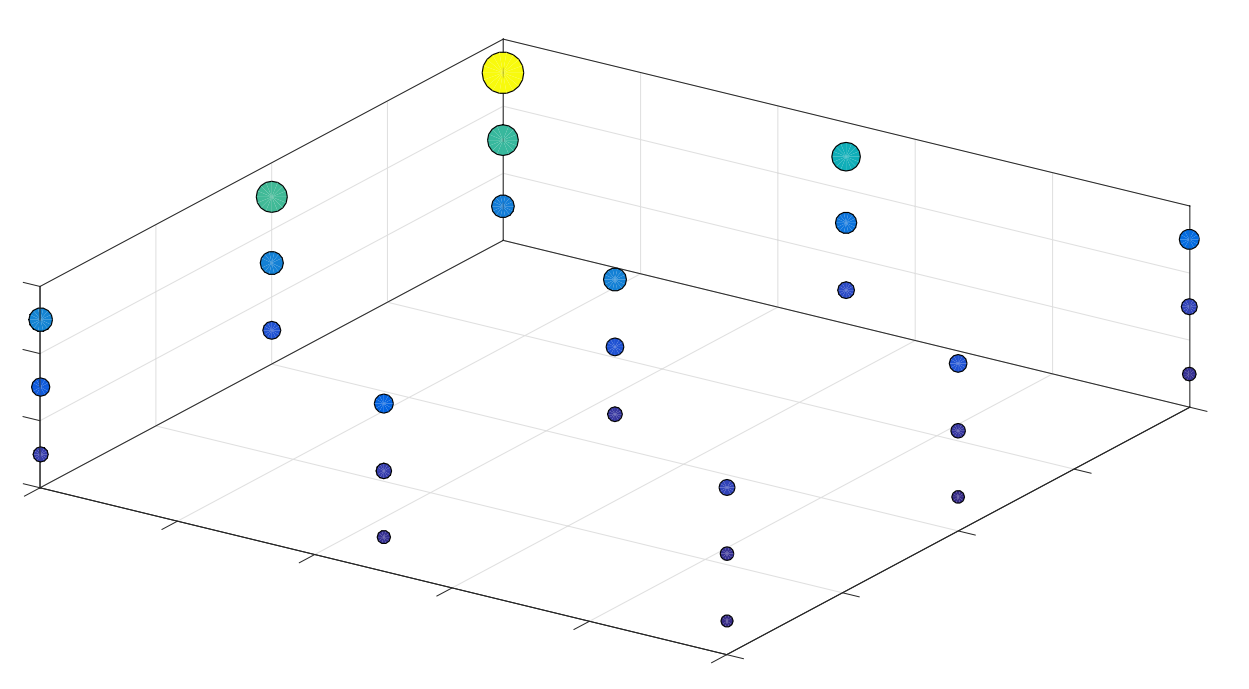

HEP (\%)

1.4

1.2

1

0.8

0.6

0.4

0.2

Figure 28. Human Error Probability (right hand bar) plotted against Shift Length, Spinal Load, and Peak Hand Load

in Figures 28 for the HEP, which increases from $0.1 \%$ to 1.7\%, and in Figure 30 for rework rate which increases from 0.08 Products/Hr to 0.9 Products/ $\mathrm{Hr}$ as the three risk factors are increased from their lowest levels to their highest levels. The production rate in Figure 29 shows the inverse response: when all three risk factors are low, the production rate is highest at 60 
Products/Hr; however, as the three risk factors are increased simultaneously, the production rate drops to 59.4 Products/Hr. Hence, the combined effect of simultaneous exposure to high levels of all three risk factors results in greater injury, error and rework, and lower production than if the operators were exposed to high levels of only one of the risk factors.

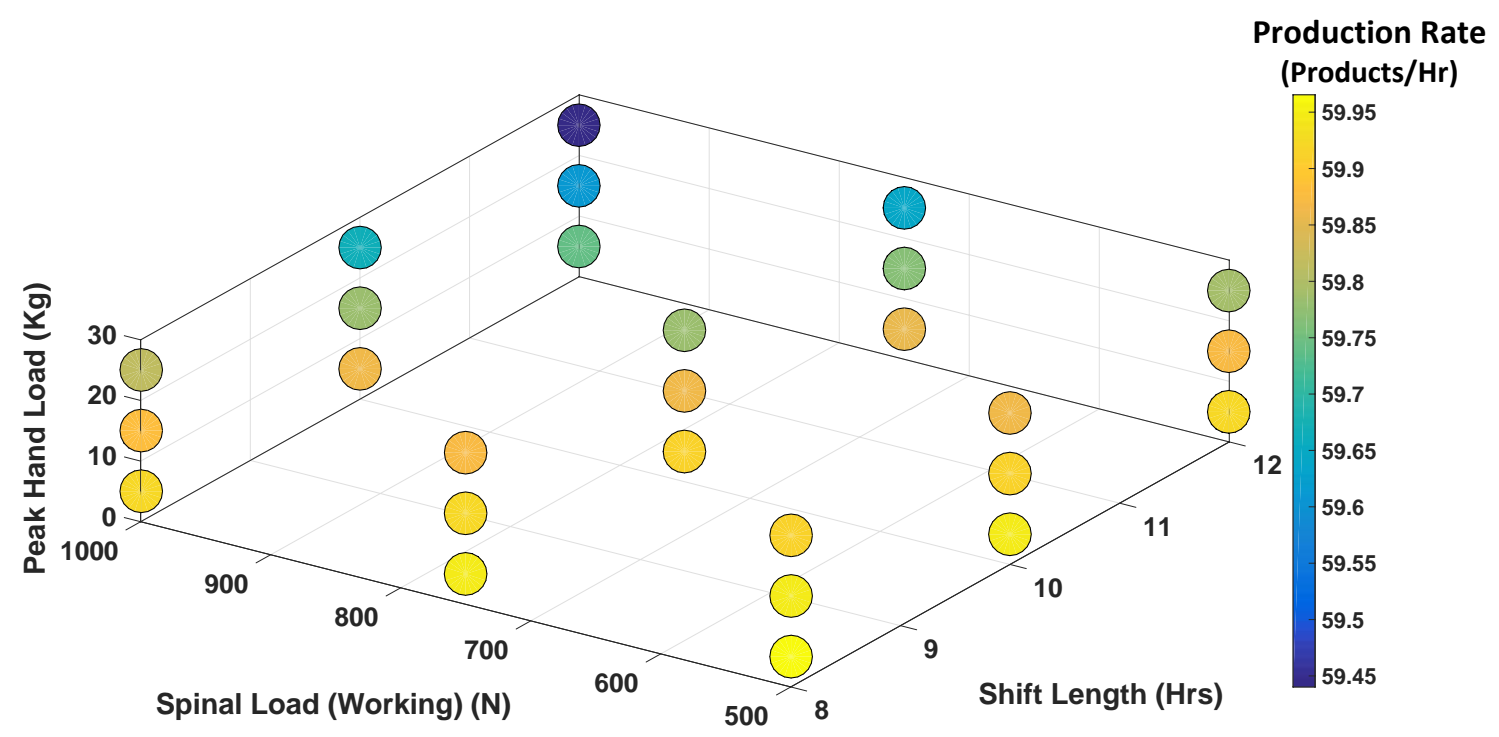

Figure 29. Production Rate (right hand bar) plotted against Shift Length, Spinal Load, and Peak Hand Load

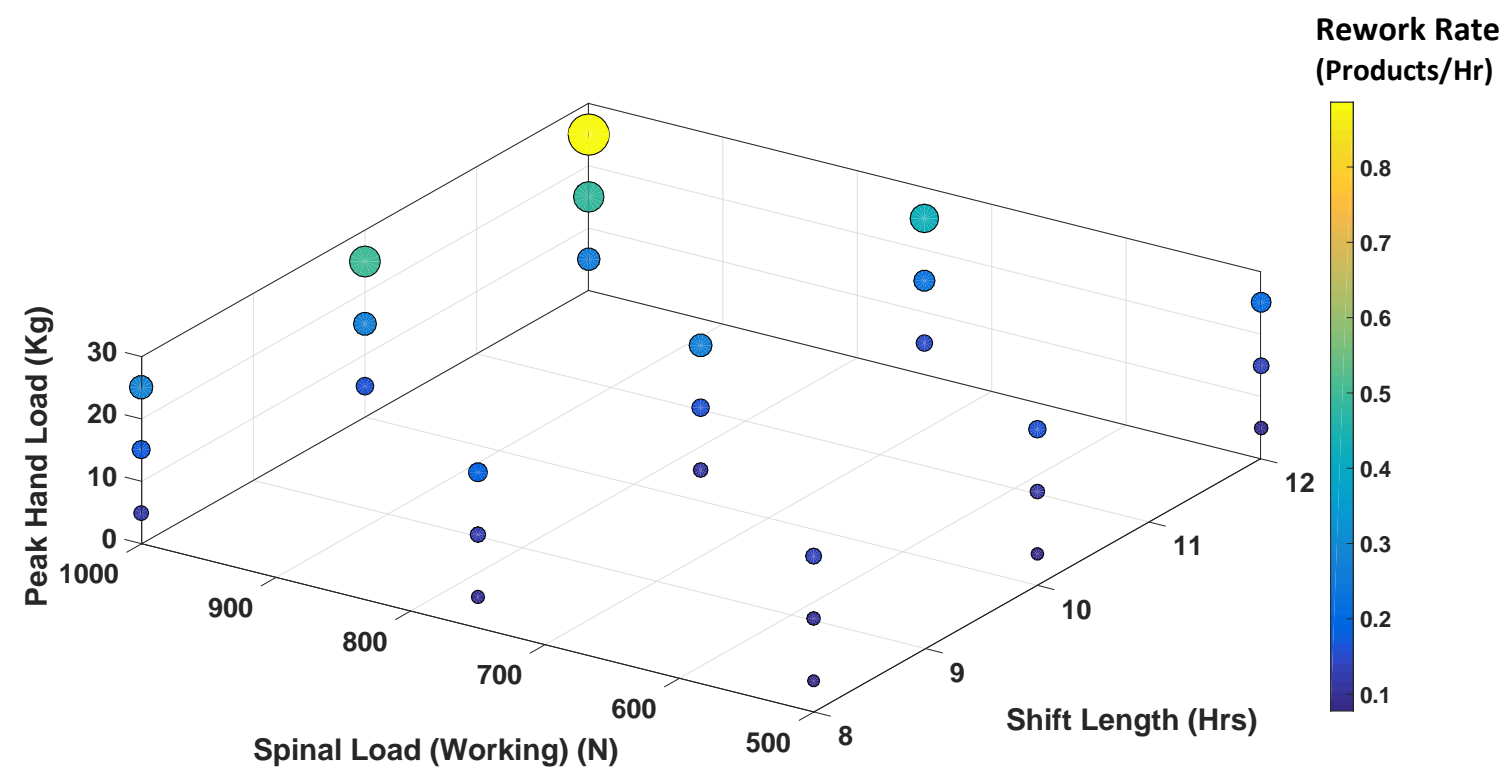

Figure 30. Rework Rate (right hand bar) plotted against Shift Length, Spinal Load, and Peak Hand Load 


\subsubsection{Face Validation}

When presented with the model structure, the quality and H\&S managers approved of the model logic and the conceptual links used within the model. One of them commented, "I didn't really see anything that was missing...it all makes sense from the flow perspective."

\subsection{Discussion}

The current study showed a novel application of SD modeling as a tool that highlights the effects of HF on performance and quality, and may be used to help managers understand this link. The manufacturing model developed in this chapter highlights the importance of HF in the design of work environment. In particular, physical load on the operators' bodies can not only injure the operators, but also affect the quality of their work and the resulting performance of the production system.

Most of the model output parameters were within their range recorded in the literature, while some parameters differed. LBP prevalence (or fRP) from the base case model ranged between 0$1.3 \%$ while the literature records higher values for prevalence, ranging between $7-15 \%$ (Garg et al., 2014; Inoue et al., 2014). This difference can be attributed to the different definitions or criteria used to determine LBP among individuals. The current study uses a relatively conservative definition where a LBP episode is only counted if the individual reports it to the occupational health services at their workplace (Kerr, 1998). However, some studies may count a LBP case individual based on subjective pain ratings (Garg et al., 2014; Inoue et al., 2014). This difference may be the primary reason for a lower LBP prevalence in the model output. The HEP and production rate from the model were closer to their values found in literature. HEP from the base case model ranged between $0.23-0.32 \%$, which fell within $0.002 \%-4 \%$, the range of for HEP found in the literature (Givi et al., 2015; Sobhani, 2014). The production rate for the model remained at $\sim 60$ products/hour, which was also close to the production rate of 52 cars/hour observed by Falck \& Rosenqvist (2014) at the automotive assembly plant they studied.

The current model showed minimal effects of the risk factors on the production rate of the assembly plant. This was true for the manufacturing plant whose managers we interviewed, since their assembly line was automated and the overall production rate remained constant. The current 
formulation, where the percentage injured at work and percentage absent at any given time were multiplied by their weight factors, resulted in a very small effect of injury on productivity. However, depending on the type of assembly line being modeled, the formulation may be modified to yield effects between 3\%-34\% as found in the literature (Sobhani, 2014).

Of the five risk factors analyzed in simulation results, Takt Time differed the most in trends. As Takt time was increased, the injury remained the constant while there was a sharp drop in the production rate, and the resulting yield and rework rates. This is because the model does not capture the effect of kinematic velocity on injury. Without any velocity effects, as long as the active cycle time is the same fraction of Takt time, the average spinal load will remain the same and the LBP prevalence will not be affected. However, in reality, as the Takt time is reduced, the operators may be forced to perform the same task in a shorter amount of time, increasing the risk of MSD injuries resulting from high work pace (Kerr, 1998; Landsbergis, Cahill, \& Schnall, 1999; Norman et al., 1998). Future models may consider including the kinematic velocity as a risk factor to observe its long-term effects on injury and productivity.

The results from the model teach some useful lessons regarding the relationship between the risk factors, the health of the operators, and the system performance. The time-based outputs of the base case model not only show that the presence of risk factors increases the likelihood of injury (Kerr, 1998; Norman et al., 1998), but also that as time passes, more people become injured and develop pain. This continuous rise in injuries, and the resulting drop in quality and productivity, is due to the reoccurrence of LBP injuries (Hoy et al., 2010; Marras et al., 2007). The incidence of a LBP injury acts like a tipping point where once a person has been injured, they are likely to suffer subsequent re-injuries, resulting in a downward spiral of greater quality and productivity losses. To avoid this cycle of LBP injury reoccurrence, managers need to implement proactive solutions, like including HF in workplace design, that can provide a healthy work environment where operators do not develop discomfort or injury, and thereby costs associated with quality and productivity losses are avoided (Falck \& Rosenqvist, 2014; Rose et al., 2013).

The results of the sensitivity analysis show some risk factors to have a steeper slope and therefore a greater effect on injury and performance than other risk factors. For the work 
environment modeled, Shift Length has the greatest effect on injury and system performance, with fRP increasing by $0.31 \%$ and HEP increasing by $0.04 \%$ for every extra hour worked. Machine Time, on the other hand, has the least effect on injury and system performance. Such model results that highlight which risk factors can have a greater effect on health and performance are very useful since they can help managers target the risk factors within their production systems that affect the performance of their systems the most.

This study shows the feasibility of using SD modeling to create models at the level of the system or organization that can explore the effects of design factors and policy issues. This method is different than other commonly used modeling techniques in the industry such as Discrete Event Simulation (DES) and Agent Based Modeling (ABM). Where DES and ABM look to model finer details and individual, discrete aspects within a system (Borshchev, 2013), SD usually models aggregates within the system (Sterman, 2000). The purpose of each modeling technique also differs: DES is often used to understand the process or special events that take place within a system; ABM is used to model changes within a system as a result of interactions between individuals; SD, on the other hand, is used to model and understand the cause-effect-feedback relationships and behaviors within a system (Borshchev, 2013). Since SD models are based on the mental models of managers, such models could also provide managers with a platform to test their assumptions about the system (Sterman, 2000). Compared to other modeling techniques, SD provides the managers with a different understanding and perspective of the important factors and interactions within the system.

\subsubsection{Model Validity}

The current model is based on the empirical relationships found in the literature (Bernard \& Putz-Anderson, 1997; National Research Council, 2001). Most of these studies used in the model look at a specific production system or assembly line. We assume for the current model that the studies from these different contexts apply validly to our model. Some of the model relationships were also assumed by the research team or estimated by the industrial managers. The relationships and values that were estimated by the research team were done so due to unavailability of research studies that look at the parameters needed for the model. To the researcher's knowledge, these values are reasonable estimates for an automotive assembly line; 
however, empirical values may be substituted within the model as they become available in the literature. Further research is needed to address these gaps, which are listed in the sections below.

The model has only been face-validated with a small sample, namely a Quality manager and a Health \& Safety manager in a manufacturing company. A complete validation of the model is outside of the scope of this project. However, for further validation of the modeling approach, the model needs to be adapted to a specific manufacturing plant or a station within the plant. This would require talking to managers and obtaining data regarding the risk factors and quality outputs for the plant/station; modifying the model structure to include these risk factors and quality outputs specific to the plant/station; and comparing the output of the model to the data obtained from that plant or station over similar multi-year time frames.

\subsubsection{Mangers' Perspectives}

The managers made some suggestions that could better cater the model to their needs. The managers mentioned that the model would be easier to understand if it was adapted to a specific team or station rather than a general assembly line. This could also facilitate model validation as the results of the model could then be compared to the health and performance outputs for that team or station. The quality manager also noted that the model would be more useful for them if it could show which stations were leading to quality and productivity problems so that those stations could then be targeted for future changes and interventions. These suggestions could be incorporated into future versions of the model to better cater the model to the interests of industrial managers.

Another area that requires further research is regarding the effect of pain on work pace. When asked about whether a person with pain performs slower and holds back the line, the H\&S manager indicated that the company did not measure such effects. However, research into such effects can help determine whether pain can contribute to errors and production defects at individual stations. It may also redirect the focus of HF-related research that currently looks mainly at reported injuries (Kerr, 1998; Norman et al., 1998) to also include pain by itself as a health outcome and productivity and quality indicator (Garg et al., 2014). 


\subsubsection{Future Work}

The main objective of the current study was to show the feasibility of using the SD modeling technique to quantify the link between HF and health of the operators as well as the performance of the system. Therefore, a basic model was developed that could be followed and easily understood by managers. The current model only looks at LBP injuries. However, the model may be adapted to look at other aspects of how HF affects health and system performance.

MSD injuries related to other body parts, such upper extremity shoulder pain, could also be included in the model. This would require adding the risk factors specific to the MSD for each body part, while creating feedback links to accommodate for any interactions between these risk factors. Other biomechanical risk factors could be used in the model to explore their affect on the model output (Kerr, 1998; Norman et al., 1998). For example, repetitive work facilitates learning (Givi et al., 2015; Helander, 2006) but increases the likelihood of MSD injury (WorkSafeBC, 2001), and injury-related turnover (Winterton, 2004). If an operator performing a repetitive task is injured, and fails to return to work because of their injury, a new operator will take their place. This can change the overall experience or learning pool of operators, their productivity and the quality of their work. Such factors could be included in the model to explore the combined effect of the risk factors on injury, turnover, experience, and productivity. As quantitative research around cognitive and psychosocial risk factors grows, risk factors in these areas may also be included in the model to explore the cognitive and psychosocial side of the problem.

The model building process also brought forward many gaps in the literature, where quantitative data was unavailable for a model variable or relationship. Each of these gaps can provide avenues for further research. One such area is that of the reoccurrence of LBP injuries, where the time delay between exposure to risk factors and the occurrence of injury (Orchard, James, Portus, Kountouris, \& Dennis, 2009); as well as the effect of each injury episode on the likelihood of a subsequent injury have not been studied in depth in the manufacturing context. The time delay is important to quantify since the managers may not observe the effects of a design risk factor or intervention immediately, and this can make it difficult for them to attribute changes in certain health or quality outputs to their true cause(s) (Sterman, 2000). Some of the studies found on the reoccurrence of LBP injuries show that if an individual has prior LBP 
history, they are at a greater risk of another injury episode (Cassidy, Côté, Carroll, \& Kristman, 2005; Marras et al., 2007; Wasiak, Kim, \& Pransky, 2006). However, these studies do not quantify the increase in the likelihood of each subsequent injury/episode that results from the onset of a LBP injury/episode. The current model assumed a declining increase in LBP risk after the first LBP injury. However, further research needs to be performed to develop realistic LBP reoccurrence models that can show how each LBP episode affects the probability of a subsequent episode of pain or injury.

Another area that requires further research is that of the relationship between risk factors (or workload) and HEP. For the SD model, we needed a HEP model that could show HEP as a function of the time spent working and workload exposure. However, the available research does not provide a model of HEP as a time-based function of the risk factors. HEP models by Givi et al. (2015) and Myszewski (2010) show HEP as a continuous function of time but do not account for workload in their models. Some of the existing fatigue models (Dode, Greig, Zolfaghari, \& Neumann, 2016; Neumann et al., 2016; Perez et al., 2014) show fatigue as a function of time and workload (\% maximum voluntary contractions); however, there are few studies that provide a quantitative model directly linking workload to HEP. Therefore, there is a need for a HEP model that can show HEP as a function of time spent on the job and the risk factor (or workload) level.

The following list summarizes the research questions that need to be answered to address the gaps in research discussed above:

1. How long is the delay between exposure to risk factors and the onset of muscle injury for an assembly line operator?

2. How does workload and time spent working affect Human Error Probability (HEP) (continuous time model at the shift level)?

3. By how much does each LBP episode $\left(1^{\text {st }}, 2^{\text {nd }}, 3^{\text {rd }}, \ldots\right)$ increase the probability for a subsequent LBP episode $\left(2^{\text {nd }}, 3^{\text {rd }}, 4^{\text {th }}, \ldots\right)$ ?

4. a) What factors contribute to defective or unfinished products at a station?

b) (How) Does pain by itself (without injury) affect the ability of an assembly line operator to finish a task in the assigned time? 


\subsection{Conclusion}

The study demonstrated a novel application of SD modeling as a tool that can help managers, designers and others within the industry understand the effect of HF risk factors on the health of the operators as well as the performance of the manufacturing system. The model quantified the effects of LBP risk factors on the health of operators as well as the performance of a production system. These health and performance effects could grow stronger with the passage of time.

Over the 5-year simulation period of the base model, percentage of operators reporting pain increased from $\sim 0 \%$ to $1.3 \%$, HEP increased by $40 \%$, production rate dropped by $0.2 \%$, and rework rate rose by $40 \%$. This highlights a cautionary point for managers and designers who may not see an immediate impact of a poor design but may face quality problems over time.

The health and performance effects could also become stronger if the operators were exposed to multiple risk factors simultaneously. The experimental analysis results for the highest level of Shift Length, Spinal Load and Peak Hand Load, combined, produced 15 times higher fraction of operators reporting pain, 10 times higher HEP, 0.9\% lower production rate, and 10 times higher rework rate compared to the combined lowest level of the three risk factors. Hence, proactive HF inclusive design is needed to avoid the development of LBP and the associated quality and productivity losses observed in the model results. The current model shows the feasibility of the modeling technique, with further development of the current model and detailed model validation to be performed as future work. 


\section{Chapter 3 - A SD Model Linking HF Risk Factors to Health and Quality of Care in Nursing}

\subsection{Introduction}

In the last few decades, the nursing literature has started to focus more on the problems of high nursing workload and low staffing and their impact on patient safety. A 2005 national survey reported more than $50 \%$ of nurses arriving early or staying late, and working through their breaks to meet their work demands (Shields \& Wilkins, 2006). Three in ten nurses reported working an average of 5.4 hours of paid overtime every week, while nearly half the sample reported working 4 hours of unpaid overtime per week (Shields \& Wilkins, 2006). High workload and low staffing has not only been associated with nurse burnout and job dissatisfaction (Aiken, Clarke, Sloane, Sochalski, \& Silber, 2002), but directly links to patient quality of care (Duffield et al., 2011; B. Rogers, Buckheit, \& Ostendorf, 2013; Tucker \& Spear, 2006). In addition to this, high workload and low staffing also have long-term consequences for the nurse shortage, with the Canadian Nursing Association estimating a nurse shortage of 60,000 full-time equivalent registered nurses (RNs) by 2022 in the absence of any workplace reforms (Canadian Nurses Association, 2013). The current situation makes it critical to provide better work conditions for the nurses to ensure improved quality of care and greater nurse retention. Modeling can further this agenda by highlighting and helping administrators and policy-makers understand the links between HF, nurses' health and patient quality of care, in order to gain their support for better work policies and healthier work environments.

System Dynamics has been previously used by researchers in healthcare to explore a diverse set of problems: to study the factors that contribute to waiting times in accident and emergency units (Lane, Monefeldt, \& Rosenhead, 2000); to model patient satisfaction in a sustainable healthcare system (Faezipour \& Ferreira, 2013; Marshall et al., 2013); to plan and design chronic illness management programs (Hirsch \& Homer, 2004); and to study the effect of various healthcare policies on different care units (Cooke et al., 2007). However, the technique has not been used to address the problem of nursing workload and staffing, and its consequences on both nurses' 
health as well as patient quality of care. The current study will address this gap by exploring SD modeling as a tool to understand some aspects of this problem.

Aim: The aim of this chapter is to explore how the SD modeling technique can be used as a tool to understand the effect of HF on nurses' health and patient quality of care in a healthcare environment.

The study will address the following specific research questions:

1. For the model based on average (base) values, what time-based trends are displayed by the model in terms of nurse fatigue, burnout, absenteeism and medical errors?

2. How do model parameters, such as hospital budget, shift length, nurse workweek, and absence policies, independently affect model output?

The remainder of Chapter 3 is organized as follows: the model building process is described in Section 3.2 while the steps followed for model testing are described in Section 3.3. The results of model testing are presented in Section 3.4, and discussed in Section 3.5.

\subsection{Methodology}

The model building process used to build the nursing SD model is similar to the one used previously to build the manufacturing SD model, where a model framework was developed and used as the underlying logic for the model. A conceptual causal loop diagram (CLD) was developed next, which showed the causal links between various factors within the system. The CLD was based on the model framework, and the cause-and-effect relationships available in the literature, including studies by Garrett (2008); A. E. Rogers, Hwang, Scott, Aiken, \& Dinges (2004); Scott, Hofmeister, Rogness, \& Rogers (2010); as well as those provided by a patient care manager. The variables within the CLD were then operationalized according to their definitions available in the literature. Each link was then converted into a quantitative relationship, based on empirical relationships and data available in the research studies. Where data was unavailable, estimates by a patient care manager and the research team were used. The final simulation model was built and run in the SD software Vensim ("Vensim PLE Plus," n.d.). 
For the healthcare model, the research team interviewed a patient care manager from a local hospital. The interview session was audio-recorded and handwritten notes were made to prevent any loss of information. Key information was extracted from the recording, including any quantitative data that the manager provided.

A preliminary model that was built based on the literature was presented to the manager. The manager suggested changes and additions to the model, some of which were incorporated into the current model and others discussed as future work. The manager was also asked for estimates for some of the relationships and data missing in the research literature. For the relationships, the manager provided an estimate of the low, average and high values of the dependent variables, given the low, average and high values for the independent variables. These relationships will be described in greater detail in the methodology for the simulation model.

\subsubsection{Model Assumptions}

A nursing unit was used as the context for the healthcare model. The model represents a hypothetical nursing unit with 8 nurses who provide care for patients with medium illness severity. To simplify the model, it is assumed that the pool of nurses remains the same with no nurse leaving the job and no new nurses being hired. The nurses are classified as healthy, burntout and absent. If a nurse feels burnt-out, he or she can only recover by taking time off. Absent nurses are assumed to always be covered by temporary, qualified nurses outside of the pool of full-time nurses, and hence do not affect the workload of full-time nurses. All nurses are assumed to be healthy at the start of the simulation, while some of them are exposed to varying workload and may develop fatigue during the simulation.

\subsubsection{Model Framework}

The modeling framework from Chapter 2 was adapted to the healthcare context, and is shown in Figure 31. The nursing model focuses on the 'risk factors' for burnout, since nurse fatigue and burnout is a common problem in healthcare, with literature showing up to $86 \%$ nurses meeting the criteria for burnout syndrome (Cañadas-De la Fuente et al., 2015; Mealer, Burnham, Goode, Rothbaum, \& Moss, 2009). Link A' (Figure 31) shows that risk factors, such as high workload, 


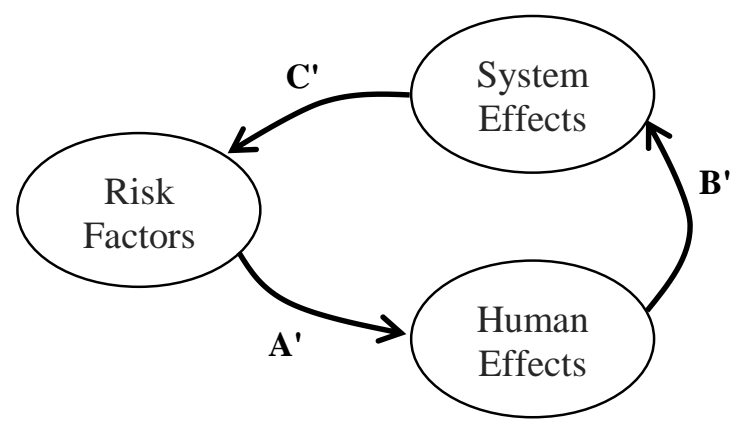

Figure 31. Model Framework showing the logic used to build the model

can affect the health of the nurses. These health effects can range from physical and mental fatigue (Trinkoff, Geiger-Brown, Brady, Lipscomb, \& Muntaner, 2006) to burnout and cynicism (Schaufeli \& Greenglass, 2001). Nurses' health can affect their ability to provide patient care and perform their tasks (Link B'; Figure 31) (Canadian Nurses Association, 2010). However, the quality of patient care they are able to provide can in turn affect the condition of their patients, where a lapse in patient care can create further workload for the nurses (Link $\mathbf{C}^{\prime}$; Figure 31), creating a feedback loop.

\subsubsection{Causal Loop Diagram}

The conceptual causal loop diagram (CLD) in Figure 32 shows the main causal links between HF and the quality of care. The letters in Figure 32 (A-O) refer to the links between each pair of variables, and appear in alphabetical order in the text. The CLD was developed based on the cause and effect relationships in the literature as well as input from the patient care manager. The conceptual map starts with the patient acuity or severity of illness. A nurse can usually take care of multiple patients who are mobile, with less severe conditions. On the other hand, if a patient is severely ill and requires close monitoring and care, such as one in an ICU unit, a nurse can only take care of one or two such patients at a time. Hence, the more severely ill a patient is, the more care they require, and the higher the nurse to patient ratio will be (Links A \& B) (Welton, ZoneSmith, \& Bandyopadhyay, 2009). However, because of budget limitations (Link C), sometimes the actual, or scheduled, nurse-patient ratio (NPR) may be lower than that required based on the patient acuity, resulting in a staff storage (Links D \& E) (Boyle, 2015; Seago, 2002). Because of this shortage, nurses on duty may have to take care of more patients and perform additional tasks, increasing their workload (Link F) (Duffield \& O’Brien-Pallas, 2003). High workload can 


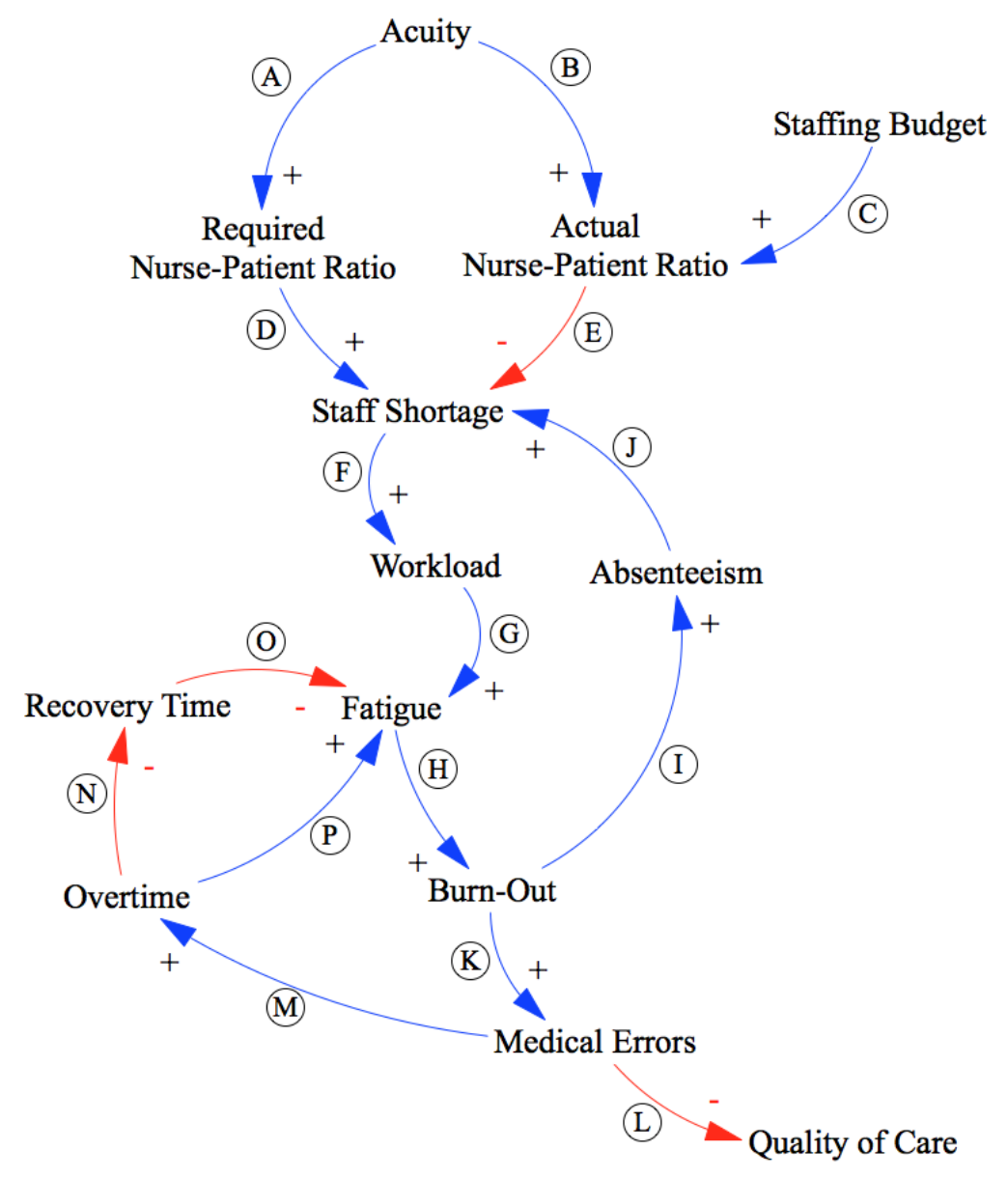

Figure 32. Causal Loop Diagram showing the links between HF and quality of care in nursing result in psychological and physical stress and fatigue (Link G) (Wallace, Lemaire, \& Ghali, 2009), increasing the risk for nurses to feel burnt-out and emotionally exhausted (Link H) (Garrett, 2008). Nurses feeling burnt-out often take time off from work (Link I) (Parker \& Kulik, 1995; Zboril-Benson, 2001), where such unscheduled absences could create further shortage of staff and higher workload for nurses on duty (Link J) (Unruh, Joseph, \& Strickland, 2007). When nurses feel burnt-out, they are also more likely to make mistakes in patient care, especially while giving medication (Link K) (Smith-Miller, Shaw-Kokot, Curro, \& Jones, 2014). These errors not only negatively impact the quality of patient care and patient safety (Link L) (Kiekkas et al., 2008; A. Rogers et al., 2004), but also create a feedback to nurses' workload. The more errors that are made, the longer nurses would have to stay past their shift to correct for the errors and follow any additional protocol resulting from these errors (Link M) (Wolf \& Hughes, 2008). Overtime not only adds to the working hours of the nurse but also reduces the time they may have to rest and recover from the fatigue of the day (Link N) (Givi et al., 2015), feeding back to 
create greater fatigue (Links $\mathbf{O} \& \mathbf{P}$ ) and burnout, more errors and lower quality of care (A. Rogers et al., 2004; Scott et al., 2010).

The CLD developed here highlights the cause-effect links that conceptually connect HF to quality of care in healthcare. The development of the quantitative simulation model based on the model framework and the CLD is described in the next section.

\subsubsection{Simulation Model}

The complete simulation model is shown in Figure 33. The simulation model is divided into the same three sections as the model framework (Figure 31) - risk factors, human effects and system effects. The relationship for each link within these sections was either derived from available empirical relationships in the literature, or estimated by the manager and research team where empirical data was unavailable. These relationships are explained in detail in the following sections. The model parameters in the figures have been numbered in the order that they appear in the text. 


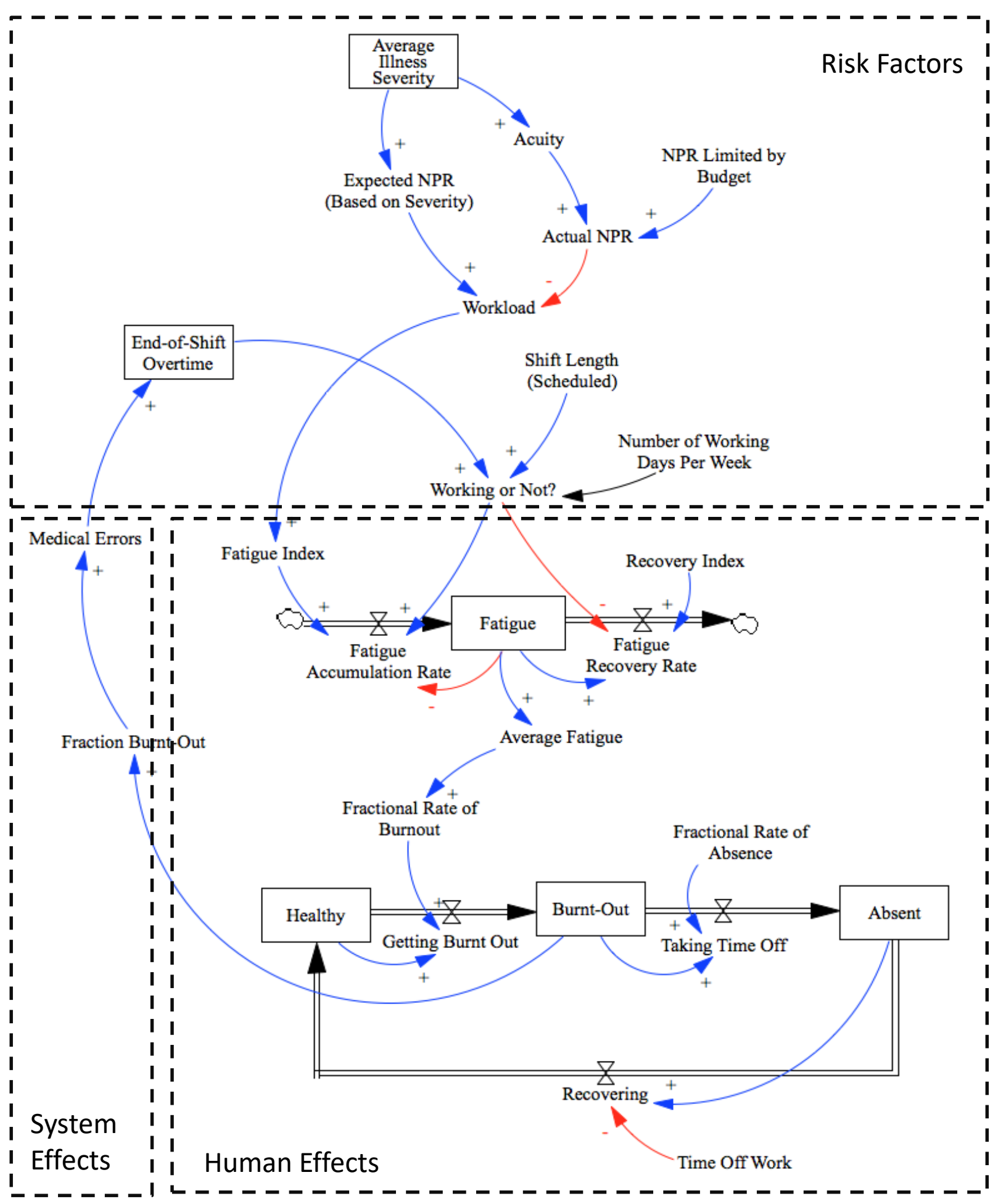

Figure 33. Healthcare simulation model, divided into risk factors, human effects and system effects 


\section{$\underline{\text { Risk Factors }}$}
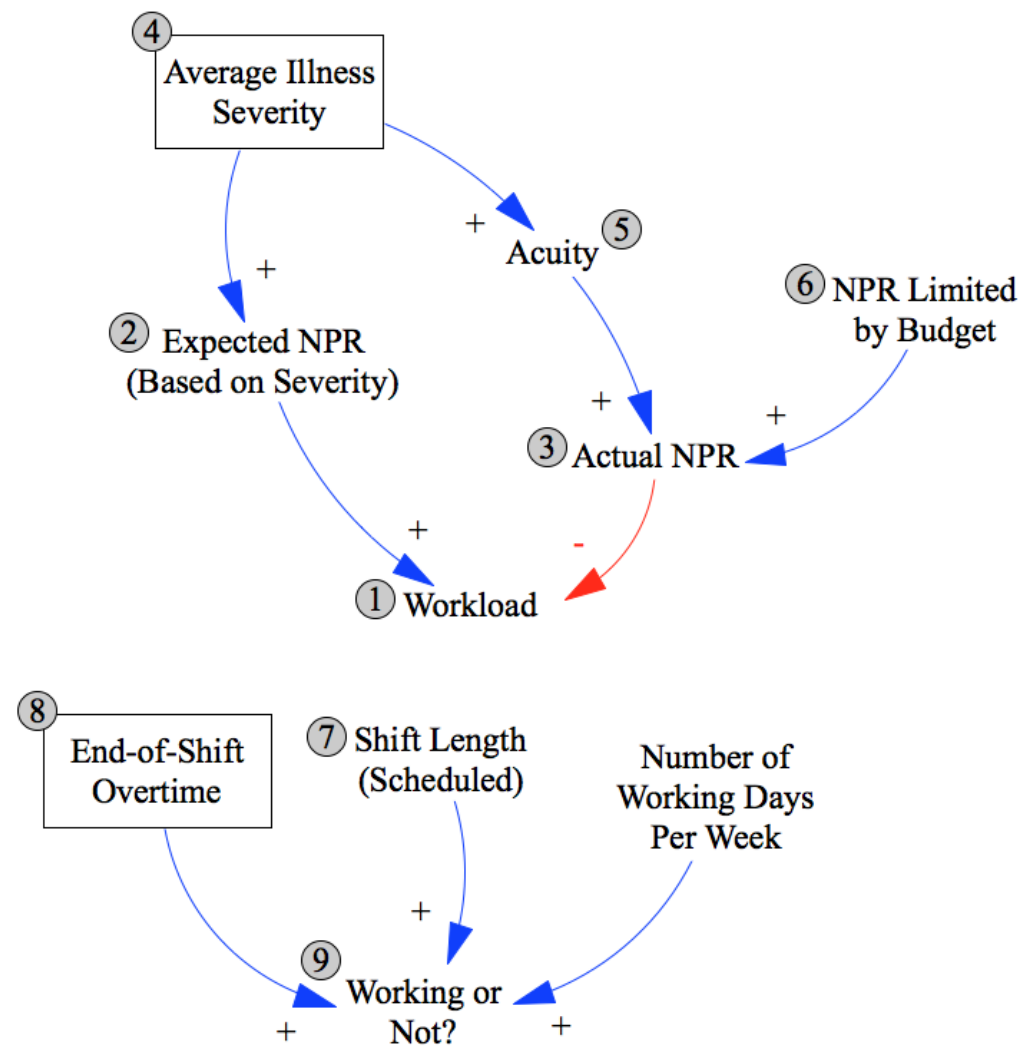

Figure 34. The 'Risk Factors' section of the full-simulation model in Figure 33, isolated to illustrate the link between risk factors and workload

The 'risk factors' section of the model is shown in Figure 34. The two main risk factors for the healthcare model are workload intensity and length of exposure. Nursing workload can be measured in multiple ways. One approach used in the literature is by measuring the nurse to patient ratio (NPR) (Berry \& Curry, 2012). For this model, workload (1) is defined by the researcher as the ratio of the expected NPR (2) to the actual NPR (3), where the expected NPR is that which would be needed to satisfactorily attend to the patient needs (Welton et al., 2009), while the actual NPR is that scheduled by the hospital.

The expected NPR (2) is a function of the average patient illness severity (4), where the average illness severity was defined by the researcher as a continuous illness severity scale between 0 2.99, with 0 marking the lowest severity level and 2.99 marking the highest severity level. The expected NPR (2) is based on the patient assignment used by Welton et. al (2009), where the authors show that NPR is, on average, 1:8 for low severity patients, 1:3 for intermediate severity 
patients, and 1:1 for high severity patients. For the model, the NPR for the lowest severity was adjusted to 1:6 to make it closer to the minimum NPR often seen in hospitals in Ontario, as suggested by a member of the research team experienced with Ontario hospitals. Fitting this patient assignment to our severity scale gives the following function for expected NPR (2):

$$
N P R_{\text {expected }}=(0.1558 * \exp (0.5973 * \text { Illness Severity }))
$$

The actual or scheduled NPR (3), on the other hand, is a function of the patient acuity (5) and NPR limited by hospital budget (6). The patient acuity (5) represents the severity metric used by hospitals and is in discrete steps. For the model, it is defined by the researcher as the whole number portion of the continuous Illness Severity value described above. Since Illness Severity ranges between $0-2.99$, the patient acuity (5) has 3 distinct levels $(0=$ low acuity, $1=$ medium acuity, 2 = high acuity). The actual NPR (3) is calculated using the same formulation as Eq. (12) using acuity (5) in place of "Illness Severity". However, the actual NPR (3) can only increase up to a NPR limit based on the hospital budget (6).

The second risk factor is the length of time the nurses are on duty, and therefore being exposed to the workload. This length of exposure includes the scheduled shift length (7) as well as any overtime (8) that the nurse may work. In the model, this is represented by the binary variable "Working or Not?" (9), that takes on the value 1 during the shift (scheduled and overtime) and remains 0 otherwise.

The two risk factors, workload (1) and length of exposure ("Working or Not?"; (9)) cause the health effects for the nurses explained in the next section.

\section{Human Effects}

The 'health effects' section of the model is shown in Figure 35. When the nurses are exposed to the risk factors mentioned above, they develop fatigue, which results in burnout and absenteeism. The current study defines fatigue as the short-term exhaustion of physical and mental resources. This is different from burnout, which is consists of depersonalization, emotional exhaustion and a sense of low personal accomplishment (Maslach, Jackson, \& Leiter, 1997) resulting from longterm physical and mental exhaustion. 


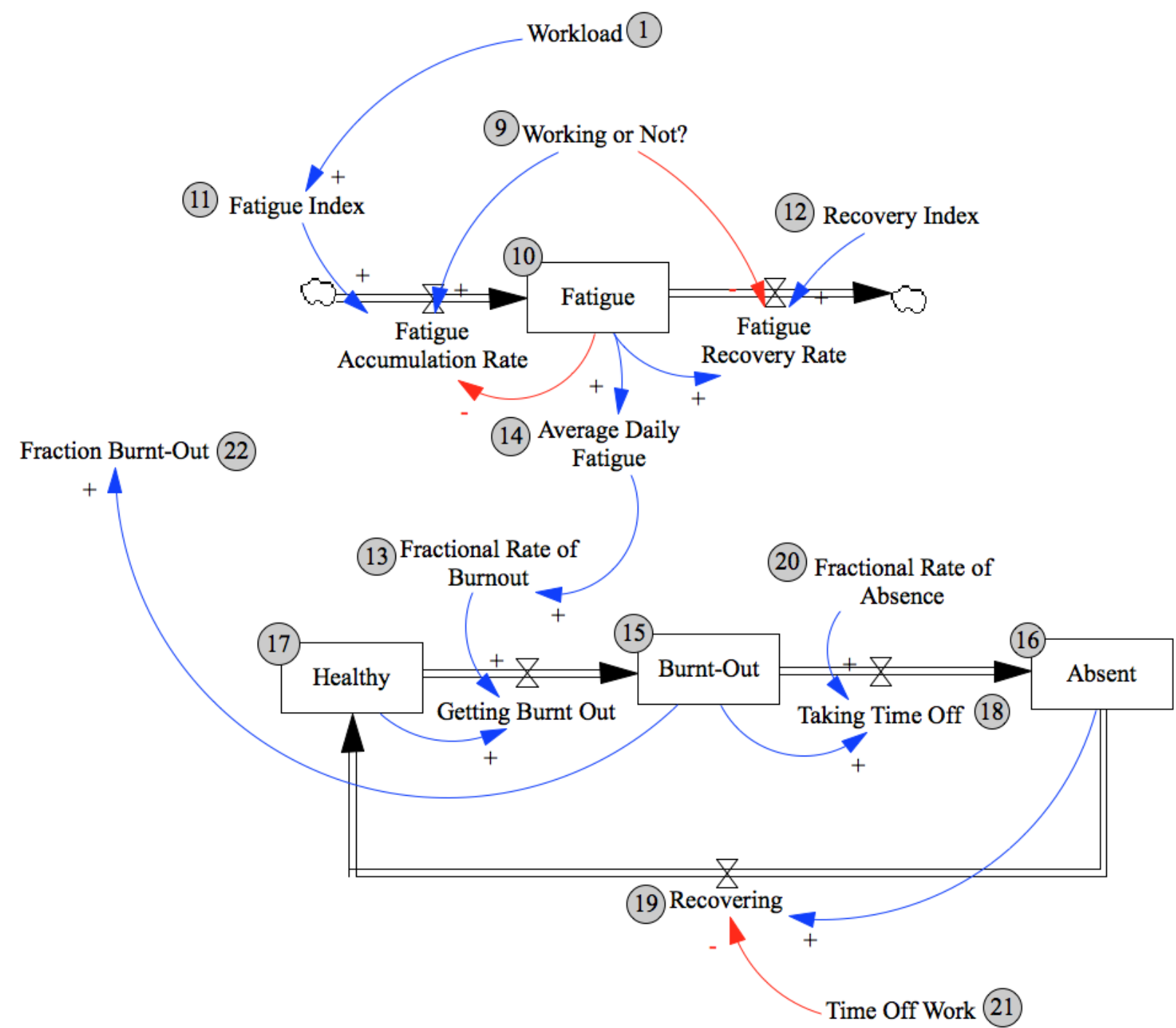

Figure 35. The 'Human Effects' section of the full-simulation model in Figure 33, isolated to illustrate the link between workload and burnout

The fatigue (10) shown in the model is a combination of physical tiredness and psychological stress, and is modeled as a scale between 0 and 100\%, where 0 represents no fatigue among nurses, and 100\% represent complete physical and psychological exhaustion. Fatigue (10) accumulates when the nurses are working and decreases as they recover during off-shift hours (cf. Jaber et al., 2013):

$$
\begin{aligned}
& \text { Fatigue } \\
& =100 \times\left\{\begin{array}{c}
1-\exp \{-(\text { Fatigue Index }) \cdot t\} \\
\exp \{-(\text { Recovery Index }) \cdot t\}
\end{array} \quad \text { if }{ }^{\prime}{\text { Working or Not }{ }^{\prime}=1}^{\prime}=1\right. \\
& \text { otherwise }
\end{aligned}
$$


where the fatigue index (or time constant) (11) and the recovery index (12) are calculated by assuming that nurses would reach 0.60 (or 60\%) fatigue if they worked 8 consecutive hours (Martin, 2015; Winwood, Winefield, \& Lushington, 2006), and recover 40\% of their fatigue if they rested (off-shift) for 16 consecutive hours (Barker \& Nussbaum, 2011; Martin, 2015; Winwood et al., 2006).

It is assumed by the researcher that the nurses would fatigue faster if their workload (1) is higher, making the fatigue index a function of workload. For intermediate workload, the fatigue index (11) takes on the value mentioned above (60\% fatigue in 8 hours); for the lowest workload level, the fatigue index is calculated by assuming nurses reach $20 \%$ fatigue in 8 hours; for the highest workload levels, nurses are assumed to reach 97\% fatigue in 8 hours (Barker \& Nussbaum, 2011; Winwood et al., 2006). Fitting a curve to these values gives the following:

$$
\text { Fatigue Index }=(0.1145 *(\text { Workload }))-0.0573
$$

High levels of workload and fatigue can eventually lead to burnout (Greenglass, Burke, \& Fiksenbaum, 2001; Van Bogaert, Clarke, Willems, \& Mondelaers, 2013). The fractional rate of burnout (13) was one of the relationships developed based on manager's estimates obtained from the interview, where a curve was fitted to the low, medium and high burnout values provided by the manager:

$$
\text { Fractional Rate of Burnout }=0.0002 * \exp (6.0552 * \text { Average Fatigue })
$$

where the average daily fatigue (14) is the fatigue (10) averaged over 24 hours.

It is assumed that nurses can only recover by taking time off. Hence, some of the nurses who feel burnt-out at work (15) will take some time off (16), and then recover back to the healthy state (17), where the rate of absence (18) and recovery (19) are dependent on the fractional rate of absence (20) and time off work (21), respectively (Sterman, 2000). The fraction of nurses at work feeling burnout (22) affects the quality of patient care and this link is described in the 'System Effects' section of the model. 


\section{System Effects (Medical Errors)}

The 'System Effects' section of the model is shown in Figure 36. The current model uses the number of medical errors (23) to represent the effect of nurses' health on system performance.

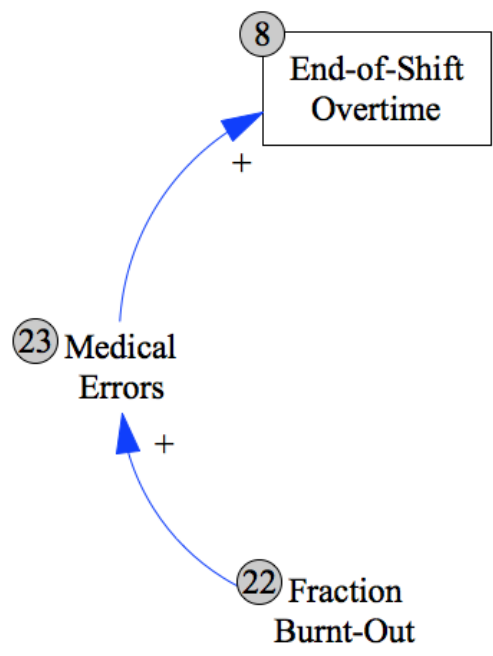

Figure 36. The 'System Effects' section of the full-simulation model in Figure 33, isolated to illustrate the link between burnout, medical errors, and resulting overtime work

As more nurses feel burnt-out, they are at a greater risk of making errors (Cimiotti, Aiken, Sloane, \& Wu, 2012; Shanafelt et al., 2010), which can compromise patient safety (Garrett, 2008). For the model, the medical errors (23) were assumed to be a function of the fraction of nurses feeling burnt out (fB) (22), and were determined by fitting the following curve to the low, medium and high estimates of errors (per unit-day) provided by the manager:

$$
\text { Medical Errors }=(13.373 \cdot \mathrm{fB})+1.0947
$$

The medical errors in turn affect the length of overtime a nurse has to stay past her shift. The length of overtime was estimated by the patient care manager as an average of 45 minutes for each error made by the nurse. This feeds back to increase the workload for the nurse further, creating the risk of a feedback loop with increasing workload, burnout, errors and overtime (Figure 36).

Table 4 lists the definitions for each of the model parameters. The model building process above shows structurally how nursing workload can affect both the health of the nurses as well as quality of care provided by nurses. The next section will test the model for trends between the risk factors, and human and system outputs. 
Table 4. Definitions for Healthcare Model Parameters

\begin{tabular}{|c|c|c|}
\hline Model Parameter & Units & Description \\
\hline Absent & Nurses & $\begin{array}{l}\text { The number of nurses that are absent because burnout at any } \\
\text { given time }\end{array}$ \\
\hline Actual NPR & Nurses/Patient & $\begin{array}{l}\text { Nurse-Patient Ratio scheduled by the hospital based on their } \\
\text { acuity measures }\end{array}$ \\
\hline Acuity & Dimensionless & $\begin{array}{l}\text { A discrete severity metric used by hospitals to determine how } \\
\text { severely ill a patient is }\end{array}$ \\
\hline Average Fatigue & $\%$ & Fatigue averaged over 24 hours \\
\hline Average Illness Severity & Dimensionless & $\begin{array}{l}\text { A continuous scale between } 0-2.99 \text { that represents, on average, } \\
\text { how severely ill the patients are }\end{array}$ \\
\hline Burnt Out & Nurses & $\begin{array}{l}\text { The number of nurses that feel burnt-out due to constant } \\
\text { exhaustion of physical and mental resources }\end{array}$ \\
\hline End-of-Shift Overtime & Hours & $\begin{array}{l}\text { The unscheduled extra time that the nurses work after their } \\
\text { scheduled shift }\end{array}$ \\
\hline $\begin{array}{l}\text { Expected NPR } \\
\text { (Based on Severity) }\end{array}$ & Nurse/Patient & $\begin{array}{l}\text { Nurse-Patient Ratio needed to satisfactorily attend to the patient } \\
\text { needs }\end{array}$ \\
\hline Fatigue & $\%$ & $\begin{array}{l}\text { A } 0-100 \% \text { scale that shows the extent of short-term exhaustion } \\
\text { of physical and mental resources }\end{array}$ \\
\hline Fatigue Accumulation Rate & $\% /$ Hour & The rate at which fatigue increases during the shift \\
\hline Fatigue Index & 1/Hour & Fatigue accumulation time constant \\
\hline Fatigue Recovery Rate & $\% /$ Hour & The rate at which fatigue recovers during the off-shift hours \\
\hline Fraction Burnt-Out (fB) & $\begin{array}{l}\% \text { of Total } \\
\text { Nurses }\end{array}$ & The fraction of total nurses that feel burnt-out \\
\hline $\begin{array}{l}\text { Fractional Rate of Absence } \\
\text { (fRA) }\end{array}$ & 1/Hour & $\begin{array}{l}\text { The fraction of burnt-out nurses per hour that take time off to } \\
\text { recover }\end{array}$ \\
\hline $\begin{array}{l}\text { Fractional Rate of Burnout } \\
\text { (fRB) }\end{array}$ & 1/Hour & The fraction of healthy nurses per hour that feel burnt-out \\
\hline Getting Burnt Out & Nurses/Hour & The number of healthy nurses per hour that feel burnt-out \\
\hline Healthy & Nurses & The number of nurses that are healthy (at work with no burnout) \\
\hline Medical Errors & Errors/Unit/Day & $\begin{array}{l}\text { The number of errors or mistakes made by the nurses in a unit } \\
\text { on any given day }\end{array}$ \\
\hline NPR Limited by Budget & Nurses/Patient & $\begin{array}{l}\text { The maximum NPR that can be scheduled based on the hospital } \\
\text { budget }\end{array}$ \\
\hline $\begin{array}{l}\text { Number of Working Days Per } \\
\text { Week }\end{array}$ & Days & $\begin{array}{l}\text { Number of days, on average, that the nurses are scheduled to } \\
\text { work in a given week }\end{array}$ \\
\hline Recovering & Nurses/Hour & $\begin{array}{l}\text { The number of absent nurses per hour that return to work after } \\
\text { recovering from burnout }\end{array}$ \\
\hline Recovery Index & 1/Hour & Fatigue recovery time constant \\
\hline "Shift Length (Scheduled)" & Hours & $\begin{array}{l}\text { The numbers of hours of scheduled work the nurses perform in } \\
\text { a given day }\end{array}$ \\
\hline Taking Time Off & Nurses/Hour & $\begin{array}{l}\text { The number of burnt-out nurses per hour that take 1-day off to } \\
\text { recovering from burnout }\end{array}$ \\
\hline Time Off Work & Hour & The average time the nurses on absence spend away from work \\
\hline Working or Not? & Dimensionless & $\begin{array}{l}\text { Binary variable that shows if the nurses are on shift }(=1) \text { or not } \\
(=0)\end{array}$ \\
\hline Workload & Dimensionless & The ratio of Expected NPR to Actual NPR \\
\hline
\end{tabular}




\subsection{Model Testing}

The model was run with two sets of inputs to understand model behavior: (1) an average or base case set of values, and (2) a one-factor-at-a-time (OFAT) (Daniel, 1994) sensitivity analysis. Each of these will be discussed in detail in the sections below.

\subsubsection{Base Model}

The model was run with the base case values given in Table 5. For some parameters, the values were estimated as an average of the range found in the referenced literature; for other parameters for which no empirical data could be found in the literature, estimates by the manager and the research team based on their knowledge of the healthcare system were used instead. The model was only run for a period of 4 weeks ( $672 \mathrm{Hrs}$ ) as the model reached a steady state by the end of the $4^{\text {th }}$ week, making longer runs redundant.

Four model output parameters from the base case run of the model are shown in the results: fatigue level; percentage of total nurses that are feeling burnt-out; percentage of total nurses that are absent; and the average number of medical errors made in a unit everyday. For fatigue, the results for only Week 1 are shown first to enable better visualization of the trend, followed by the results for the entire 4-week simulation period.

Table 5. Model parameter values for the Base Healthcare Model

\begin{tabular}{|l|c|l|}
\hline \multicolumn{1}{|c|}{ Model Parameter } & Base Case Value & \multicolumn{1}{c|}{ Reference/Reason } \\
\hline Fractional Rate of Absence & $\begin{array}{c}1.5 \% \text { of Burnt-out } \\
\text { nurses/Year }\end{array}$ & Based on manager's estimate obtained in interview \\
\hline NPR Limited by Budget & $1: 2$ & Based on researcher's estimate \\
\hline $\begin{array}{l}\text { Number of Working Days } \\
\text { Per Week }\end{array}$ & 5 Days & $\begin{array}{l}\text { (Barker \& Nussbaum, 2011; A. Rogers et al., 2004); } \\
40 \text { hrs per wk/8 hrs per shift = 5 shifts per wk }\end{array}$ \\
\hline Recovery Index & $\begin{array}{c}40 \% \text { recovery in } \\
16 \mathrm{Hrs}\end{array}$ & $\begin{array}{l}\text { (Barker \& Nussbaum, 2011; Martin, 2015; Winwood } \\
\text { et al., 2006) }\end{array}$ \\
\hline "Shift Length (Scheduled)" & $8 \mathrm{Hrs}$ & (Winwood et al., 2006) \\
\hline Time Off Work & $24 \mathrm{Hrs}$ & Based on manager's estimate obtained in interview \\
\hline Average Illness Severity & 1.4 & $\begin{array}{l}\text { Set to intermediate level patient severity by the } \\
\text { researcher }\end{array}$ \\
\hline Overtime per Error & $0.75 \mathrm{Hrs}$ & Based on manager's estimate obtained in interview \\
\hline
\end{tabular}




\subsubsection{Sensitivity Analysis}

A one-factor-at-a-time (OFAT) sensitivity analysis (Daniel, 1994) was performed, using the values for model parameters listed in Table 6. A maximum operational range was determined for each variable using the literature, or estimated based on the manager's and research team's knowledge and experience. The range was then divided into seven data values. For a given parameter, the model was run for a period of 4 weeks with each of the seven values while all other parameters within the model were held at their base case values (Table 5).

Of the factors listed in Table 6, the results only show the five that had the greatest effect on the model output for the sensitivity analysis: NPR Limited by Budget, Shift Length (Hrs), Number of Working Days Per Week (Days), Fractional Rate of Absence (\%/Year) and Time Off Work (Days). For each of these five factors, the 'peak value' corresponding to the last working day of the $2^{\text {nd }}$ week was chosen as the time point to be compared in order to make the comparison of results consistent. For NPR Limited by Budget, Shift Length and Number of Days, the residual fatigue present at the end of the $2^{\text {nd }}$ week is also shown in the results below.

Table 6. Healthcare Model Parameter Values Used in the Sensitivity Analysis (Values in bold refer to the base case model)

\begin{tabular}{|c|c|c|c|c|c|c|c|c|}
\hline \multirow[t]{2}{*}{ Model Parameter } & \multicolumn{7}{|c|}{ Values } & \multirow{2}{*}{$\begin{array}{c}\text { Reference/ } \\
\text { Reason }\end{array}$} \\
\hline & $1^{\text {st }}$ & $2^{\text {nd }}$ & $3^{\text {rd }}$ & $4^{\text {th }}$ & $5^{\text {th }}$ & $6^{\text {th }}$ & $7^{7^{\text {th }}}$ & \\
\hline $\begin{array}{l}\text { Fractional Rate of } \\
\text { Absence (\%/Year) }\end{array}$ & 0.05 & 0.88 & 1.50 & 2.53 & 3.35 & 4.18 & 5.00 & $\begin{array}{l}\text { Based on } \\
\text { researcher's } \\
\text { estimate }\end{array}$ \\
\hline $\begin{array}{l}\text { NPR Limited by Budget } \\
\text { (Nurse:Patient) }\end{array}$ & $1: 6.00$ & $1: 5.17$ & $1: 4.34$ & $1: 3.51$ & $1: 2.68$ & $1: 2.00$ & $1: 1.00$ & $\begin{array}{l}\text { (Welton et al., } \\
\text { 2009) }\end{array}$ \\
\hline $\begin{array}{l}\text { Number of Working } \\
\text { Days Per Week (Days) }\end{array}$ & 1.00 & 2.00 & 3.00 & 4.00 & 5.00 & 6.00 & 7.00 & $\begin{array}{c}\text { Based on } \\
\text { researcher's } \\
\text { estimate }\end{array}$ \\
\hline $\begin{array}{l}\text { Recovery Index } \\
\text { (\% recovery in } 16 \mathrm{Hrs})\end{array}$ & 20.00 & 26.67 & 33.33 & 40.0 & 46.67 & 53.33 & 60.00 & $\begin{array}{c}\text { (Barker \& } \\
\text { Nussbaum, } \\
\text { 2011; Martin, } \\
\text { 2015; Winwood } \\
\text { et al., 2006) }\end{array}$ \\
\hline $\begin{array}{l}\text { Shift Length (Scheduled) } \\
\text { (Hrs) }\end{array}$ & 4.00 & 5.33 & 6.67 & 8.00 & 9.33 & 10.67 & 12.00 & $\begin{array}{l}\text { Based on } \\
\text { manager's } \\
\text { estimate }\end{array}$ \\
\hline $\begin{array}{l}\text { Time Off Work (Days } \\
\text { Absent) }\end{array}$ & 1.00 & 4.00 & 8.00 & 12.00 & 16.00 & 20.00 & 24.00 & $\begin{array}{c}\text { (Shields \& } \\
\text { Wilkins, 2006) }\end{array}$ \\
\hline Average Illness Severity & 1.00 & 1.20 & 1.40 & 1.60 & 1.80 & 2.00 & $\begin{array}{r}\text { Rando } \\
\mathrm{m}\end{array}$ & $\begin{array}{c}\text { Based on range } \\
\text { defined }\end{array}$ \\
\hline Overtime per Error (Hrs) & 0.00 & 0.50 & 0.75 & 1.50 & 2.00 & 2.50 & 3.00 & (Bae, 2012) \\
\hline
\end{tabular}




\subsection{Results}

\subsubsection{Base Case Model}

The base case model results address the following research question: For the model based on average (base) values, what time-based trends are displayed by the model in terms of nurse fatigue, burnout, absenteeism and medical errors?

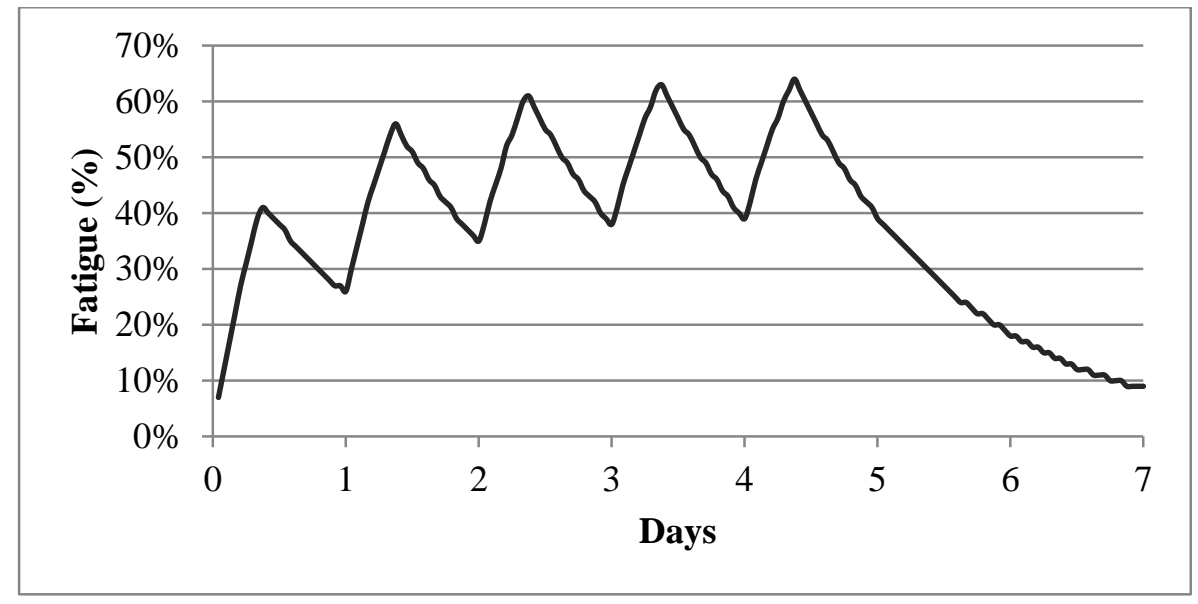

Figure 37. Time-series graph showing changes in Fatigue level over one week

The Fatigue level among the nurses for the first week of simulation is shown in Figure 37. For each working day, fatigue increases throughout the shift, peaks at the end of the shift and then drops during off-shift hours. The graph shows two important results: first, the peak or highest level of fatigue experienced by nurses rises throughout the week, from $41 \%$ at the end of the first shift to $64 \%$ at the end of the last shift in the week shown. Secondly, the residual fatigue, or the fatigue that remains unrecovered, also increases after each shift, rising from $26 \%$ at the start of the second shift to $39 \%$ at the start of their fifth shift. Nurses working a 5-day week, with the weekend off, experience the lowest fatigue at the start of their first shift in the week. For every subsequent shift within the week, nurses start the shift more fatigued than the previous shift. This also results in the nurses experiencing even higher levels of fatigue at the end of each subsequent shift. The last part of the graph shows a sharp drop in fatigue that results from the nurses recovering over the two-day weekend, which is the only time when nurses recover enough to reach the same level of fatigue as the start of the previous week. 


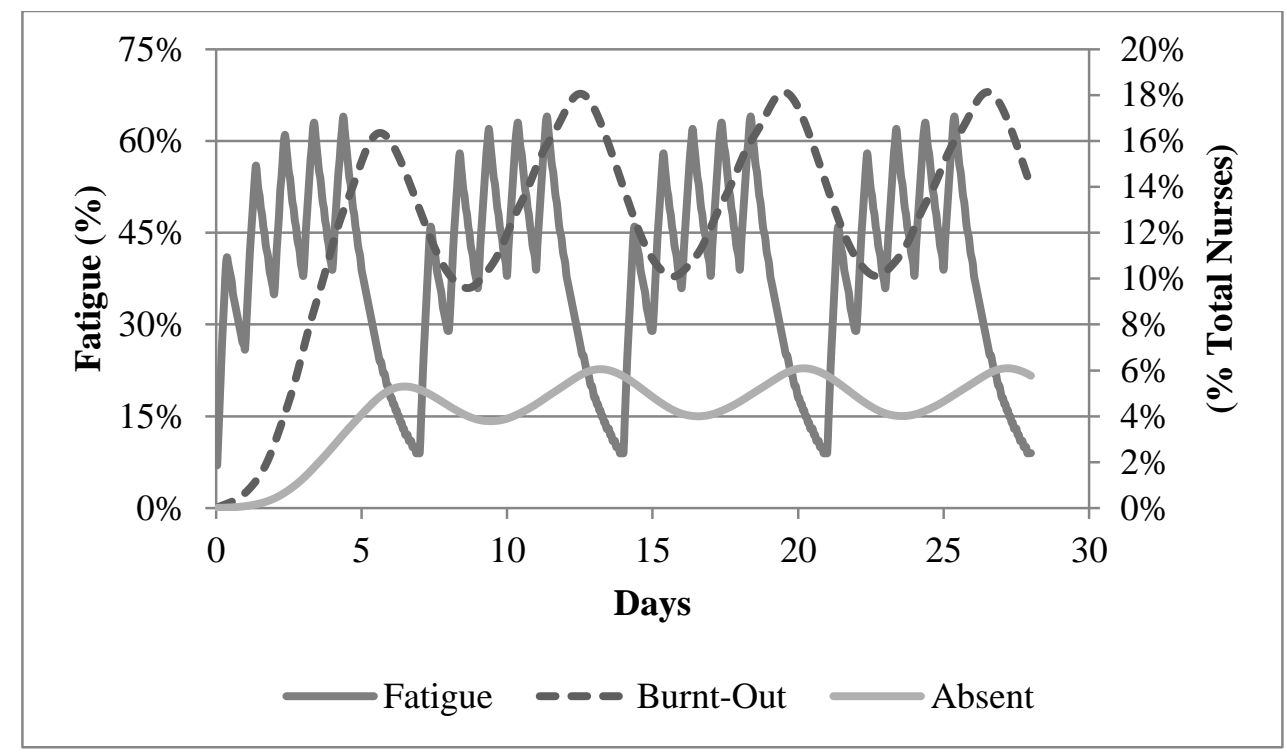

Figure 38. Fatigue (Left Axis) with the Percentage of Total Nurses who are Burnt-Out, and Absent (Right Axis) for the 4-week simulation period

The fatigue is plotted on the left axis in Figure 38, and the percentage of nurses that are burntout, and absent on the right axis, for the 4-week simulation period. The model outputs show an overall increasing trend for the first two weeks, after which the system falls into a steady state. As the fatigue grows throughout the week, so do burnout and absenteeism. However, there is a delay of about 24-hours between when the fatigue reaches its highest point in the week (64\%) and when burnout reaches the peak value (18\%), and about a 45-hour delay when absenteeism reaches its peak value (6\%) for the week. As fatigue drops over the weekend, the burnout and absenteeism also show a corresponding drop, with burnout decreasing to $10 \%$ after a time delay of about 40 hours, and absenteeism decreasing to $4 \%$ after a time delay of approximately 60 hours after fatigue reaches its lowest point. The delay is important because even though the level of fatigue itself is low on the weekend and at the start of each week, the level of burnout is highest during this time. The resulting absenteeism is highest at the beginning of each week.

The number of medical errors made in a unit on a given day is shown on the left axis in Figure 39, with the percentage burnout on the right axis, plotted against the 4-week simulation period. Since burnout alone is assumed to affect the medical errors, the medical errors follow the same pattern as burnout, where they rise throughout the week, peak near the end of the week at $\sim 4$ errors/unit/day and then continue to drop into the beginning of the subsequent week to $\sim 2.4$ errors/unit/day. This pattern repeats every week creating a periodic trend. 


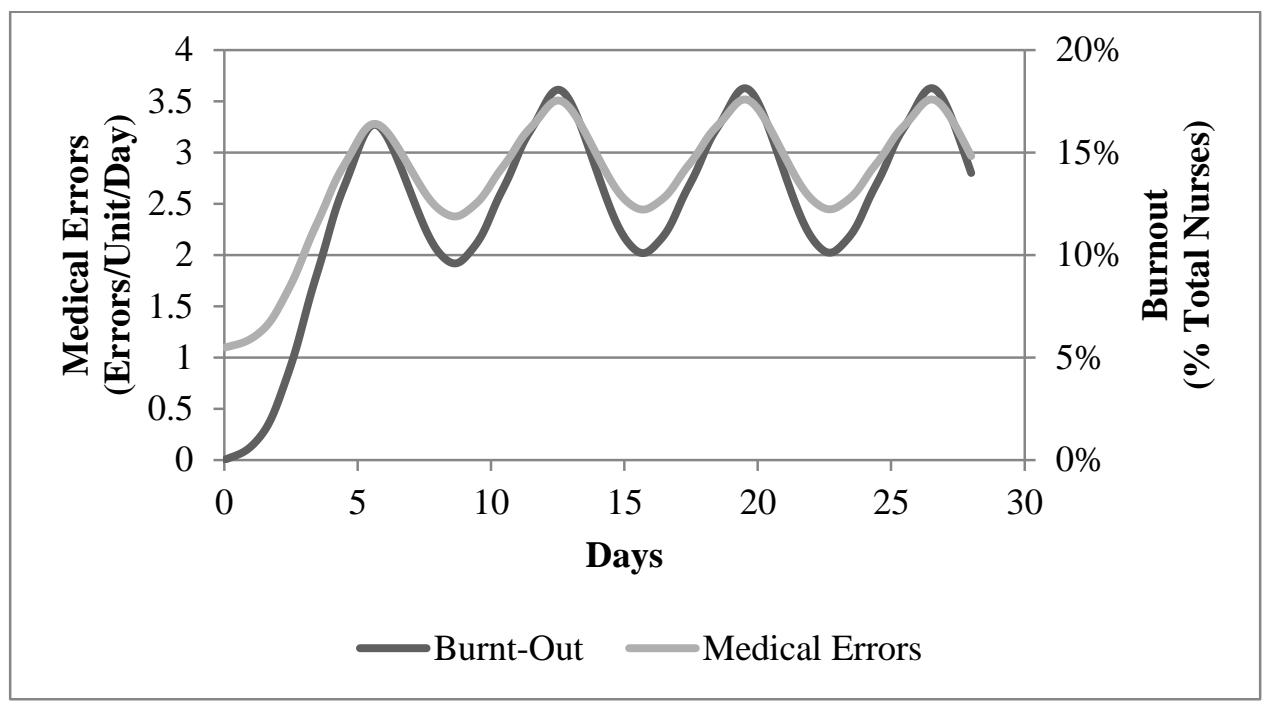

Figure 39. The number of Medical Errors (Left Axis) with Burnout (Right Axis) for the 4-week simulation period

\subsubsection{Sensitivity Analysis}

The results of sensitivity analysis address the following research question: How do model parameters, such as hospital budget, shift length, workweek, and absence policies, independently affect model output?

The results of the sensitivity analysis are shown in Figures 40-45. While the model output was affected by changes in all five variables mentioned, only Fractional Rate of Absence and Time Off Work produced output that was time-varying; for the other three parameters, the system entered a steady state by the end of the $4^{\text {th }}$ week. The figures show the model input and output values as a percentage of their base case values. The values mentioned in the text are the absolute values for any given parameter.

The model output as the NPR Limited by Budget is varied is shown in Figure 40. As the maximum NPR limit is increased in Figure 40 (A), all four output variables decrease to their base case values and then remain at the base case value. Fatigue drops from $100 \%$ to $64 \%$, percentage burnout drops from $56 \%$ to $18 \%$ of total nurses, percentage absent drops from $1.6 \%$ to $0.5 \%$ of total nurses, and medical errors drop from 8.6 errors/unit/day to 3.5 error/unit/day. On the other hand, as budget becomes tighter and fewer nurses are scheduled to address to the needs 
of the same number of patients and tasks as before, the workload and resulting fatigue increases for nurses on duty, as does the risk of nurse burnout. As more nurses feel burnt-out, more medical errors are made during care delivery, and more nurses take time off to recover. The graph at the bottom (Figure 40 (B)) shows that not only does the peak fatigue decrease as this NPR limit is raised, with nurses feeling less fatigued by the end of the week, but the residual or unresolved fatigue also drops from $13 \%$ to $9 \%$, suggesting that the nurses start their week feeling healthier as well.

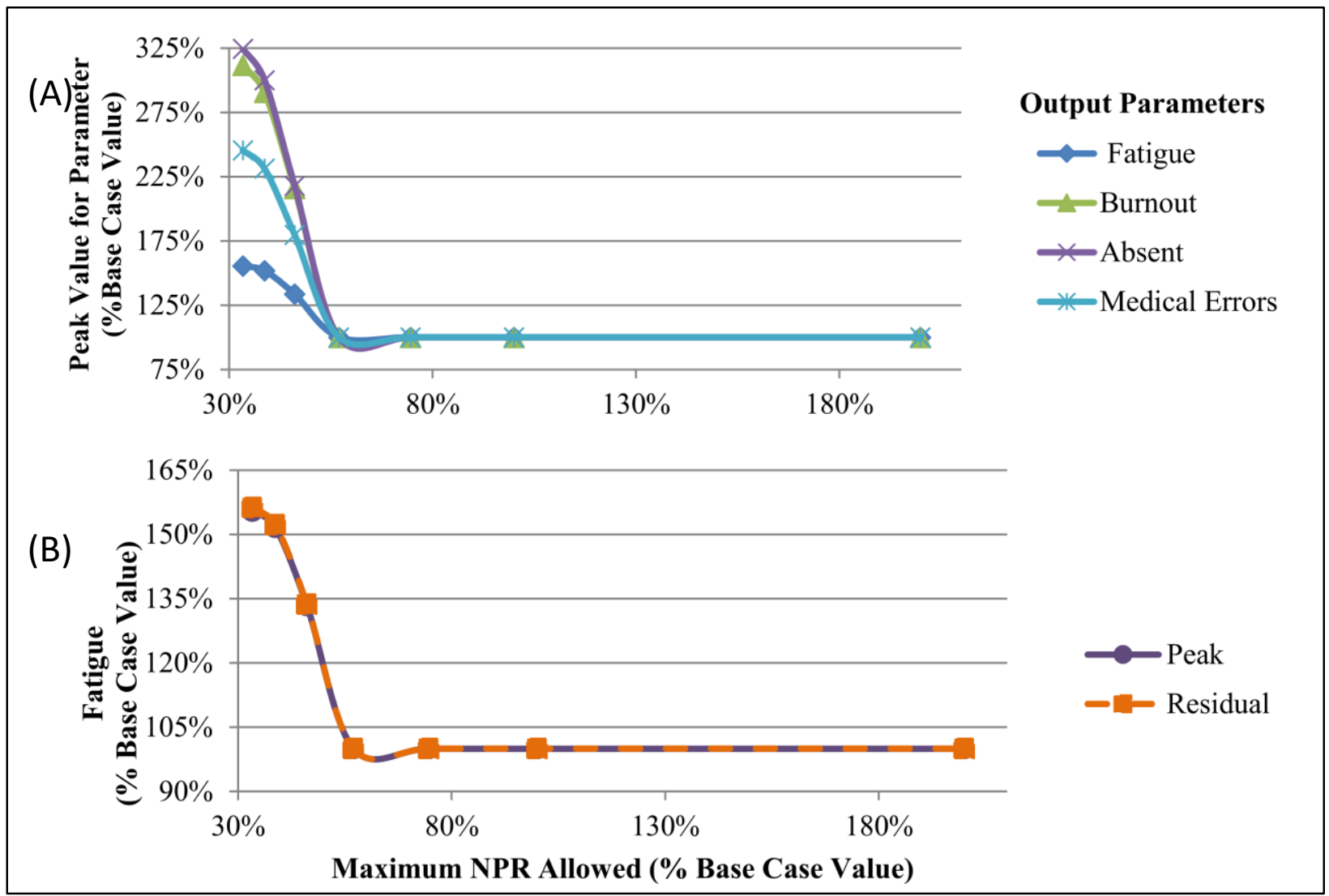

Figure 40. Peak values for Fatigue, Percentage Burnout, Percentage Absent and Medical Errors (A); and Peak Fatigue and Residual Fatigue (B) as NPR Limited by Budget is varied

The model's sensitivity to changes in shift length is shown in Figure 41 (A). The peak fatigue increases from $41 \%$ to $80 \%$; percentage burnout increases from $7 \%$ to $36 \%$ of total nurses; percentage absent increases from $0.2 \%$ to $1 \%$ of total nurses; and medical errors increase from 2 errors/unit/day to 5 errors/unit/day as shift length is increased from 4 hours to 12 hours. Hence, the longer shifts the nurses work, the more fatigued and burnout out they feel by the end of the week, the more medical errors they make in patient care, and the more likely they are to take time off. The residual fatigue shown in Figure 41 (B) also increases from $5 \%$ to $12 \%$ for the 
same increase in shift length, with a steeper slope compared to the peak fatigue. As nurses work longer hours, they not only feel more fatigued at the end of the week but also less recovered by the start of the next week.

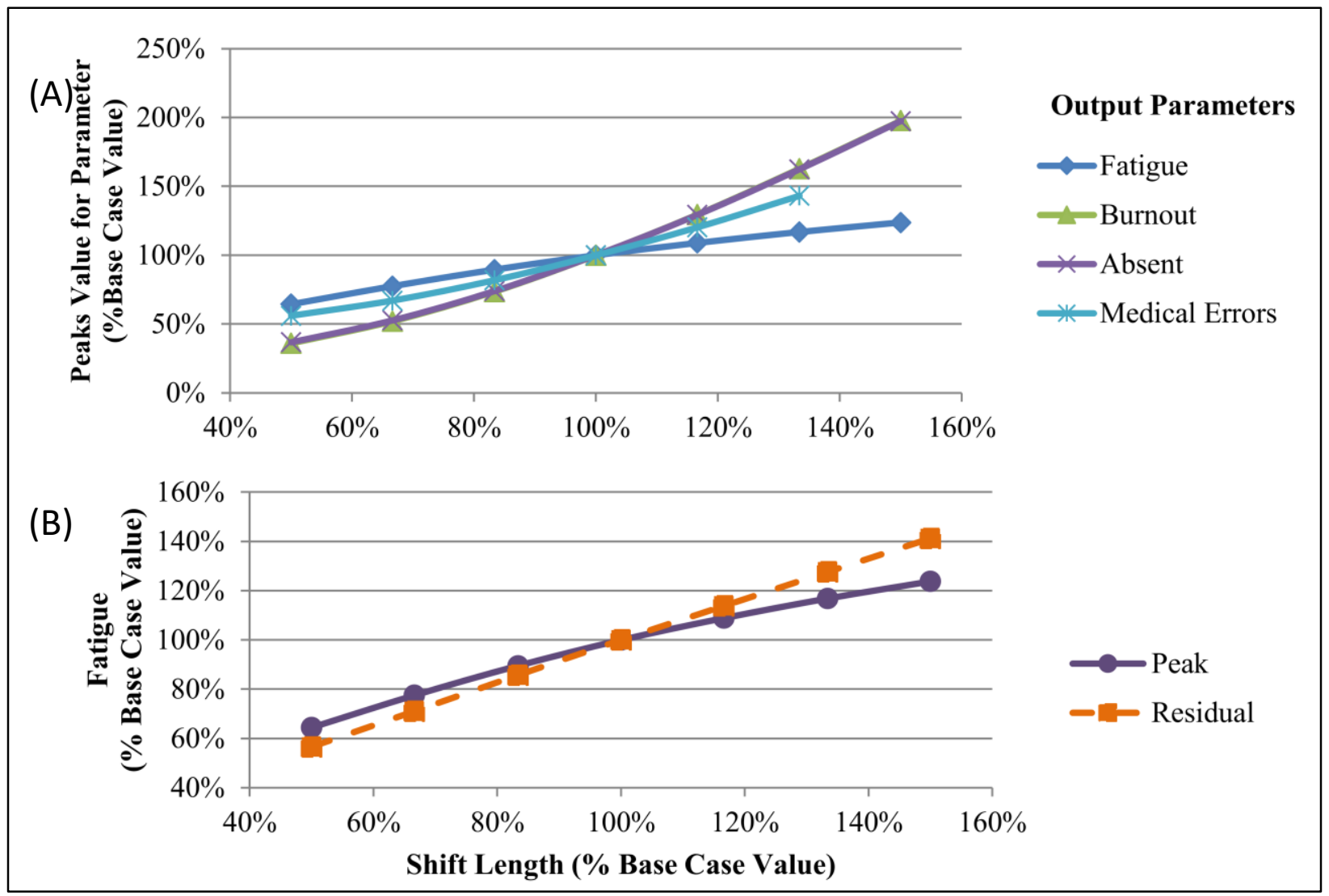

Figure 41. Peak values for Fatigue, Percentage Burnout, Percentage Absent and Medical Errors (A); and Peak Fatigue and Residual Fatigue (B) as Shift Length is varied

The output of the sensitivity analysis for the Number of Working Days Per Week is shown in Figure 42. The top graph (Figure 42 (A)) shows an almost linear increase in burnout (3\% to 22\% of total nurses), absenteeism (0.1\% to $0.6 \%$ of total nurses), and medical errors (1.5 errors/unit/day to 4 errors/unit/day) as the number of working days in a week is increased from 1 day to 7 days. Hence, as nurses work more days in the week, not only more of them feel burntout and are at a risk of making an error, but also more nurses take time off. The fatigue, however, shows a different trend, where it rises from $41 \%$ to $64 \%$, but then beyond the 4-day workweek ( $80 \%$ base case for Number of Working Days), the peak fatigue does not change. The peak and residual fatigue corresponding to the same increase in the number of working days is shown in Figure 42 (B). Even though the peak fatigue reaches its maximum increase around Day 4, the 
residual fatigue continues to show an exponential increase (1\% to $41 \%)$ for the entire testing range of the number of working days.

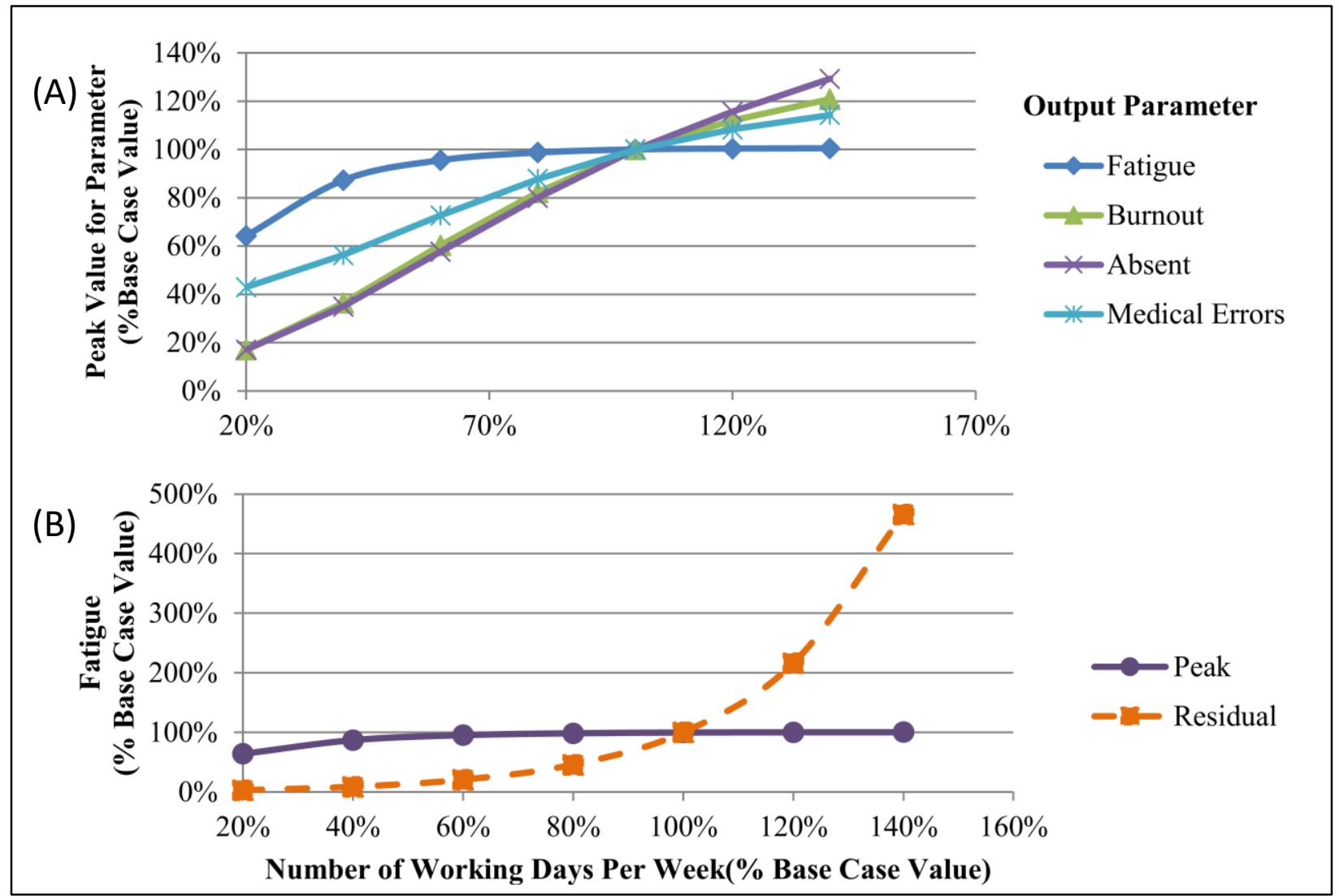

Figure 42. Peak values for Fatigue, Percentage Burnout, Percentage Absent and Medical Errors (A); and Peak Fatigue and Residual Fatigue (B) as Number of Working Days Per Week is varied

Figure 43 (A) shows the peak values for the four main output variables as the Fractional Rate of Absence, or the frequency of burnout nurses taking time off per hour, is varied. For Fractional Rate of Absence (fRA) smaller than $0.88 \% / \mathrm{Yr}$ ( $59 \%$ base case value), the burnout and medical errors show a sharp drop as fRA is increased, with burnout dropping from $54 \%$ to $25 \%$ of total nurses, and medical errors decreasing from 8.3 to 4.5 errors/unit/day. For the same increase in fRA, absenteeism rises from $0.05 \%$ to $0.4 \%$ of total nurses. However, as fractional rate of absence rises past $0.88 \% / \mathrm{Yr}$, the slopes for burnout, absenteeism and medical errors become less steep. Fatigue, on the other hand, remains relatively constant throughout the testing range of the fRA. Since the fatigue levels remain the same, so does the rate at which nurses enter the burntout state. However, as the rate of absence decreases, fewer of these burnt-out nurses take time off, and more of them continue to work, resulting in a greater fraction of nurses at work feeling burnt-out as well as more medical errors. 
Out of the parameters tested, fRA was one of the two that showed a time-varying response for the sensitivity analysis. Figure 43 (B) shows the changes in Medical Errors against time, as the Fractional Rate of Absence is varied. While the curves for the rate of absence values greater than $0.88 \% / Y r$ show a steady state, periodic pattern, the smallest fRA $(0.05 \% / \mathrm{Yr})$ shows a stable increase, from 1 to 11 errors/unit/day over the 4-week simulation period.

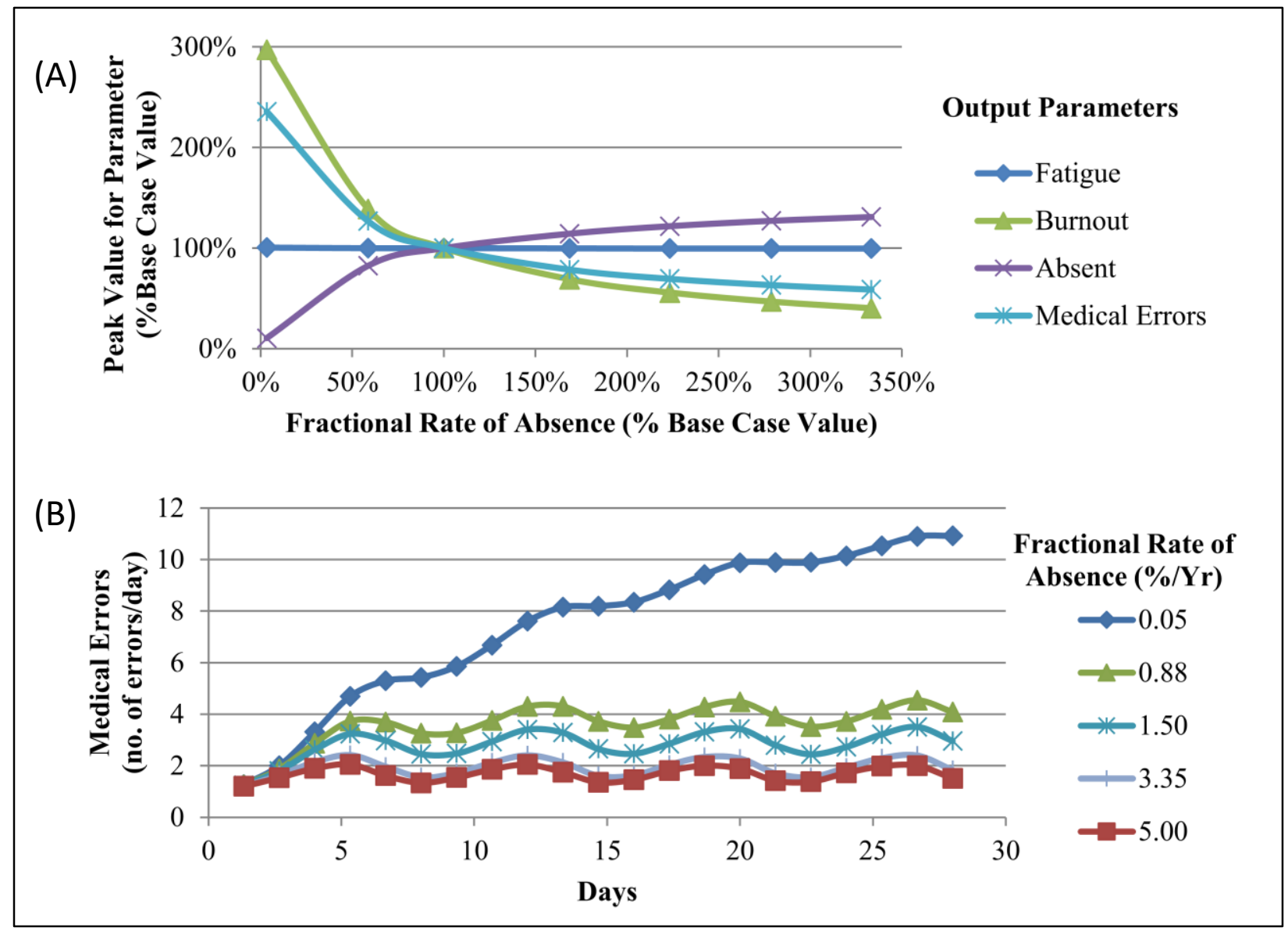

Figure 43. Peak values for Fatigue, Percentage Burnout, Percentage Absent and Medical Errors as the Fractional Rate of Absence is varied (A); Time-series graph with varying Fractional Rate of Absence for Medical Errors (B)

The sensitivity analysis results for Time Off Work (Figure 44 (A)) show that as nurses take longer to return to work and the Time Off Work increases, the fatigue remains relatively constant, while the burnout and medical errors show a slight decrease since healthy, qualified nurses are assumed to cover for absent nurses. The percentage burnout drops from $18 \%$ to $13 \%$ of total nurses, and medical errors reduce from 3.5 errors/unit/day to 2.8 errors/unit/day as time off work is increased from 1 day to 24 days. Absenteeism, on the other hand, rises drastically ( $0.5 \%$ to $3.2 \%$ total nurses) as nurses take longer time away from work. 
The Time Off Work is the second parameter that showed a time-varying response for the sensitivity analysis. The changes in medical errors with time, as the Time Off Work is varied, are shown in Figure 44 (B). For a 1-day absence, the medical errors show an almost periodic, steady state response. However, for absences longer than a week, the peak medical errors begin to decrease with the passage of time, reducing from 3.2 errors/unit/day to 2.4 errors/unit/day for average absence duration of 24 days.

(A)

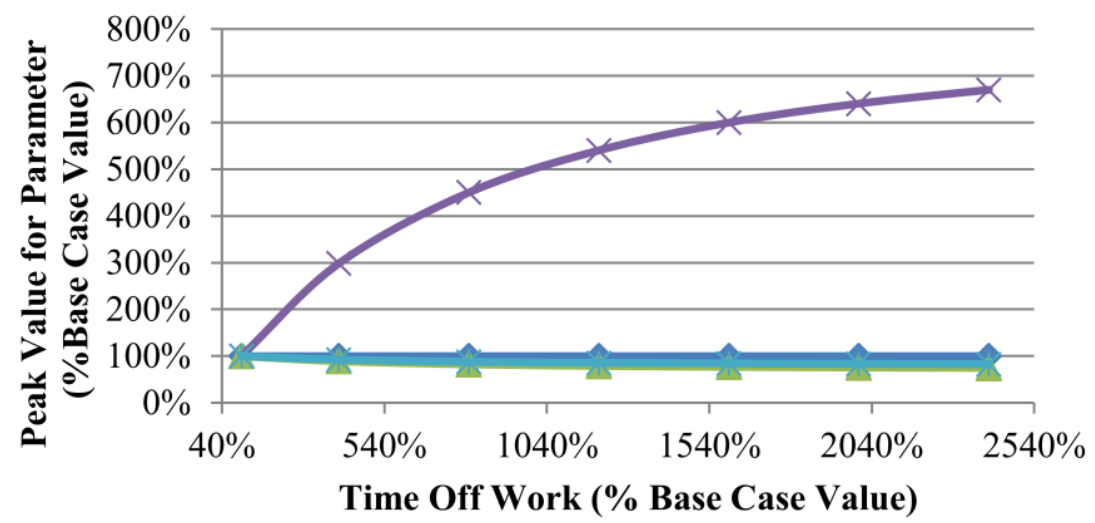

Output Parameter

$\sim$ Fatigue

$\rightarrow$ Burnout

$\leftarrow$ Absent

*-Medical Errors

Time Off Work (\% Base Case Value)

(B)

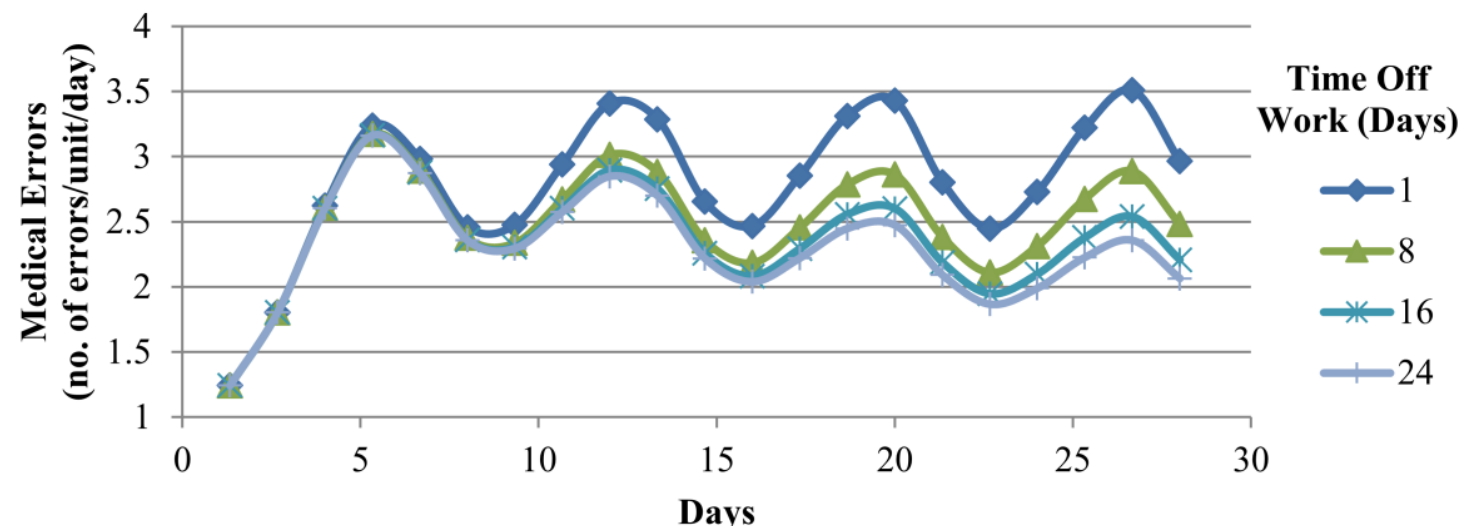

Figure 44. Peak values for Fatigue, Percentage Burnout, Percentage Absent and Medical Errors as the Time Off

Work is varied (A); Time-series graph with varying Fractional Rate of Absence for Medical Errors (B)

\subsection{Discussion}

The modeling process successfully showed a novel application of the SD modeling technique to understand the links between HF and quality of care. SD provides a platform to test manager assumptions and helps understand system behavior in response to various policy issues. The relationships and data values for the current model were derived from both the literature as well 
as manager assumptions. Where the data from literature differed from the estimates provided by the manager, the latter was given preference to create a model closer to the structure of Ontario hospitals. This also holds true with the SD modeling process (Sterman, 2000), where the model is built around the mental models of key individuals within the system.

The modeling results demonstrated and quantified the effect of various policy issues in nursing. Longer work shifts and mandatory overtime not only lead to health problems for the nurses, but also put the safety of the patients at risk. A 12-hour shift can double the burnout percentage of nurses and increase medical errors by $50 \%$ compared to an 8-hour shift. Literature also supports this finding, where long shifts and mandatory overtime can triple the chances that the nurses make at least one error within their shift (A. Rogers et al., 2004; Scott et al., 2010). Policies that mandate early return-to-work (RTW) and limit nurse absence, without addressing the underlying psychological stress that leads to absenteeism, may also prove detrimental to both the nurses' health and patients' safety. This is because while such policies can lead to fewer nurses being away from work and hence, in theory lead to lesser need for nurse replacement, it can also result in a growing pool of nurses at work who experience burnout. Higher levels of burnout at work can not only lead to job dissatisfaction for the nurse but also put the patient safety at risk as nurses make more medical errors. The ability to quantify the long-term effects of different policies on nurses' health and quality of care is one of the strongest advantages of the SD modeling technique.

The model output variables ranged around their values found in research literature, with some exceptions. The prevalence of burnout from the model ranged between 10-18\%, which was within the range of 4-44\% found within the literature (Ribeiro et al., 2014). However, setting the absenteeism and error rate based on the manager's estimates resulted in higher values compared to the literature. The model showed an error rate of 2-4 errors/unit/day for the base case model. Rogers et al. (2004) found a much lower error rate in their study, with 199 errors for 5317 shifts (or $\sim 0.7$ errors/unit/day). While the model provided an hourly error rate, the referenced study, on the other hand, provides the cumulative number of errors made in a given number of shifts of various lengths performed by different nurses. The difference in the kind of information provided by the model and the literature, the methods of data gathering, and the specific context of a 
study, make it difficult to perform a conclusive comparison between the model output and research studies. Similarly, the percentage of absent nurses for the base model results ranged between 4-6\% at any given time, with each absence resulting in a 1-day leave. Research studies, on the other hand, show an incidence rate of 7.5-10\%/year of absenteeism due to disability and illness (Dabboussy \& Uppal, 2012; Jacobson Consulting Inc., 2015; Shields \& Wilkins, 2006), which translates into $\sim 0.02-0.03 \%$ /day. The difference between the model output and research may be attributed to the inconsistency in the definitions for absenteeism, where the model defines absence as the time taken away from work to recover burnout, while the references study looks at absenteeism resulting from disability and illness. These differences make it difficult to compare the model output data to the data available in research.

The results of the base case model showed the time-varying response of the model output for the chosen model inputs. The model entered into a steady state after the first two weeks. However, intuitively, one would expect that a high nurse workload would result in high fatigue and burnout, which would lead to more medical errors and resulting overtime. High overtime would further fatigue the nurses, creating a feedback cycle. However, no such trend was seen in the base case model results. This may be due to the nature of the exponential fatigue model used. The fatigue model used in the current study is an increasing exponential decay function, where the slope for the dependent variable is the steepest for the smallest values of dependent variable but becomes smaller as the dependent variable grows larger. Hence, for the model, overtime resulted in a larger increase in fatigue when fatigue was low but a diminishing increase as fatigue became larger. The present fatigue model was used because of its popularity in literature (Givi et al., 2015; Jaber et al., 2013; Konz, 1998) and simplicity of use. However, other fatigue models such as those proposed by Perez (2011) and Rose et al. (1992) may be used within the model to determine changes in the model behavior and feedbacks.

The sensitivity analysis results showed the model response to changes in each model input. The sensitivity analysis results for the NPR limit due to budget restrictions initially showed a sharp drop in the model output parameters, which eventually settled to their base case values. This pattern resulted because the illness severity among patients is assumed to remain constant. As a result, fatigue, burnout, absenteeism and medical error decrease as NPR limit is raised, so long as 
there is need for more nurses. However, once the budget meets the number of nurses needed based on illness severity, raising the NPR limit further will, in theory, not affect the model outputs, as any additional nurses would be considered "extra". Changing the illness severity would affect the NPR at which the model output curve flattens, and hence may provide an area for further experimentation in future work.

The current model assumes that replacement nurses who cover for absent nurses are outside of the pool of full-time nurses, and are always equally qualified and capable to perform the job. To keep the current model simple, the model only looked at the feedback from burnout to medical errors and fatigue. However, absenteeism may also create a feedback where sufficient or equally experienced nurses are not available for cover, and a nurse from the current employee pool has to work an extra shift or overtime to compensate for the absence of another nurse. Future adaptations of the model could include this link from absenteeism to fatigue and workload to further understand the interactions at play within the system.

\subsubsection{Model Validity}

Data and relationships for the model were derived either from the literature, or estimated by the manager or the research team. While nursing literature was used in the former case, most of these research studies focused on a specific context within the hospital or healthcare system. For the current model, it is assumed that literature from these different contexts applies validly. The remaining relationships for the model consisted either of estimates from the patient care manager or were decided upon through a consensus of opinions of the research team. Both the manager and a member of the research team possessed extensive knowledge and experience of the nursing occupation and the healthcare system. As a result, these values and relationships can be considered close estimates of the healthcare system modeled. Since the intent of the current model was to help managers understand the importance of HF, it was essential to include their mental models to increase their trust and receptivity to the model outcomes. However, as empirical data becomes available for these estimated relationships, the model may be tested with these empirical data as well to determine any differences in model behavior. 
While the focus of the current model was decided upon by the research team, three specific aspects to the model building process - model boundary, model structure and logic, and model data and relationships - determined the results produced by the final model. The same problem could be modeled differently had alternate factors and linkages been used within the model.

The model boundary determines the factors to be included within the model. It depends on the specific problem of interest often defined by the manager(s) or key individuals within the system. For the current model, the model boundary was chosen based on the availability of qualitative and quantitative data. When the current model was presented to the patient care manager, the manager mentioned other factors that were of interest and could be included in the model to create a different perspective to the HF-quality problem. An example of this would be adding the variables of teamwork and trust to the model as suggested by the manager. Therefore, the model boundary may differ between models addressing the same problem depending on the specific system to be modeled and the factors relevant to the user of the model.

Expanding on the example of teamwork and trust, the patient care manager that we interviewed thought these factors to be central to the workings of a unit. According to the manager's mental model, teamwork and trust encourage staff to take the extra time required for safety procedures, decreasing likelihood of injuries. It also reduces stress and workload since the team would support and help out each other in completing their tasks. This would be an example of model logic being derived from the mental models of manager(s) regarding their system. Model logic, or the way various factors are linked within the model, is another important factor in determining the final model. In this case, the manager's mental model plays a central role in determining the structure and logic of the model. In addition to the mental model, the current model also used literature to determine the model logic and various links within the model. Hence, the mental models of managers, and other model users, determine how factors or elements within a SD model are linked.

Finally, once the factors and links within the model are decided upon, quantitative relationships and data are entered into the model. These values are obtained by studying the information available regarding the system. However, where required information is unavailable, estimates 
by people who know the system well can be used instead. For the current model, quantitative data was obtained from the literature, with estimates by the research team and quality of care manager used instead where such data was unavailable.

These three aspects of model building, together, determine the results produced by the final simulation model. The model is most flexible to boundary and logic changes at earlier stages of model building, while quantitative data and relationships may be modified at any stage of the model building process.

\subsubsection{Modeling Challenges}

One of the main challenges faced while building the healthcare model was the scarcity of quantitative, empirical data. Numerous research studies look at survey data that provide important quantitative information regarding fatigue and burnout (Barker \& Nussbaum, 2011; Canadian Nurses Association, 2010; Winwood et al., 2006), and quality of care (Berry \& Curry, 2012; Naidu, 2009; Shields \& Wilkins, 2006). However, very few studies quantify the relationship between these factors or variables (Roelen et al., 2013; A. Rogers et al., 2004; Scott et al., 2010). An example would be the fatigue model used within the current model. While studies use survey instruments to measure fatigue among nurses (Barker \& Nussbaum, 2011; Winwood et al., 2006), no nursing fatigue model exists that can show the progression of fatigue with time as workload is varied. Because of this gap, a fatigue model previously developed in a manufacturing context had to be used for the current healthcare model (Givi et al., 2015). Similarly, while fatigue and burnout have been linked with poor patient quality of care (Aiken et al., 2002; Barker \& Nussbaum, 2011; Canadian Nurses Association, 2010), no models of human error in nursing were found that could predict medical errors based on fatigue levels or burnout. As a result, an estimate of the fatigue-burnout relationship was developed through discussions with the patient care manager. However, there is a need for more studies that can quantitatively define and model the relationships between these key variables.

\subsubsection{Future Work}

The main advantage of using SD modeling in healthcare and nursing is that the technique allows the managers and policy-makers to test the long-term implications of their policies before 
introducing them into the system. This was seen in the results of the sensitivity analysis, where a low absence rate and early RTW was shown to decrease absenteeism among nurses, but increase burnout and medical errors. Future adaptations of the model may test other important policies to understand their effect on nurses' health and the quality of care. The patient care manager mentioned a few such policies that may be included in future models. An example would be studying the numbers of shift changes resulting from a mix of shifts, where nurses working shorter shifts must pass their duties onto the nurse that takes over. The manager indicated that the process of shift change could create psychological stress for the nurses and increase their workload, affecting the quality of care they are able to provide. Another policy that can affect quality of patient care is the currently occurring replacement of Registered Nurses (RNs) with Registered Practical Nurses (RPNs) in Ontario, where the former obtains a 4-years bachelors degree in Nursing while the latter obtains a 2- or 3-year diploma in Practical Nursing (HealthForceOntario, 2016). As long as RPNs are only required to deal with patients that have less-complex conditions, the quality of care may not be affected. However, recent studies have shown that more and more RNs are being replaced by RPNs (Grinspun, Harripaul-Yhap, Jarvi, \& Lenartowych, 2016). Future SD models may study the affect of this replacement on patient safety and quality of care.

While healthcare and nursing policies are one direction for future versions of the model, other changes may also be built into the current model. The current model focuses at one particular aspect of work demands - the Nurse Patient Ratio (NPR). However, literature has shown that NPR alone is not a comprehensive measure of nursing work demands (Baernholdt, Cox, \& Scully, 2010; Beswick, Hill, \& Anderson, 2010). Hence, other physical and psychosocial factors such as spinal load or frequency of interruptions per shift may also be included in the model to understand how each of these factors affects the model output. Another possible additional to the current model may be including the costs associated with burnout, absenteeism, medical errors and overtime. The model can then be used for cost optimization to determine the policies that generate the least cost for the unit or institution while maintaining a high quality of care for the patients. 


\subsection{Conclusion}

This chapter showed a novel application of SD in healthcare as a tool that can help understand the effects of nursing workload on nurses' health and patient quality of care. A conceptual model was built using factors around the HF-quality problem found in the nursing literature. The conceptual model was then used to build a simulation model, with quantitative data and relationships derived from the literature, or estimated by the research team and the patient care manager. The base case model results showed that peak fatigue increases by $40 \%$, burnout increases by $80 \%$, absenteeism increases by $50 \%$, and medical errors increase by $67 \%$ within a given week for nurses working 8-hours shifts 5-days a week. The results of the sensitivity analysis showed that, in general, fatigue, burnout, absenteeism and medical errors decrease as NPR limit is raised, and increase as shift length and length of workweek increase. The largest change in the model output was seen as the rate of absence was increased, with burnout decreasing by 6 times, and medical errors decreasing by 3 times. The ability to show the longterm effects of different policies on nurses' health and quality of care is one of the strongest advantages of the SD modeling technique. The current study showed the results of policies around absenteeism, where burnout and medical errors rise as absence rate and time allowed off work are decreased. However, the model may be further developed in future to include and test other policies that can affect health and performance of nurses. 


\section{Chapter 4 - General Discussion}

The current study presented a novel application of SD modeling to highlight the long-term effects of HF on both employee health and system performance within a product-based manufacturing company, and a service-based healthcare unit. Consistent with theory and empirical evidence, the manufacturing model showed that LBP risk factors resulting from lack of HF in the design not only cause injuries to the assembly line operators but also lead to more defective products and lower quality (Kerr, 1998; Kolus et al., 2014; Sobhani, 2014; Zare et al., 2016). Similarly, the healthcare model showed that if nurses were exposed to high workload because of staff shortage, this would not only increase burnout and absenteeism for the nurses but also increase the risk for medical errors, lowering quality of care (Aiken et al., 2002; Berry \& Curry, 2012; Garrett, 2008; Parker \& Kulik, 1995). Each model showed the application of SD for a different HF-related problem, where the manufacturing model focused on the effect of HFrelated design factors, while the results of the healthcare model explored the effects of various HF-related policy issues. Despite the differences in the risk factors for each work environment, the results from SD models in both manufacturing and healthcare highlight that HF considerations are important for any organization's strategic goals so long as humans are part of its system. The current study successfully demonstrated the feasibility of using SD as a tool that can help managers' understand the importance of HF in achieving the quality and productivity goals for different work systems.

Previous research studies have quantified various aspects of the HF-quality problem modeled in this thesis. Kerr (1998) determined the odds ratio for various LBP injury risk factors within an automotive assembly line. Di Pasquale et al. (2015), Givi et al. (2015) and Sobhani (2014) developed human error models that determine the human error probability under different conditions. Similarly in healthcare literature, A. E. Rogers et al. (2004) and Scott et al. (2010) quantified the relationship between work duration of the nurses and the odds of error. Aiken et al. (2002) showed the relationship between nurse staffing, and the odds of burnout in nurses and patient mortality. These studies model specific aspects of the HF-quality problem. The SD models developed in this study, however, combined the available literature as well as managers' 
experience to provide a more comprehensive understanding of the underlying HF-related mechanisms that could lead to quality and productivity losses.

Most ergonomic tools and approaches provide a "snap-shot" or a single time-point analysis of the health problem in a given population (Sobhani, 2014). The current models address this issue by presenting a dynamic, long-term behavior of the system in response to HF-related risk factors. This is critical for HF-related issues because, as both the manufacturing and healthcare models show, there is often a delay between the exposure to risk factors and the resulting health and quality effects. If this time delay is ignored, the managers and decision-makers may not be able to correctly attribute these health problems and quality losses resulting from lack of HF to their true cause.

The SD models developed in the current study only include specific risk factors. For the manufacturing model, only three of the multiple LBP risk factors measured by Kerr (1998) are used as model inputs. However, other LBP risk factors are also important contributors to LBP injuries (Kerr, 1998; Norman et al., 1998). Furthermore, LBP injuries are not the only health conditions that can affect the health of the operators. Other MSD injuries, and physical and psychological stressors may also affect the performance of the assembly line operators (Báez, Rodríguez, Limón, \& Tlapa, 2014; Hansson et al., 2010). Hence, it can be expected that the results of the current manufacturing model quantify only part of the effect of HF on assembly line productivity and quality, and therefore underestimate total impact. Similarly, the healthcare model uses nurse staffing as a workload indicator. However, other physical, psychological and emotional stressors may contribute to the nurses' physical and mental health, and ability to provide high quality care to their patients. An example would be manual patient handling in the absence of an assistive lift device that can increase the risk of LBP among nurses (Daynard et al., 2001). Therefore, both the manufacturing and healthcare models only look at specific risk factors most common in their respective industries and may capture only a part of the HF-quality problem. For a more complete analysis of the effect of HF on quality, future models may need to include all the risk factors known to affect the health of employees within a system. 
The current models were built using validated empirical data from the literature, supplemented with managers' estimates. Future SD models could also be based entirely on managers' mental models and company records, which could enable model validation by comparing the model results to the output of the real system. The models built in this study demonstrated the use of SD modeling as a tool that can help understand the importance of HF in achieving a company's strategic goals. The model building process helps the managers understand the link between HF and quality, while the model results can help them identify the risk factors that contribute the most to their HF-related quality problems. The managers can then target these high-impact risk factors and work with HF-specialists and ergonomists to reduce their exposure levels.

While further development and validation of the current models is needed, the models provide an important foundation for future models in this area. The next steps for this research would be to share the model results with researchers through journal publications, and with top managements and coalition groups to encourage discussions that could raise awareness regarding the important of HF for the quality outcomes of an organization. 


\section{Chapter 5 - Conclusion}

This thesis study demonstrated two novel applications of SD modeling as a tool that can help managers, designers and others within the industry understand the effect of HF risk factors on the health of operators and quality of product in a manufacturing company; and the health of nurses and quality of patient care within a healthcare nursing unit. For the manufacturing model, the model results showed that LBP risk factors could increase injuries in operators, with injury prevalence increasing by up to 15 times for simultaneous exposure to high levels of Shift Length, Spinal Load and Peak Hand Load. This in turn affects the performance of the operators and the quality and productivity of the system, where human error probability increased by up to 10 times, production rate decreased by $\sim 1 \%$ as the production flow was assumed automated, and rework rate increased by up to 10 times. The results of the healthcare model quantified the effects of workload on quality of care, where high workload could increase burnout and absenteeism for the nurses, while putting quality of patient care at risk. On the other hand, as nurse staffing is increased, nursing workload decreases and fewer nurses feel fatigued or burntout. The largest change in the healthcare model output was seen as more nurses were allowed time off, with burnout decreasing by 6 times, and medical errors decreasing by 3 times. The ability of SD modeling to show the long-term affects of different design factors and policy issues on employees' health and system performance makes it a highly useful tool for addressing the HF-quality issue. The current models demonstrated the feasibility of using the SD modeling technique to address the HF-quality issue, with further development of the models and detailed model validation to be performed as future work. 


\section{Appendices}

Appendix A: Calculation of the Constant $\alpha_{0}$ for the Regression Model in the Manufacturing Model

The constant for the regression model was not available and therefore calculated indirectly using the prevalence rate for LBP injury in the population. 1-year prevalence was used as this provides a better estimate of the LBP episodes compared to incidence rate, which often excludes recurrent injuries. The equation provided by Sobhani (2014) was modified to calculate the probability of injury from the prevalence (Eq. (6)):

For a prevalence of $18 \%$, the probability of injury is

$$
P_{\text {Pain }}=1-\frac{1}{e^{0.18}}=0.165
$$

The probability can then be used to calculate the combined odds

$$
\text { Combined Odds }=\frac{P_{\text {Injury }}}{1-P_{\text {Injury }}}=0.197
$$

and

$$
\alpha_{0}=\sum_{i=1}^{n} \beta_{i} X_{i}-\ln (\text { Combined Odds })
$$

Weighted mean was used for the risk factors values in Eq. (6) as an indicator of the population level risk. 


\section{Appendix B: Manufacturing Model Documentation}

(01) $\quad$ Absent $=$

INTEG (Injured Taking Time Off-Recovering After Leave, 0)

Units: People

(02) Active Cycle Time Modified=

Active Cycle Time Theoretical*(1+(Effect of Presenteeism on Active Cycle Time

*"Fraction In-Pain")+(Effect of Absenteeism on Active Cycle Time*Fraction Absent))

Units: Minute/Products

(03) Active Cycle Time Theoretical=

Takt Time-Machine Time

Units: Minute/Products

(04) Average Load=

(("Spinal Load (Working)"*Active Cycle Time Modified)+("Spinal Load (Waiting)"

*Machine Time $) /($ Active Cycle Time Modified+Machine Time)

Units: Newtons

(05) Combined Odds=

EXP $\left(-5.27+(1.31 *\right.$ Prior Injury Fraction $)+\left(-0.48^{*} 12.4\right)+\left(0.63^{*} 6\right)+(0.27 * 12)+(0.88$

$* 0.21)+(0.26 * 3.8)+(-0.02 * 56.5)+(0.05 *$ Peak Hand Load $)+(0.002 * 354)+\left(\left(6 *\left(10^{\wedge}-\right.\right.\right.$

$8))^{*}$ Cumulative Load Per Shift))*"Working or Not?"

Units: Dmnl

(06) Cumulative Load Per Shift=

Average Load*(Shift Length*Seconds Per Hour)

Units: Newtons*Second/Shift

(07) Day of Week=

Units: Day

INTEG ("Time Passing with 7-Day Reset", 0)

(08) Effect of Absenteeism on Active Cycle Time=

0.1

Units: Dmnl $[0,1,0.1]$

(09) Effect of Presenteeism on Active Cycle Time=

0.166

Units: Dmnl [0,1,0.1]

(10) FINAL TIME $=1825$

Units: Day

(11) Fraction Absent=

Absent/Total Workforce

Units: Dmnl

(12) "Fraction In-Pain"=

In Pain/Total Workforce 
Units: Dmnl

(13) Fractional Rate of Absence=

$(15.5 / 100) / 260$

Units: 1/Day

Note: Absence Rate/(52 weeks * 5days)

(14) Getting Injured= (Healthy*Prevalence)

Units: People/Day

(15) Healthy=

INTEG ( Recovering After Leave+Recovering without Leave-Getting Injured, 100)

Units: People

(16) Human Error Probability= $((0.001 * \operatorname{EXP}(3.912 *$ Probability of Pain $)) *(1-"$ Fraction In-Pain") $)+$ $((((0.001 * \operatorname{EXP}(3.912 *$ Probability of Pain $)) * 5)) /(((0.001 * \operatorname{EXP}(3.912 *$ Probability of Pain )$\left.)^{* 4)+1)}\right) *$ "Fraction In-Pain")

Units: Dmnl

Note: Exponential equation between 1/1000-1/10

(17) In Pain=

INTEG ( Getting Injured-Injured Taking Time Off-Recovering without Leave, 0)

Units: People

(18) INITIAL TIME $=0$

Units: Day

(19) Injured Taking Time Off=

In Pain*Fractional Rate of Absence*"Working or Not?"

Units: People/Day

(20) Machine Time $=$ $0.05^{*}$ Takt Time

Units: Minute/Products

(21) Minutes to Day= $1 /(24 * 60)$

Units: Day/Minute

(22) Peak Hand Load=

14.3

Units: Kilogram

(23) Prevalence $=$

$\mathrm{LN}(1 /(1-$ Probability of Pain $)) / 260$

Units: 1/Day [?,1]

(24) Prior Injury Fraction=

(Total Prior Injuries/Total Workforce)/((Total Prior Injuries/Total Workforce)+1) 
Units: Dmnl

(25) Prior Injury Rate=

Recovering After Leave+Recovering without Leave

Units: People/Day

(26) Probability of Pain=

Combined Odds/(1+Combined Odds)

Units: Dmnl

(27) Production Rate $=$

("Working or Not?")/((Active Cycle Time Modified+Machine Time)*Minutes to Day)

Units: Products/Day

(28) Recovering After Leave $=$

Absent/Time Off Work

Units: People/Day

(29) Recovering without Leave $=$

(In Pain/Time in Pain)-(Injured Taking Time Off)

Units: People/Day

(30) Rework=

INTEG (Rework Rate, 0)

Units: Products

(31) Rework Rate $=$

(1-Yield Factor)*Reworkable Fraction*Production Rate

Units: Products/Day

(32) Reworkable Fraction=

0.9

Units: Dmnl

(33) Right First Time=

INTEG (Yield Rate, 0)

Units: Products

(34) SAVEPER =

TIME STEP

Units: Day $[0, ?]$

Note: The frequency with which output is stored.

(35) Scrap $=$

INTEG (Scrap Rate, 0)

Units: Products

(36) Scrap Rate=

(1-Yield Factor)*(1-Reworkable Fraction)*Production Rate

Units: Products/Day 
(37) Seconds Per Hour= 3600

Units: Second/Hour

(38) Shift Length= 8

Units: Hour/Shift

(39) Shift Lookup( $[(0,0)-(10,10)],(0,0),(1 \mathrm{e}-06,1),(0.333,1),(0.333001,0),(1,0),(1,1),(1.333$

$, 1),(1.333,0),(2,0),(2,1),(2.333,1),(2.333,0),(3,0),(3,1),(3.333,1),(3.333$

$, 0),(4,0),(4,1),(4.333,1),(4.333,0),(7,0))$

Units: Dmnl

(40) "Spinal Load (Waiting)"= 406

Units: Newtons

(41) "Spinal Load (Working)"= 826

Units: Newtons

(42) Takt Time $=$

1

Units: Minute/Products

(43) Time in Pain=

42

Units: Day

(44) Time Off Work=

34

Units: Day

(45) "Time Passing with 7-Day Reset"=

IF THEN ELSE((MODULO(Time,7)=0):AND:(Time>0),-(7/TIME STEP)+1, 1 ) Units: Day/Day

(46) TIME STEP $=0.015625$

Units: Day [0,?]

Note: The time step for the simulation.

(47) Total Prior Injuries= INTEG (Prior Injury Rate, 0)

Units: People

(48) Total Workforce $=$

Healthy+In Pain+Absent

Units: People

(49) "Working or Not?"= 
Shift Lookup(Day of Week)

Units: Dmnl

(50) Yield Factor=

1-Human Error Probability

Units: Dmnl [0,1,0.05]

(51) Yield Rate=

Yield Factor*Production Rate

Units: Products/Day 


\section{Appendix C: Results of Sensitivity Analysis for the Manufacturing Model}

Tables A1-A5 list the results of the sensitivity analysis as a percentage difference, with the base model output used as reference.

Table A1. Sensitivity Analysis results for varying machine time

\begin{tabular}{|c|c|c|c|c|c|c|c|c|}
\hline & \multirow{2}{*}{$\begin{array}{l}\text { Time } \\
\text { (days) }\end{array}$} & \multirow{2}{*}{$0.6 \mathrm{~s}$} & \multirow{2}{*}{$1.5 \mathrm{~s}$} & \multirow{2}{*}{$2.5 \mathrm{~s}$} & $\begin{array}{l}\text { BASE } \\
\text { CASE }\end{array}$ & \multirow{2}{*}{$3.9 \mathrm{~s}$} & \multirow{2}{*}{$4.8 \mathrm{~s}$} & \multirow{2}{*}{$6 s$} \\
\hline & & & & & $3 \mathrm{~s}$ & & & \\
\hline \multirow{8}{*}{ 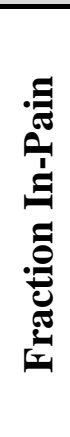 } & 1 Week & $2.6 \%$ & $1.6 \%$ & $0.6 \%$ & $1.4 \mathrm{E}-03$ & $-1.0 \%$ & $-1.9 \%$ & $-3.2 \%$ \\
\hline & 1 Month & $2.6 \%$ & $1.6 \%$ & $0.6 \%$ & $4.4 \mathrm{E}-03$ & $-1.0 \%$ & $-1.9 \%$ & $-3.2 \%$ \\
\hline & 6 Months & $2.7 \%$ & $1.7 \%$ & $0.7 \%$ & $9.0 \mathrm{E}-03$ & $-1.0 \%$ & $-1.9 \%$ & $-3.2 \%$ \\
\hline & 1 Year & $2.7 \%$ & $1.7 \%$ & $0.7 \%$ & $9.5 \mathrm{E}-03$ & $-1.0 \%$ & $-2.0 \%$ & $-3.3 \%$ \\
\hline & 2 Year & $2.9 \%$ & $1.8 \%$ & $0.7 \%$ & $1.0 \mathrm{E}-02$ & $-1.1 \%$ & $-2.1 \%$ & $-3.5 \%$ \\
\hline & 3 Year & $3.0 \%$ & $1.9 \%$ & $0.7 \%$ & $1.1 \mathrm{E}-02$ & $-1.1 \%$ & $-2.2 \%$ & $-3.6 \%$ \\
\hline & 4 Year & $3.1 \%$ & $1.9 \%$ & $0.8 \%$ & $1.2 \mathrm{E}-02$ & $-1.1 \%$ & $-2.3 \%$ & $-3.8 \%$ \\
\hline & 5 Year & $3.2 \%$ & $2.0 \%$ & $0.8 \%$ & $1.3 \mathrm{E}-02$ & $-1.2 \%$ & $-2.3 \%$ & $-3.8 \%$ \\
\hline \multirow{8}{*}{ 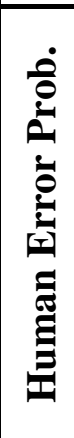 } & 1 Week & $1.9 \%$ & $1.2 \%$ & $0.5 \%$ & $2.3 \mathrm{E}-03$ & $-0.7 \%$ & $-1.4 \%$ & $-2.3 \%$ \\
\hline & 1 Month & $1.9 \%$ & $1.2 \%$ & $0.5 \%$ & $2.3 \mathrm{E}-03$ & $-0.7 \%$ & $-1.4 \%$ & $-2.3 \%$ \\
\hline & 6 Months & $2.1 \%$ & $1.3 \%$ & $0.5 \%$ & $2.4 \mathrm{E}-03$ & $-0.8 \%$ & $-1.5 \%$ & $-2.5 \%$ \\
\hline & 1 Year & $2.2 \%$ & $1.4 \%$ & $0.5 \%$ & $2.5 \mathrm{E}-03$ & $-0.8 \%$ & $-1.6 \%$ & $-2.7 \%$ \\
\hline & 2 Year & $2.5 \%$ & $1.5 \%$ & $0.6 \%$ & $2.6 \mathrm{E}-03$ & $-0.9 \%$ & $-1.8 \%$ & $-3.0 \%$ \\
\hline & 3 Year & $2.7 \%$ & $1.7 \%$ & $0.7 \%$ & $2.8 \mathrm{E}-03$ & $-1.0 \%$ & $-2.0 \%$ & $-3.3 \%$ \\
\hline & 4 Year & $3.0 \%$ & $1.8 \%$ & $0.7 \%$ & $3.0 \mathrm{E}-03$ & $-1.1 \%$ & $-2.1 \%$ & $-3.5 \%$ \\
\hline & 5 Year & $3.1 \%$ & $1.9 \%$ & $0.8 \%$ & $3.1 \mathrm{E}-03$ & $-1.1 \%$ & $-2.3 \%$ & $-3.7 \%$ \\
\hline \multirow{8}{*}{ 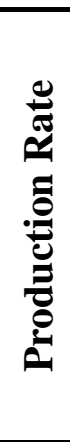 } & 1 Week & $0.0 \%$ & $0.0 \%$ & $0.0 \%$ & 59.99 & $0.0 \%$ & $0.0 \%$ & $0.0 \%$ \\
\hline & 1 Month & $0.0 \%$ & $0.0 \%$ & $0.0 \%$ & 59.96 & $0.0 \%$ & $0.0 \%$ & $0.0 \%$ \\
\hline & 6 Months & $0.0 \%$ & $0.0 \%$ & $0.0 \%$ & 59.91 & $0.0 \%$ & $0.0 \%$ & $0.0 \%$ \\
\hline & 1 Year & $0.0 \%$ & $0.0 \%$ & $0.0 \%$ & 59.91 & $0.0 \%$ & $0.0 \%$ & $0.0 \%$ \\
\hline & 2 Year & $0.0 \%$ & $0.0 \%$ & $0.0 \%$ & 59.90 & $0.0 \%$ & $0.0 \%$ & $0.0 \%$ \\
\hline & 3 Year & $0.0 \%$ & $0.0 \%$ & $0.0 \%$ & 59.89 & $0.0 \%$ & $0.0 \%$ & $0.0 \%$ \\
\hline & 4 Year & $0.0 \%$ & $0.0 \%$ & $0.0 \%$ & 59.89 & $0.0 \%$ & $0.0 \%$ & $0.0 \%$ \\
\hline & 5 Year & $0.0 \%$ & $0.0 \%$ & $0.0 \%$ & 59.88 & $0.0 \%$ & $0.0 \%$ & $0.0 \%$ \\
\hline \multirow{8}{*}{ 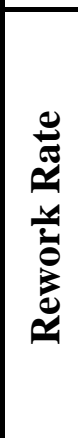 } & 1 Week & $1.9 \%$ & $1.2 \%$ & $0.5 \%$ & 0.12 & $-0.7 \%$ & $-1.4 \%$ & $-2.3 \%$ \\
\hline & 1 Month & $1.9 \%$ & $1.2 \%$ & $0.5 \%$ & 0.12 & $-0.7 \%$ & $-1.4 \%$ & $-2.3 \%$ \\
\hline & 6 Months & $2.1 \%$ & $1.3 \%$ & $0.5 \%$ & 0.13 & $-0.8 \%$ & $-1.5 \%$ & $-2.5 \%$ \\
\hline & 1 Year & $2.2 \%$ & $1.4 \%$ & $0.5 \%$ & 0.13 & $-0.8 \%$ & $-1.6 \%$ & $-2.7 \%$ \\
\hline & 2 Year & $2.5 \%$ & $1.5 \%$ & $0.6 \%$ & 0.14 & $-0.9 \%$ & $-1.8 \%$ & $-3.0 \%$ \\
\hline & 3 Year & $2.7 \%$ & $1.7 \%$ & $0.7 \%$ & 0.15 & $-1.0 \%$ & $-2.0 \%$ & $-3.2 \%$ \\
\hline & 4 Year & $2.9 \%$ & $1.8 \%$ & $0.7 \%$ & 0.16 & $-1.1 \%$ & $-2.1 \%$ & $-3.5 \%$ \\
\hline & 5 Year & $3.1 \%$ & $1.9 \%$ & $0.8 \%$ & 0.17 & $-1.1 \%$ & $-2.3 \%$ & $-3.7 \%$ \\
\hline
\end{tabular}


Table A2. Sensitivity Analysis results for varying peak hand load

\begin{tabular}{|c|c|c|c|c|c|c|c|c|}
\hline & \multirow{2}{*}{$\begin{array}{l}\text { Time } \\
\text { (days) }\end{array}$} & \multirow{2}{*}{ 0 KG } & \multirow{2}{*}{$10 \mathrm{KG}$} & $\begin{array}{l}\text { BASE } \\
\text { CASE } \\
\end{array}$ & \multirow{2}{*}{$20 \mathrm{KG}$} & \multirow{2}{*}{$30 \mathrm{KG}$} & \multirow{2}{*}{$40 \mathrm{KG}$} & \multirow{2}{*}{$51.5 \mathrm{KG}$} \\
\hline & & & & $14.3 \mathrm{KG}$ & & & & \\
\hline \multirow{8}{*}{ 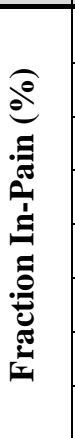 } & 1 Week & $-48.2 \%$ & $-17.6 \%$ & $1.4 \mathrm{E}-03$ & $28.5 \%$ & $95.0 \%$ & $186.2 \%$ & $323.8 \%$ \\
\hline & 1 Month & $-48.1 \%$ & $-17.6 \%$ & $4.4 \mathrm{E}-03$ & $28.4 \%$ & $94.8 \%$ & $185.5 \%$ & $321.8 \%$ \\
\hline & 6 Months & $-48.5 \%$ & $-17.8 \%$ & 9.0E-03 & $28.9 \%$ & $97.0 \%$ & $190.7 \%$ & $331.4 \%$ \\
\hline & 1 Year & $-49.4 \%$ & $-18.3 \%$ & $9.5 \mathrm{E}-03$ & $30.0 \%$ & $102.0 \%$ & $202.5 \%$ & $353.7 \%$ \\
\hline & 2 Year & $-51.0 \%$ & $-19.2 \%$ & $1.0 \mathrm{E}-02$ & $32.0 \%$ & $110.1 \%$ & $219.5 \%$ & $379.4 \%$ \\
\hline & 3 Year & $-52.4 \%$ & $-19.9 \%$ & $1.1 \mathrm{E}-02$ & $33.4 \%$ & $115.3 \%$ & $227.7 \%$ & $385.7 \%$ \\
\hline & 4 Year & $-53.5 \%$ & $-20.4 \%$ & $1.2 \mathrm{E}-02$ & $34.4 \%$ & $118.0 \%$ & $229.7 \%$ & $381.2 \%$ \\
\hline & 5 Year & $-54.3 \%$ & $-20.8 \%$ & $1.3 \mathrm{E}-02$ & $35.0 \%$ & $118.8 \%$ & $227.8 \%$ & $371.6 \%$ \\
\hline \multirow{8}{*}{ 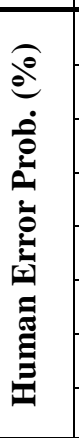 } & 1 Week & $-30.9 \%$ & $-12.2 \%$ & $2.3 \mathrm{E}-03$ & $22.1 \%$ & $85.6 \%$ & $200.0 \%$ & $424.2 \%$ \\
\hline & 1 Month & $-31.3 \%$ & $-12.4 \%$ & $2.3 \mathrm{E}-03$ & $22.6 \%$ & $88.0 \%$ & $207.3 \%$ & $445.5 \%$ \\
\hline & 6 Months & $-32.9 \%$ & $-13.2 \%$ & $2.4 \mathrm{E}-03$ & $24.6 \%$ & $98.6 \%$ & $240.5 \%$ & $534.2 \%$ \\
\hline & 1 Year & $-34.4 \%$ & $-14.0 \%$ & $2.5 \mathrm{E}-03$ & $26.5 \%$ & $109.2 \%$ & $272.5 \%$ & $610.3 \%$ \\
\hline & 2 Year & $-37.2 \%$ & $-15.5 \%$ & $2.6 \mathrm{E}-03$ & $30.2 \%$ & $128.7 \%$ & $326.9 \%$ & $716.0 \%$ \\
\hline & 3 Year & $-39.7 \%$ & $-16.8 \%$ & $2.8 \mathrm{E}-03$ & $33.5 \%$ & $145.1 \%$ & $366.0 \%$ & $770.2 \%$ \\
\hline & 4 Year & $-42.0 \%$ & $-18.0 \%$ & $3.0 \mathrm{E}-03$ & $36.4 \%$ & $158.0 \%$ & $390.9 \%$ & $790.3 \%$ \\
\hline & 5 Year & $-44.1 \%$ & $-19.1 \%$ & 3.1E-03 & $38.8 \%$ & $167.4 \%$ & $404.6 \%$ & $790.4 \%$ \\
\hline \multirow{8}{*}{ 鞄 } & 1 Week & $0.0 \%$ & $0.0 \%$ & 59.99 & $0.0 \%$ & $0.0 \%$ & $0.0 \%$ & $-0.1 \%$ \\
\hline & 1 Month & $0.0 \%$ & $0.0 \%$ & 59.96 & $0.0 \%$ & $-0.1 \%$ & $-0.1 \%$ & $-0.2 \%$ \\
\hline & 6 Months & $0.1 \%$ & $0.0 \%$ & 59.92 & $0.0 \%$ & $-0.1 \%$ & $-0.3 \%$ & $-0.5 \%$ \\
\hline & 1 Year & $0.1 \%$ & $0.0 \%$ & 59.91 & $0.0 \%$ & $-0.2 \%$ & $-0.3 \%$ & $-0.5 \%$ \\
\hline & 2 Year & $0.1 \%$ & $0.0 \%$ & 59.91 & $-0.1 \%$ & $-0.2 \%$ & $-0.4 \%$ & $-0.6 \%$ \\
\hline & 3 Year & $0.1 \%$ & $0.0 \%$ & 59.91 & $-0.1 \%$ & $-0.2 \%$ & $-0.4 \%$ & $-0.7 \%$ \\
\hline & 4 Year & $0.1 \%$ & $0.0 \%$ & 59.90 & $-0.1 \%$ & $-0.2 \%$ & $-0.4 \%$ & $-0.7 \%$ \\
\hline & 5 Year & $0.1 \%$ & $0.0 \%$ & 59.89 & $-0.1 \%$ & $-0.2 \%$ & $-0.4 \%$ & $-0.7 \%$ \\
\hline \multirow{8}{*}{ 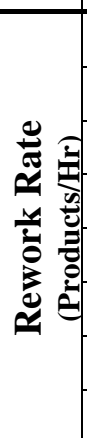 } & 1 Week & $-30.8 \%$ & $-12.2 \%$ & 0.12 & $22.1 \%$ & $85.6 \%$ & $199.9 \%$ & $423.8 \%$ \\
\hline & 1 Month & $-31.3 \%$ & $-12.4 \%$ & 0.12 & $22.5 \%$ & $87.9 \%$ & $206.9 \%$ & $444.2 \%$ \\
\hline & 6 Months & $-32.9 \%$ & $-13.2 \%$ & 0.13 & $24.5 \%$ & $98.4 \%$ & $239.5 \%$ & $531.2 \%$ \\
\hline & 1 Year & $-34.4 \%$ & $-14.0 \%$ & 0.13 & $26.4 \%$ & $108.9 \%$ & $271.4 \%$ & $606.6 \%$ \\
\hline & 2 Year & $-37.1 \%$ & $-15.5 \%$ & 0.14 & $30.1 \%$ & $128.3 \%$ & $325.3 \%$ & $711.0 \%$ \\
\hline & 3 Year & $-39.7 \%$ & $-16.8 \%$ & 0.15 & $33.4 \%$ & $144.6 \%$ & $364.1 \%$ & $764.3 \%$ \\
\hline & 4 Year & $-42.0 \%$ & $-18.0 \%$ & 0.16 & $36.3 \%$ & $157.4 \%$ & $388.8 \%$ & $784.0 \%$ \\
\hline & 5 Year & $-44.0 \%$ & $-19.0 \%$ & 0.17 & $38.7 \%$ & $166.7 \%$ & $402.3 \%$ & $783.8 \%$ \\
\hline
\end{tabular}


Table A3. Sensitivity Analysis results for varying shift length

\begin{tabular}{|c|c|c|c|c|c|c|c|c|}
\hline & $\begin{array}{l}\text { Time } \\
\text { (days) }\end{array}$ & 4 Hrs & 5.33 Hrs & $6.66 \mathrm{Hrs}$ & $\begin{array}{c}\text { BASE } \\
\text { CASE } \\
8 \mathrm{Hrs}\end{array}$ & 9.33 Hrs & $\begin{array}{c}10.66 \\
\text { Hrs }\end{array}$ & $12 \mathrm{Hrs}$ \\
\hline \multirow{8}{*}{ 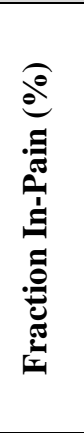 } & 1 Week & $-72.1 \%$ & $-54.1 \%$ & $-32.9 \%$ & $1.4 \mathrm{E}-03$ & $38.4 \%$ & $94.4 \%$ & $167.1 \%$ \\
\hline & 1 Month & $-74.1 \%$ & $-55.7 \%$ & $-34.0 \%$ & $4.4 \mathrm{E}-03$ & $39.6 \%$ & $97.8 \%$ & $173.4 \%$ \\
\hline & 6 Months & $-74.8 \%$ & $-56.4 \%$ & $-34.6 \%$ & $9.0 \mathrm{E}-03$ & $40.7 \%$ & $101.3 \%$ & $181.2 \%$ \\
\hline & 1 Year & $-75.5 \%$ & $-57.4 \%$ & $-35.4 \%$ & $9.5 \mathrm{E}-03$ & $42.6 \%$ & $107.5 \%$ & $195.1 \%$ \\
\hline & 2 Year & $-76.9 \%$ & $-59.0 \%$ & $-36.9 \%$ & $1.0 \mathrm{E}-02$ & $45.8 \%$ & $117.9 \%$ & $217.2 \%$ \\
\hline & 3 Year & $-78.0 \%$ & $-60.4 \%$ & $-38.1 \%$ & $1.1 \mathrm{E}-02$ & $48.3 \%$ & $125.1 \%$ & $230.5 \%$ \\
\hline & 4 Year & $-78.9 \%$ & $-61.6 \%$ & $-39.1 \%$ & $1.2 \mathrm{E}-02$ & $50.0 \%$ & $129.5 \%$ & $236.9 \%$ \\
\hline & 5 Year & $-79.7 \%$ & $-62.5 \%$ & $-39.9 \%$ & $1.3 \mathrm{E}-02$ & $51.1 \%$ & $131.7 \%$ & $238.4 \%$ \\
\hline \multirow{8}{*}{ 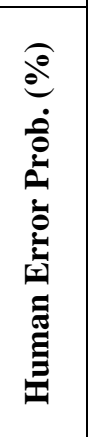 } & 1 Week & $-30.4 \%$ & $-22.9 \%$ & $-13.1 \%$ & $2.3 \mathrm{E}-03$ & $17.4 \%$ & $40.6 \%$ & $71.9 \%$ \\
\hline & 1 Month & $-31.1 \%$ & $-23.5 \%$ & $-13.5 \%$ & $2.3 \mathrm{E}-03$ & $18.0 \%$ & $42.5 \%$ & $75.9 \%$ \\
\hline & 6 Months & $-33.3 \%$ & $-25.4 \%$ & $-14.9 \%$ & $2.4 \mathrm{E}-03$ & $20.4 \%$ & $50.0 \%$ & $92.8 \%$ \\
\hline & 1 Year & $-35.1 \%$ & $-27.1 \%$ & $-16.1 \%$ & $2.5 \mathrm{E}-03$ & $22.7 \%$ & $57.1 \%$ & $109.4 \%$ \\
\hline & 2 Year & $-38.5 \%$ & $-30.2 \%$ & $-18.4 \%$ & $2.6 \mathrm{E}-03$ & $27.0 \%$ & $70.7 \%$ & $139.8 \%$ \\
\hline & 3 Year & $-41.7 \%$ & $-33.0 \%$ & $-20.4 \%$ & $2.8 \mathrm{E}-03$ & $30.9 \%$ & $82.5 \%$ & $164.4 \%$ \\
\hline & 4 Year & $-44.5 \%$ & $-35.5 \%$ & $-22.3 \%$ & 3.0E-03 & $34.3 \%$ & $92.0 \%$ & $182.3 \%$ \\
\hline & 5 Year & $-47.0 \%$ & $-37.8 \%$ & $-23.9 \%$ & 3.1E-03 & $37.1 \%$ & $99.2 \%$ & $193.9 \%$ \\
\hline \multirow{8}{*}{ 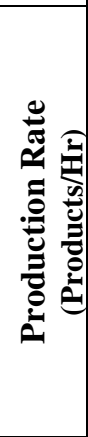 } & 1 Week & $0.0 \%$ & $0.0 \%$ & $0.0 \%$ & 59.99 & $0.0 \%$ & $0.0 \%$ & $0.0 \%$ \\
\hline & 1 Month & $0.0 \%$ & $0.0 \%$ & $0.0 \%$ & 59.96 & $0.0 \%$ & $-0.1 \%$ & $-0.1 \%$ \\
\hline & 6 Months & $0.1 \%$ & $0.1 \%$ & $0.0 \%$ & 59.92 & $-0.1 \%$ & $-0.1 \%$ & $-0.3 \%$ \\
\hline & 1 Year & $0.1 \%$ & $0.1 \%$ & $0.1 \%$ & 59.91 & $-0.1 \%$ & $-0.2 \%$ & $-0.3 \%$ \\
\hline & 2 Year & $0.1 \%$ & $0.1 \%$ & $0.1 \%$ & 59.91 & $-0.1 \%$ & $-0.2 \%$ & $-0.3 \%$ \\
\hline & 3 Year & $0.1 \%$ & $0.1 \%$ & $0.1 \%$ & 59.91 & $-0.1 \%$ & $-0.2 \%$ & $-0.4 \%$ \\
\hline & 4 Year & $0.1 \%$ & $0.1 \%$ & $0.1 \%$ & 59.90 & $-0.1 \%$ & $-0.2 \%$ & $-0.4 \%$ \\
\hline & 5 Year & $0.2 \%$ & $0.1 \%$ & $0.1 \%$ & 59.89 & $-0.1 \%$ & $-0.3 \%$ & $-0.5 \%$ \\
\hline \multirow{8}{*}{ 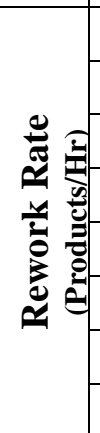 } & 1 Week & $-30.4 \%$ & $-22.9 \%$ & $-13.1 \%$ & 0.12 & $17.4 \%$ & $40.6 \%$ & $71.8 \%$ \\
\hline & 1 Month & $-31.0 \%$ & $-23.5 \%$ & $-13.5 \%$ & 0.12 & $18.0 \%$ & $42.4 \%$ & $75.7 \%$ \\
\hline & 6 Months & $-33.2 \%$ & $-25.4 \%$ & $-14.9 \%$ & 0.13 & $20.4 \%$ & $49.7 \%$ & $92.3 \%$ \\
\hline & 1 Year & $-35.0 \%$ & $-27.0 \%$ & $-16.1 \%$ & 0.13 & $22.6 \%$ & $56.9 \%$ & $108.8 \%$ \\
\hline & 2 Year & $-38.4 \%$ & $-30.1 \%$ & $-18.3 \%$ & 0.14 & $26.9 \%$ & $70.4 \%$ & $139.0 \%$ \\
\hline & 3 Year & $-41.6 \%$ & $-32.9 \%$ & $-20.4 \%$ & 0.15 & $30.8 \%$ & $82.1 \%$ & $163.4 \%$ \\
\hline & 4 Year & $-44.4 \%$ & $-35.5 \%$ & $-22.2 \%$ & 0.16 & $34.2 \%$ & $91.6 \%$ & $181.0 \%$ \\
\hline & 5 Year & $-46.9 \%$ & $-37.7 \%$ & $-23.9 \%$ & 0.17 & $36.9 \%$ & $98.7 \%$ & $192.6 \%$ \\
\hline
\end{tabular}


Table A4. Sensitivity Analysis results for varying spinal load (working)

\begin{tabular}{|c|c|c|c|c|c|c|c|c|}
\hline & $\begin{array}{l}\text { Time } \\
\text { (days) }\end{array}$ & $351 \mathrm{~N}$ & $510 \mathrm{~N}$ & $668 N$ & $\begin{array}{c}\text { BASE } \\
\text { CASE } \\
826 \mathrm{~N}\end{array}$ & $985 \mathrm{~N}$ & $1143 N$ & $1301 \mathrm{~N}$ \\
\hline \multirow{8}{*}{ 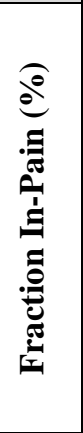 } & 1 Week & $-51.2 \%$ & $-37.7 \%$ & $-20.9 \%$ & $1.4 \mathrm{E}-03$ & $25.8 \%$ & $56.9 \%$ & $94.2 \%$ \\
\hline & 1 Month & $-51.2 \%$ & $-37.7 \%$ & $-20.9 \%$ & $4.4 \mathrm{E}-03$ & $25.8 \%$ & $56.8 \%$ & $94.0 \%$ \\
\hline & 6 Months & $-51.6 \%$ & $-38.1 \%$ & $-21.1 \%$ & $9.0 \mathrm{E}-03$ & $26.2 \%$ & $58.0 \%$ & $96.2 \%$ \\
\hline & 1 Year & $-52.5 \%$ & $-38.9 \%$ & $-21.7 \%$ & $9.5 \mathrm{E}-03$ & $27.2 \%$ & $60.6 \%$ & $101.1 \%$ \\
\hline & 2 Year & $-54.1 \%$ & $-40.4 \%$ & $-22.7 \%$ & $1.0 \mathrm{E}-02$ & $29.0 \%$ & $65.0 \%$ & $109.1 \%$ \\
\hline & 3 Year & $-55.5 \%$ & $-41.6 \%$ & $-23.5 \%$ & $1.1 \mathrm{E}-02$ & $30.3 \%$ & $68.1 \%$ & $114.3 \%$ \\
\hline & 4 Year & $-56.6 \%$ & $-42.6 \%$ & $-24.1 \%$ & $1.2 \mathrm{E}-02$ & $31.2 \%$ & $70.0 \%$ & $117.0 \%$ \\
\hline & 5 Year & $-57.5 \%$ & $-43.3 \%$ & $-24.6 \%$ & $1.3 \mathrm{E}-02$ & $31.7 \%$ & $71.0 \%$ & $117.8 \%$ \\
\hline \multirow{8}{*}{ 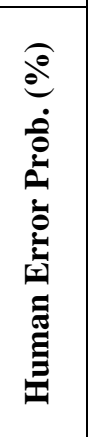 } & 1 Week & $-32.6 \%$ & $-24.8 \%$ & $-14.4 \%$ & $2.3 \mathrm{E}-03$ & $19.9 \%$ & $47.2 \%$ & $84.8 \%$ \\
\hline & 1 Month & $-33.0 \%$ & $-25.2 \%$ & $-14.6 \%$ & $2.3 \mathrm{E}-03$ & $20.3 \%$ & $48.4 \%$ & $87.1 \%$ \\
\hline & 6 Months & $-34.7 \%$ & $-26.6 \%$ & $-15.5 \%$ & $2.4 \mathrm{E}-03$ & $22.1 \%$ & $53.3 \%$ & $97.6 \%$ \\
\hline & 1 Year & $-36.2 \%$ & $-28.0 \%$ & $-16.4 \%$ & $2.5 \mathrm{E}-03$ & $23.8 \%$ & $58.2 \%$ & $108.0 \%$ \\
\hline & 2 Year & $-39.0 \%$ & $-30.4 \%$ & $-18.1 \%$ & $2.6 \mathrm{E}-03$ & $27.1 \%$ & $67.4 \%$ & $127.3 \%$ \\
\hline & 3 Year & $-41.6 \%$ & $-32.7 \%$ & $-19.6 \%$ & $2.8 \mathrm{E}-03$ & $30.1 \%$ & $75.5 \%$ & $143.5 \%$ \\
\hline & 4 Year & $-44.0 \%$ & $-34.8 \%$ & $-21.0 \%$ & $3.0 \mathrm{E}-03$ & $32.6 \%$ & $82.3 \%$ & $156.2 \%$ \\
\hline & 5 Year & $-46.1 \%$ & $-36.6 \%$ & $-22.2 \%$ & 3.1E-03 & $34.8 \%$ & $87.7 \%$ & $165.6 \%$ \\
\hline \multirow{8}{*}{ 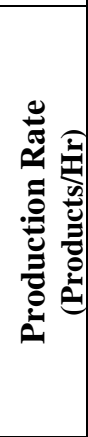 } & 1 Week & $0.0 \%$ & $0.0 \%$ & $0.0 \%$ & 59.99 & $0.0 \%$ & $0.0 \%$ & $0.0 \%$ \\
\hline & 1 Month & $0.0 \%$ & $0.0 \%$ & $0.0 \%$ & 59.96 & $0.0 \%$ & $0.0 \%$ & $-0.1 \%$ \\
\hline & 6 Months & $0.1 \%$ & $0.1 \%$ & $0.0 \%$ & 59.92 & $0.0 \%$ & $-0.1 \%$ & $-0.1 \%$ \\
\hline & 1 Year & $0.1 \%$ & $0.1 \%$ & $0.0 \%$ & 59.91 & $0.0 \%$ & $-0.1 \%$ & $-0.2 \%$ \\
\hline & 2 Year & $0.1 \%$ & $0.1 \%$ & $0.0 \%$ & 59.91 & $0.0 \%$ & $-0.1 \%$ & $-0.2 \%$ \\
\hline & 3 Year & $0.1 \%$ & $0.1 \%$ & $0.0 \%$ & 59.91 & $-0.1 \%$ & $-0.1 \%$ & $-0.2 \%$ \\
\hline & 4 Year & $0.1 \%$ & $0.1 \%$ & $0.0 \%$ & 59.90 & $-0.1 \%$ & $-0.1 \%$ & $-0.2 \%$ \\
\hline & 5 Year & $0.1 \%$ & $0.1 \%$ & $0.0 \%$ & 59.89 & $-0.1 \%$ & $-0.1 \%$ & $-0.2 \%$ \\
\hline \multirow{8}{*}{ 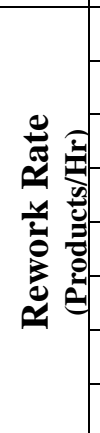 } & 1 Week & $-32.5 \%$ & $-24.8 \%$ & $-14.3 \%$ & 0.12 & $19.9 \%$ & $47.2 \%$ & $84.7 \%$ \\
\hline & 1 Month & $-33.0 \%$ & $-25.2 \%$ & $-14.6 \%$ & 0.12 & $20.3 \%$ & $48.3 \%$ & $87.0 \%$ \\
\hline & 6 Months & $-34.7 \%$ & $-26.6 \%$ & $-15.5 \%$ & 0.13 & $22.1 \%$ & $53.2 \%$ & $97.3 \%$ \\
\hline & 1 Year & $-36.2 \%$ & $-27.9 \%$ & $-16.4 \%$ & 0.13 & $23.8 \%$ & $58.1 \%$ & $107.7 \%$ \\
\hline & 2 Year & $-39.0 \%$ & $-30.4 \%$ & $-18.1 \%$ & 0.14 & $27.1 \%$ & $67.2 \%$ & $126.9 \%$ \\
\hline & 3 Year & $-41.6 \%$ & $-32.7 \%$ & $-19.6 \%$ & 0.15 & $30.0 \%$ & $75.3 \%$ & $143.0 \%$ \\
\hline & 4 Year & $-43.9 \%$ & $-34.7 \%$ & $-21.0 \%$ & 0.16 & $32.5 \%$ & $82.1 \%$ & $155.7 \%$ \\
\hline & 5 Year & $-46.0 \%$ & $-36.5 \%$ & $-22.2 \%$ & 0.17 & $34.7 \%$ & $87.4 \%$ & $164.9 \%$ \\
\hline
\end{tabular}


Table A5. Sensitivity Analysis results for varying takt time

\begin{tabular}{|c|c|c|c|c|c|c|c|c|}
\hline & $\begin{array}{c}\text { Time } \\
\text { (days) }\end{array}$ & $0.5 \mathrm{~min}$ & $0.66 \mathrm{~min}$ & $0.83 \min$ & $\frac{\text { BASE CASE }}{1 \mathrm{~min}}$ & $1.16 \mathrm{~min}$ & $1.32 \mathrm{~min}$ & $1.5 \mathrm{~min}$ \\
\hline \multirow{8}{*}{ 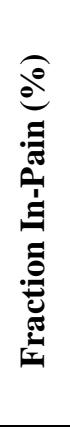 } & 1 Week & $0.0 \%$ & $0.0 \%$ & $0.0 \%$ & $1.4 \mathrm{E}-03$ & $0.0 \%$ & $0.0 \%$ & $0.0 \%$ \\
\hline & 1 Month & $0.0 \%$ & $0.0 \%$ & $0.0 \%$ & $4.4 \mathrm{E}-03$ & $0.0 \%$ & $0.0 \%$ & $0.0 \%$ \\
\hline & 6 Months & $0.0 \%$ & $0.0 \%$ & $0.0 \%$ & $9.0 \mathrm{E}-03$ & $0.0 \%$ & $0.0 \%$ & $0.0 \%$ \\
\hline & 1 Year & $0.0 \%$ & $0.0 \%$ & $0.0 \%$ & $9.5 \mathrm{E}-03$ & $0.0 \%$ & $0.0 \%$ & $0.0 \%$ \\
\hline & 2 Year & $0.0 \%$ & $0.0 \%$ & $0.0 \%$ & $1.0 \mathrm{E}-02$ & $0.0 \%$ & $0.0 \%$ & $0.0 \%$ \\
\hline & 3 Year & $0.0 \%$ & $0.0 \%$ & $0.0 \%$ & $1.1 \mathrm{E}-02$ & $0.0 \%$ & $0.0 \%$ & $0.0 \%$ \\
\hline & 4 Year & $0.0 \%$ & $0.0 \%$ & $0.0 \%$ & $1.2 \mathrm{E}-02$ & $0.0 \%$ & $0.0 \%$ & $0.0 \%$ \\
\hline & 5 Year & $0.0 \%$ & $0.0 \%$ & $0.0 \%$ & $1.3 \mathrm{E}-02$ & $0.0 \%$ & $0.0 \%$ & $0.0 \%$ \\
\hline \multirow{8}{*}{ 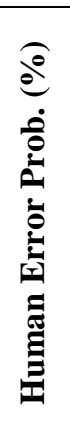 } & 1 Week & $0.0 \%$ & $0.0 \%$ & $0.0 \%$ & $2.3 \mathrm{E}-03$ & $0.0 \%$ & $0.0 \%$ & $0.0 \%$ \\
\hline & 1 Month & $0.0 \%$ & $0.0 \%$ & $0.0 \%$ & $2.3 \mathrm{E}-03$ & $0.0 \%$ & $0.0 \%$ & $0.0 \%$ \\
\hline & 6 Months & $0.0 \%$ & $0.0 \%$ & $0.0 \%$ & $2.4 \mathrm{E}-03$ & $0.0 \%$ & $0.0 \%$ & $0.0 \%$ \\
\hline & 1 Year & $0.0 \%$ & $0.0 \%$ & $0.0 \%$ & $2.5 \mathrm{E}-03$ & $0.0 \%$ & $0.0 \%$ & $0.0 \%$ \\
\hline & 2 Year & $0.0 \%$ & $0.0 \%$ & $0.0 \%$ & $2.6 \mathrm{E}-03$ & $0.0 \%$ & $0.0 \%$ & $0.0 \%$ \\
\hline & 3 Year & $0.0 \%$ & $0.0 \%$ & $0.0 \%$ & $2.8 \mathrm{E}-03$ & $0.0 \%$ & $0.0 \%$ & $0.0 \%$ \\
\hline & 4 Year & $0.0 \%$ & $0.0 \%$ & $0.0 \%$ & $3.0 \mathrm{E}-03$ & $0.0 \%$ & $0.0 \%$ & $0.0 \%$ \\
\hline & 5 Year & $0.0 \%$ & $0.0 \%$ & $0.0 \%$ & $3.1 \mathrm{E}-03$ & $0.0 \%$ & $0.0 \%$ & $0.0 \%$ \\
\hline \multirow{8}{*}{ 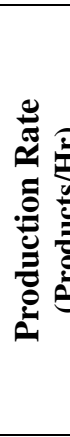 } & 1 Week & $100 \%$ & $51.52 \%$ & $20.48 \%$ & 59.99 & $-13.79 \%$ & $-24.24 \%$ & $-33.33 \%$ \\
\hline & 1 Month & $100 \%$ & $51.52 \%$ & $20.48 \%$ & 59.96 & $-13.79 \%$ & $-24.24 \%$ & $-33.33 \%$ \\
\hline & 6 Months & $100 \%$ & $51.52 \%$ & $20.48 \%$ & 59.92 & $-13.79 \%$ & $-24.24 \%$ & $-33.33 \%$ \\
\hline & 1 Year & $100 \%$ & $51.52 \%$ & $20.48 \%$ & 59.91 & $-13.79 \%$ & $-24.24 \%$ & $-33.33 \%$ \\
\hline & 2 Year & $100 \%$ & $51.52 \%$ & $20.48 \%$ & 59.91 & $-13.79 \%$ & $-24.24 \%$ & $-33.33 \%$ \\
\hline & 3 Year & $100 \%$ & $51.52 \%$ & $20.48 \%$ & 59.91 & $-13.79 \%$ & $-24.24 \%$ & $-33.33 \%$ \\
\hline & 4 Year & $100 \%$ & $51.52 \%$ & $20.48 \%$ & 59.90 & $-13.79 \%$ & $-24.24 \%$ & $-33.33 \%$ \\
\hline & 5 Year & $100 \%$ & $51.52 \%$ & $20.48 \%$ & 59.89 & $-13.79 \%$ & $-24.24 \%$ & $-33.33 \%$ \\
\hline \multirow{8}{*}{ e } & 1 Week & $100 \%$ & $51.5 \%$ & $20.5 \%$ & 0.12 & $-13.8 \%$ & $-24.2 \%$ & $-33.3 \%$ \\
\hline & 1 Month & $100 \%$ & $51.5 \%$ & $20.5 \%$ & 0.12 & $-13.8 \%$ & $-24.2 \%$ & $-33.3 \%$ \\
\hline & 6 Months & $100 \%$ & $51.5 \%$ & $20.5 \%$ & 0.13 & $-13.8 \%$ & $-24.2 \%$ & $-33.3 \%$ \\
\hline & 1 Year & $100 \%$ & $51.5 \%$ & $20.5 \%$ & 0.13 & $-13.8 \%$ & $-24.2 \%$ & $-33.3 \%$ \\
\hline & 2 Year & $100 \%$ & $51.5 \%$ & $20.5 \%$ & 0.14 & $-13.8 \%$ & $-24.2 \%$ & $-33.3 \%$ \\
\hline & 3 Year & $100 \%$ & $51.5 \%$ & $20.5 \%$ & 0.15 & $-13.8 \%$ & $-24.2 \%$ & $-33.3 \%$ \\
\hline & 4 Year & $100 \%$ & $51.5 \%$ & $20.5 \%$ & 0.16 & $-13.8 \%$ & $-24.2 \%$ & $-33.3 \%$ \\
\hline & 5 Year & $100 \%$ & $51.5 \%$ & $20.5 \%$ & 0.17 & $-13.8 \%$ & $-24.2 \%$ & $-33.3 \%$ \\
\hline
\end{tabular}




\section{Appendix D: Results of Experimental Analysis for the Manufacturing Model}

Tables A6-A9 list the results of the experimental. The values in the tables are 'peak values' corresponding to the last working day of each week.

Table A6. Fraction In Pain for Experimental Analysis input

\begin{tabular}{|c|c|c|c|c|c|c|c|c|c|c|c|}
\hline \multirow{2}{*}{ \# } & \multirow{2}{*}{$\begin{array}{c}\text { Shift } \\
\text { Length } \\
\text { (hrs) }\end{array}$} & \multirow{2}{*}{$\begin{array}{c}\text { Spinal } \\
\text { Load } \\
(\mathbf{N})\end{array}$} & \multirow{2}{*}{$\begin{array}{c}\text { Peak } \\
\text { Hand } \\
\text { Load } \\
(\mathrm{kg})\end{array}$} & \multicolumn{8}{|c|}{ Fraction In Pain (\%) } \\
\hline & & & & $1 \mathrm{~W}$ & $1 \mathrm{M}$ & $6 \mathrm{M}$ & $1 Y$ & $2 Y$ & $3 Y$ & $4 Y$ & $5 Y$ \\
\hline BASE & 8 & 826 & 14.3 & $0.1 \%$ & $0.4 \%$ & $0.9 \%$ & $1.0 \%$ & $1.0 \%$ & $1.1 \%$ & $1.2 \%$ & $1.3 \%$ \\
\hline 1 & 8 & 500 & 5 & $0.1 \%$ & $0.2 \%$ & $0.4 \%$ & $0.4 \%$ & $0.4 \%$ & $0.4 \%$ & $0.4 \%$ & $0.4 \%$ \\
\hline 2 & 8 & 500 & 15 & $0.1 \%$ & $0.3 \%$ & $0.6 \%$ & $0.6 \%$ & $0.6 \%$ & $0.7 \%$ & $0.7 \%$ & $0.7 \%$ \\
\hline 3 & 8 & 500 & 25 & $0.1 \%$ & $0.4 \%$ & $0.9 \%$ & $1.0 \%$ & $1.0 \%$ & $1.1 \%$ & $1.2 \%$ & $1.3 \%$ \\
\hline 4 & 8 & 750 & 5 & $0.1 \%$ & $0.3 \%$ & $0.5 \%$ & $0.5 \%$ & $0.6 \%$ & $0.6 \%$ & $0.6 \%$ & $0.7 \%$ \\
\hline 5 & 8 & 750 & 15 & $0.1 \%$ & $0.4 \%$ & $0.8 \%$ & $0.9 \%$ & $0.9 \%$ & $1.0 \%$ & $1.1 \%$ & $1.1 \%$ \\
\hline 6 & 8 & 750 & 25 & $0.2 \%$ & $0.6 \%$ & $1.3 \%$ & $1.4 \%$ & $1.5 \%$ & $1.7 \%$ & $1.8 \%$ & $1.9 \%$ \\
\hline 7 & 8 & 1000 & 5 & $0.1 \%$ & $0.4 \%$ & $0.8 \%$ & $0.8 \%$ & $0.9 \%$ & $0.9 \%$ & $1.0 \%$ & $1.0 \%$ \\
\hline 8 & 8 & 1000 & 15 & $0.2 \%$ & $0.6 \%$ & $1.2 \%$ & $1.3 \%$ & $1.4 \%$ & $1.5 \%$ & $1.7 \%$ & $1.8 \%$ \\
\hline 9 & 8 & 1000 & 25 & $0.3 \%$ & $0.9 \%$ & $1.8 \%$ & $2.0 \%$ & $2.2 \%$ & $2.5 \%$ & $2.7 \%$ & $2.8 \%$ \\
\hline 10 & 10 & 5 & 5 & $\%$ & $0.3 \%$ & $0.5 \%$ & $0.6 \%$ & $0.6 \%$ & $0.6 \%$ & $0.7 \%$ & $0.7 \%$ \\
\hline 11 & No & 500 & 5 & $\%$ & $0.4 \%$ & $0.9 \%$ & $0.9 \%$ & $.0 \%$ & $1.1 \%$ & $1.1 \%$ & $1.2 \%$ \\
\hline 12 & 1 & 5 & 25 & $0.2 \%$ & $0.6 \%$ & $1.4 \%$ & $1.5 \%$ & $.6 \%$ & $1.8 \%$ & $1.9 \%$ & $2.1 \%$ \\
\hline 13 & 10 & 750 & 5 & $0.1 \%$ & $0.4 \%$ & $0.9 \%$ & $0.9 \%$ & $1.0 \%$ & $1.1 \%$ & $1.1 \%$ & $1.2 \%$ \\
\hline 14 & 10 & 750 & 15 & $0.2 \%$ & $0.7 \%$ & $1.4 \%$ & $1.5 \%$ & $1.6 \%$ & $1.8 \%$ & $1.9 \%$ & $2.1 \%$ \\
\hline 15 & 10 & 750 & 25 & $0.3 \%$ & $1.0 \%$ & $2.1 \%$ & $2.3 \%$ & $2.6 \%$ & $2.9 \%$ & $3.2 \%$ & $3.4 \%$ \\
\hline 16 & 10 & 1000 & 5 & $0.2 \%$ & $0.7 \%$ & $1.4 \%$ & $1.5 \%$ & $1.7 \%$ & $1.8 \%$ & $2.0 \%$ & $2.1 \%$ \\
\hline 17 & 10 & 1000 & 15 & $0.3 \%$ & $1.0 \%$ & $2.1 \%$ & $2.3 \%$ & $2.7 \%$ & $3.0 \%$ & $3.2 \%$ & $3.4 \%$ \\
\hline 18 & 10 & 1000 & 25 & $0.4 \%$ & $1.5 \%$ & $3.2 \%$ & $3.5 \%$ & $4.1 \%$ & $4.5 \%$ & $4.8 \%$ & $5.1 \%$ \\
\hline 19 & 12 & 500 & 5 & $0.1 \%$ & $0.4 \%$ & $0.8 \%$ & $0.9 \%$ & $0.9 \%$ & $1.0 \%$ & $1.1 \%$ & $1.1 \%$ \\
\hline 20 & 12 & 5 & 15 & $0.2 \%$ & $0.6 \%$ & $1.3 \%$ & $1.4 \%$ & $1.5 \%$ & $1.7 \%$ & $1.8 \%$ & $2.0 \%$ \\
\hline 21 & 12 & 500 & 25 & $0.3 \%$ & $0.9 \%$ & $2.0 \%$ & $2.2 \%$ & $2.5 \%$ & $2.8 \%$ & $3.1 \%$ & $3.3 \%$ \\
\hline 22 & 12 & 750 & 5 & $0.2 \%$ & $0.7 \%$ & $1.4 \%$ & $1.5 \%$ & $1.7 \%$ & $1.9 \%$ & $2.1 \%$ & $2.2 \%$ \\
\hline 23 & 12 & 750 & 15 & $0.3 \%$ & $1.0 \%$ & $2.2 \%$ & $2.4 \%$ & $2.8 \%$ & $3.2 \%$ & $3.5 \%$ & $3.7 \%$ \\
\hline 24 & 12 & 750 & 25 & $0.5 \%$ & $1.6 \%$ & $3.3 \%$ & $3.8 \%$ & $4.4 \%$ & $4.9 \%$ & $5.3 \%$ & $5.6 \%$ \\
\hline 25 & 12 & 1000 & 5 & $0.3 \%$ & $1.1 \%$ & $2.5 \%$ & $2.7 \%$ & $3.1 \%$ & $3.5 \%$ & $3.8 \%$ & $4.1 \%$ \\
\hline 26 & 12 & 1000 & 15 & $0.5 \%$ & $1.7 \%$ & $3.7 \%$ & $4.1 \%$ & $4.8 \%$ & $5.4 \%$ & $5.8 \%$ & $6.1 \%$ \\
\hline 27 & 12 & 1000 & 25 & $0.7 \%$ & $2.4 \%$ & $5.2 \%$ & $5.9 \%$ & $6.9 \%$ & $7.6 \%$ & $8.0 \%$ & $8.3 \%$ \\
\hline
\end{tabular}


Table A7. Human Error Probability for Experimental Analysis input

\begin{tabular}{|c|c|c|c|c|c|c|c|c|c|c|c|}
\hline \multirow{2}{*}{$\#$} & \multirow{2}{*}{$\begin{array}{c}\text { Shift } \\
\text { Length } \\
\text { (hrs) }\end{array}$} & \multirow{2}{*}{$\begin{array}{c}\text { Spinal } \\
\text { Load } \\
(\mathbf{N})\end{array}$} & \multirow{2}{*}{$\begin{array}{c}\text { Peak } \\
\text { Hand } \\
\text { Load } \\
(\mathrm{kg})\end{array}$} & \multicolumn{8}{|c|}{ Human Error Probability (\%) } \\
\hline & & & & $1 \mathrm{~W}$ & $1 \mathrm{M}$ & $6 \mathrm{M}$ & $1 Y$ & $2 Y$ & $3 \mathrm{Y}$ & $4 Y$ & $5 Y$ \\
\hline BASE & 8 & 826 & 14.3 & $0.2 \%$ & $0.2 \%$ & $0.2 \%$ & $0.2 \%$ & $0.3 \%$ & $0.3 \%$ & $0.3 \%$ & $0.3 \%$ \\
\hline 1 & 8 & 500 & 5 & $0.1 \%$ & $0.1 \%$ & $0.1 \%$ & $0.1 \%$ & $0.1 \%$ & $0.1 \%$ & $0.2 \%$ & $0.2 \%$ \\
\hline 2 & 8 & 500 & 15 & $0.2 \%$ & $0.2 \%$ & $0.2 \%$ & $0.2 \%$ & $0.2 \%$ & $0.2 \%$ & $0.2 \%$ & $0.2 \%$ \\
\hline 3 & 8 & 500 & 25 & $0.2 \%$ & $0.2 \%$ & $0.2 \%$ & $0.2 \%$ & $0.3 \%$ & $0.3 \%$ & $0.3 \%$ & $0.3 \%$ \\
\hline 4 & 8 & 750 & 5 & $0.2 \%$ & $0.2 \%$ & $0.2 \%$ & $0.2 \%$ & $0.2 \%$ & $0.2 \%$ & $0.2 \%$ & $0.2 \%$ \\
\hline 5 & 8 & 750 & 15 & $0.2 \%$ & $0.2 \%$ & $0.2 \%$ & $0.2 \%$ & $0.2 \%$ & $0.3 \%$ & $0.3 \%$ & $0.3 \%$ \\
\hline 6 & 8 & 750 & 25 & $0.3 \%$ & $0.3 \%$ & $0.3 \%$ & $0.3 \%$ & $0.4 \%$ & $0.4 \%$ & $0.5 \%$ & $0.5 \%$ \\
\hline 7 & 8 & 1000 & 5 & $0.2 \%$ & $0.2 \%$ & $0.2 \%$ & $0.2 \%$ & $0.2 \%$ & $0.2 \%$ & $0.3 \%$ & $0.3 \%$ \\
\hline 8 & 8 & 1000 & 15 & $0.3 \%$ & $0.3 \%$ & $0.3 \%$ & $0.3 \%$ & $0.4 \%$ & $0.4 \%$ & $0.4 \%$ & $0.5 \%$ \\
\hline 9 & 8 & 1000 & 25 & $0.4 \%$ & $0.4 \%$ & $0.5 \%$ & $0.5 \%$ & $0.6 \%$ & $0.7 \%$ & $0.8 \%$ & $0.9 \%$ \\
\hline 10 & 10 & 500 & 5 & $0.2 \%$ & $0.2 \%$ & $0.2 \%$ & $0.2 \%$ & $0.2 \%$ & $0.2 \%$ & $0.2 \%$ & $0.2 \%$ \\
\hline 11 & 10 & 500 & 15 & $0.2 \%$ & $0.2 \%$ & $0.2 \%$ & $0.2 \%$ & $0.2 \%$ & $0.2 \%$ & $0.2 \%$ & $0.3 \%$ \\
\hline 12 & 10 & 500 & 25 & $0.3 \%$ & $0.3 \%$ & $0.3 \%$ & $0.3 \%$ & $0.3 \%$ & $0.4 \%$ & $0.4 \%$ & $0.4 \%$ \\
\hline 13 & 10 & 750 & 5 & $0.2 \%$ & $0.2 \%$ & $0.2 \%$ & $0.2 \%$ & $0.2 \%$ & $0.2 \%$ & $0.2 \%$ & $0.3 \%$ \\
\hline 14 & 10 & 750 & 15 & $0.3 \%$ & $0.3 \%$ & $0.3 \%$ & $0.3 \%$ & $0.3 \%$ & $0.4 \%$ & $0.4 \%$ & $0.4 \%$ \\
\hline 15 & 10 & 750 & 25 & $0.4 \%$ & $0.4 \%$ & $0.5 \%$ & $0.5 \%$ & $0.6 \%$ & $0.7 \%$ & $0.8 \%$ & $0.9 \%$ \\
\hline 16 & 10 & 1000 & 5 & $0.3 \%$ & $0.3 \%$ & $0.3 \%$ & $0.3 \%$ & $0.3 \%$ & $0.4 \%$ & $0.4 \%$ & $0.5 \%$ \\
\hline 17 & 10 & 1000 & 15 & $0.4 \%$ & $0.4 \%$ & $0.5 \%$ & $0.5 \%$ & $0.6 \%$ & $0.7 \%$ & $0.8 \%$ & $0.9 \%$ \\
\hline 18 & 10 & 1000 & 25 & $0.6 \%$ & $0.7 \%$ & $0.8 \%$ & $0.9 \%$ & $1.2 \%$ & $1.4 \%$ & $1.5 \%$ & $1.7 \%$ \\
\hline 19 & 12 & 500 & 5 & $0.2 \%$ & $0.2 \%$ & $0.2 \%$ & $0.2 \%$ & $0.2 \%$ & $0.2 \%$ & $0.2 \%$ & $0.2 \%$ \\
\hline 20 & 12 & 500 & 15 & $0.2 \%$ & $0.2 \%$ & $0.2 \%$ & $0.2 \%$ & $0.3 \%$ & $0.3 \%$ & $0.3 \%$ & $0.3 \%$ \\
\hline 21 & 12 & 500 & 25 & $0.3 \%$ & $0.3 \%$ & $0.4 \%$ & $0.4 \%$ & $0.5 \%$ & $0.5 \%$ & $0.6 \%$ & $0.6 \%$ \\
\hline 22 & 12 & 750 & 5 & $0.2 \%$ & $0.2 \%$ & $0.3 \%$ & $0.3 \%$ & $0.3 \%$ & $0.3 \%$ & $0.4 \%$ & $0.4 \%$ \\
\hline 23 & 12 & 750 & 15 & $0.3 \%$ & $0.4 \%$ & $0.4 \%$ & $0.4 \%$ & $0.5 \%$ & $0.6 \%$ & $0.7 \%$ & $0.7 \%$ \\
\hline 24 & 12 & 750 & 25 & $0.5 \%$ & $0.6 \%$ & $0.7 \%$ & $0.8 \%$ & $1.0 \%$ & $1.2 \%$ & $1.3 \%$ & $1.5 \%$ \\
\hline 25 & 12 & 1000 & 5 & $0.4 \%$ & $0.4 \%$ & $0.4 \%$ & $0.5 \%$ & $0.6 \%$ & $0.7 \%$ & $0.8 \%$ & $0.9 \%$ \\
\hline 26 & 12 & 1000 & 15 & $0.6 \%$ & $0.6 \%$ & $0.8 \%$ & $0.9 \%$ & $1.2 \%$ & $1.4 \%$ & $1.5 \%$ & $1.7 \%$ \\
\hline 27 & 12 & 1000 & 25 & $1.0 \%$ & $1.1 \%$ & $1.4 \%$ & $1.7 \%$ & $2.1 \%$ & $2.4 \%$ & $2.6 \%$ & $2.8 \%$ \\
\hline
\end{tabular}


Table A8. Production Rate for Experimental Analysis input

\begin{tabular}{|c|c|c|c|c|c|c|c|c|c|c|c|}
\hline \multirow{2}{*}{ \# } & \multirow{2}{*}{$\begin{array}{c}\text { Shift } \\
\text { Length } \\
\text { (hrs) }\end{array}$} & \multirow{2}{*}{$\begin{array}{c}\text { Spinal } \\
\text { Load } \\
(\mathbf{N})\end{array}$} & \multirow{2}{*}{$\begin{array}{c}\text { Peak } \\
\text { Hand } \\
\text { Load } \\
(\mathbf{k g})\end{array}$} & \multicolumn{8}{|c|}{ Production Rate (Products/Hr) } \\
\hline & & & & $1 \mathrm{~W}$ & $1 \mathrm{M}$ & $6 \mathrm{M}$ & $1 Y$ & $2 Y$ & $3 Y$ & $4 Y$ & $5 Y$ \\
\hline BASE & 8 & 826 & 14.3 & 59.99 & 59.96 & 59.91 & 59.91 & 59.90 & 59.89 & 59.89 & 59.88 \\
\hline 1 & 8 & 500 & 5 & 59.99 & 59.98 & 9.97 & 59.97 & 59.96 & 59.96 & 59.96 & 59.96 \\
\hline 2 & 8 & 500 & 15 & 59.99 & 59.97 & 59.95 & 59.94 & 59.94 & 59.94 & 59.93 & 59.93 \\
\hline 3 & 8 & 500 & 25 & 59.99 & 59.96 & 59.91 & 59.91 & 59.90 & 59.89 & 59.89 & 59.88 \\
\hline 4 & 8 & 750 & 5 & 59.99 & 59.98 & 59.95 & 59.95 & 59.95 & 59.94 & 59.94 & 59.94 \\
\hline 5 & 8 & 750 & 15 & 59.99 & 59.96 & 59.92 & 59.92 & 59.91 & 59.90 & 59.90 & 59.89 \\
\hline 6 & 8 & 750 & 25 & 59.98 & 59.94 & 59.88 & 59.87 & 59.85 & 59.84 & 59.83 & 59.82 \\
\hline 7 & 8 & 1000 & 5 & 59.99 & 59.96 & 59.93 & 59.92 & 59.92 & 59.91 & 59.91 & 59.90 \\
\hline 8 & 8 & 1000 & 15 & 59.98 & 59.95 & 59.89 & 59.88 & 59.87 & 59.85 & 59.84 & 59.83 \\
\hline 9 & 8 & 1000 & 25 & 59.97 & 59.92 & 59.83 & 59.81 & 59.79 & 59.77 & 59.75 & 59.73 \\
\hline 10 & 10 & 500 & 5 & 59.99 & 59.98 & 59.95 & 59.95 & 59.94 & 59.94 & .94 & 59.94 \\
\hline 11 & 10 & 500 & 15 & 59.99 & 59.96 & 59.92 & 59.91 & .91 & 59.90 & 9.89 & 59.89 \\
\hline 12 & 10 & & 25 & 5 & 5 & & 86 & 85 & 59.83 & 82 & 59.81 \\
\hline 13 & & & 5 & 9 & 5 & & 91 & & 59.90 & & 59.89 \\
\hline 14 & & - & & 59.98 & 59.94 & 59 & 59.86 & 59.84 & 59.83 & 59.82 & 59.80 \\
\hline 15 & 10 & 750 & 25 & 59.97 & 59.91 & 59.80 & 59.78 & 59.75 & 59.72 & 59.70 & 59.68 \\
\hline 16 & 10 & 1000 & 5 & 59.98 & 59.94 & 59.87 & 59.86 & 59.84 & 59.83 & 59.81 & 59.80 \\
\hline 17 & 10 & 1000 & 15 & 59.97 & 59.91 & 59.80 & 59.78 & 59.75 & 59.72 & 59.70 & 59.68 \\
\hline 18 & 10 & 1000 & 25 & 59.96 & 59.86 & 59.70 & 59.67 & 59.62 & 59.58 & 59.54 & 59.52 \\
\hline 19 & 12 & 500 & 5 & 59.99 & 59.96 & 59.92 & 59.92 & 59.91 & 59.91 & 59.90 & 59.89 \\
\hline 20 & 12 & 500 & 15 & 59.98 & 59.94 & 59.88 & 59.87 & 59.85 & 59.84 & 9.83 & 59.81 \\
\hline 21 & 12 & 500 & 25 & 59.97 & 59.91 & 59 & 59.79 & 59.76 & 59.73 & 9.71 & 59.69 \\
\hline 22 & 12 & 750 & 5 & 59.98 & 59.94 & 59.86 & 59.85 & 59.84 & 59.82 & 59.80 & 59.79 \\
\hline 23 & 12 & 750 & 15 & 59.97 & 59.90 & 59.79 & 59.77 & 59.73 & 59.70 & 59.67 & 59.65 \\
\hline 24 & 12 & 750 & 25 & 59.96 & 59.85 & 59.68 & 59.65 & 59.58 & 59.54 & 59.50 & 59.47 \\
\hline 25 & 12 & 1000 & 5 & 59.97 & 59.89 & 59.77 & 59.74 & 59.70 & 59.67 & 59.64 & 59.61 \\
\hline 26 & 12 & 1000 & 15 & 59.95 & 59.84 & 59.65 & 59.61 & 59.54 & 59.49 & 59.46 & 59.43 \\
\hline 27 & 12 & 1000 & 25 & 59.93 & 59.77 & 59.51 & 59.44 & 59.35 & 59.29 & 59.25 & 59.22 \\
\hline
\end{tabular}


Table A9. Rework Rate for Experimental Analysis input

\begin{tabular}{|c|c|c|c|c|c|c|c|c|c|c|c|}
\hline \multirow{2}{*}{ \# } & \multirow{2}{*}{$\begin{array}{l}\text { Shift } \\
\text { Length } \\
\text { (hrs) }\end{array}$} & \multirow{2}{*}{$\begin{array}{c}\text { Spinal } \\
\text { Load } \\
\text { (N) }\end{array}$} & \multirow{2}{*}{$\begin{array}{c}\text { Peak } \\
\text { Hand } \\
\text { Load } \\
(\mathbf{k g})\end{array}$} & \multicolumn{8}{|c|}{ Rework Rate (Products/Hr) } \\
\hline & & & & $1 \mathrm{~W}$ & $1 \mathrm{M}$ & $6 \mathrm{M}$ & $1 Y$ & $2 Y$ & $3 \mathbf{Y}$ & $4 Y$ & $5 Y$ \\
\hline BASE & 8 & 826 & 14.3 & 0.12 & 0.12 & 0.13 & 0.13 & 0.14 & 0.15 & 0.16 & 0.17 \\
\hline 1 & 8 & 500 & 5 & 0.08 & 0.08 & 0.08 & 0.08 & 0.08 & 0.08 & 0.08 & 0.08 \\
\hline 2 & 8 & 500 & 15 & 0.09 & 0.09 & 0.10 & 0.10 & 0.10 & 0.10 & 0.11 & 0.11 \\
\hline 3 & 8 & 500 & 25 & 0.12 & 0.12 & 0.13 & 0.13 & 0.14 & 0.15 & 0.16 & 0.17 \\
\hline 4 & 8 & 750 & 5 & 0.09 & 0.09 & 0.09 & 0.09 & 0.09 & 0.10 & 0.10 & 0.10 \\
\hline 5 & 8 & 750 & 15 & 0.12 & 0.12 & 0.12 & 0.12 & 0.13 & 0.14 & 0.15 & 0.15 \\
\hline 6 & 8 & 750 & 25 & 0.16 & 0.17 & 0.18 & 0.19 & 0.21 & 0.23 & 0.25 & 0.27 \\
\hline 7 & 8 & 1000 & 5 & 0.11 & 0.11 & 0.11 & 0.12 & 0.12 & 0.13 & 0.14 & 0.14 \\
\hline 8 & 8 & 1000 & 15 & 0.15 & 0.16 & 0.16 & 0.17 & 0.19 & 0.21 & 0.23 & 0.25 \\
\hline 9 & 8 & 1000 & 25 & 0.23 & 0.24 & 0.26 & 0.29 & 0.34 & 0.39 & 0.43 & 0.47 \\
\hline 10 & 10 & 500 & 5 & 0.08 & 0.08 & 0.08 & 0.09 & 0.09 & 0.09 & 0.09 & 0.09 \\
\hline 11 & 10 & 500 & 15 & 0.10 & 0.10 & 0.11 & 0.11 & 0.12 & 0.12 & 0.13 & 0.14 \\
\hline 12 & 10 & 500 & 25 & 0.14 & 0.14 & 0.15 & 0.16 & 0.18 & 0.20 & 0.22 & 0.23 \\
\hline 13 & 10 & 750 & 5 & 0.10 & 0.10 & 0.11 & 0.11 & 0.12 & 0.12 & 0.13 & 0.14 \\
\hline 14 & 10 & 750 & 15 & 0.14 & 0.15 & 0.16 & 0.16 & 0.18 & 0.20 & 0.22 & 0.24 \\
\hline 15 & 10 & 750 & 25 & 0.21 & 0.22 & 0.25 & 0.27 & 0.32 & 0.37 & 0.42 & 0.46 \\
\hline 16 & 10 & 1000 & 5 & 0.14 & 0.15 & 0.16 & 0.17 & 0.18 & 0.20 & 0.22 & 0.24 \\
\hline 17 & 10 & 1000 & 15 & 0.22 & 0.22 & 0.25 & 0.28 & 0.33 & 0.38 & 0.43 & 0.47 \\
\hline 18 & 10 & 1000 & 25 & 0.35 & 0.37 & 0.43 & 0.50 & 0.62 & 0.73 & 0.82 & 0.89 \\
\hline 19 & 12 & 500 & 5 & 0.09 & 0.09 & 0.09 & 0.10 & 0.10 & 0.10 & 0.11 & 0.11 \\
\hline 20 & 12 & 500 & 15 & 0.12 & 0.12 & 0.13 & 0.13 & 0.14 & 0.16 & 0.17 & 0.18 \\
\hline 21 & 12 & 500 & 25 & 0.17 & 0.17 & 0.19 & 0.21 & 0.24 & 0.28 & 0.31 & 0.34 \\
\hline 22 & 12 & 750 & 5 & 0.13 & 0.13 & 0.14 & 0.14 & 0.16 & 0.18 & 0.19 & 0.21 \\
\hline 23 & 12 & 750 & 15 & 0.18 & 0.19 & 0.21 & 0.23 & 0.28 & 0.32 & 0.36 & 0.40 \\
\hline 24 & 12 & 750 & 25 & 0.29 & 0.30 & 0.36 & 0.42 & 0.53 & 0.63 & 0.71 & 0.78 \\
\hline 25 & 12 & 1000 & 5 & 0.20 & 0.21 & 0.24 & 0.27 & 0.32 & 0.38 & 0.43 & 0.47 \\
\hline 26 & 12 & 1000 & 15 & 0.32 & 0.34 & 0.41 & 0.49 & 0.62 & 0.74 & 0.83 & 0.90 \\
\hline 27 & 12 & 1000 & 25 & 0.53 & 0.57 & 0.73 & 0.89 & 1.13 & 1.30 & 1.41 & 1.49 \\
\hline
\end{tabular}




\section{Appendix E: Healthcare Model Documentation}

(01) $\quad$ Absent $=$ INTEG (

Taking Time Off-Recovering,

$0)$

Units: Nurse

(02) Actual NPR=

IF THEN ELSE $(0.1558 * \operatorname{EXP}(0.5973 *$ Acuity $)<=$ NPR Limited by Budget,

$0.1558 * \operatorname{EXP}(0.5973 *$ Acuity $)$, NPR Limited by Budget $)$

Units: Nurse/Patient

(03) Average Daily Fatigue $=$

SMOOTH3(Fatigue, 24 )

Units: Dmnl

(04) Average Illness Severity= INTEG (

Change in Acuity,

1)

Units: Dmnl

(05) "Burnt-Out"= INTEG (

Getting Burnt Out-Taking Time Off,

$0)$

Units: Nurse

(06) Change in Acuity=

IF THEN ELSE(MODULO(Hour of Day, 1 )=0,(RANDOM UNIFORM(1.44,1.44,0)-

Average Illness Severity)/TIME STEP , 0)

Units: $1 /$ Hour

(07) Change in Overtime $=$

IF THEN ELSE(Hour of Day<=TIME STEP, $(((0.75 *$ Medical Errors*("Shift Length

(Scheduled)" /24)*(1/Total Nurses on Duty))+0.675)-"End-of-Shift Overtime")/TIME STEP, 0)

Units: Hour/Hour

(08) "End-of-Shift Overtime"= INTEG (

Change in Overtime,

$0)$

Units: Hour

(09) FINAL TIME $=672$

Units: Hour

The final time for the simulation.

(10) "Fraction Burnt-Out"=

"Burnt-Out"/Total Nurses on Duty

Units: Nurse/Nurse 
(11) Acuity= Units: Dmnl

INTEGER(Average Illness Severity)

(12) Day of Week= INTEG (

Time Passing with Week Reset, $0)$

Units: Hour

(13) "Expected NPR (Based on Severity)"= $0.1558 * \operatorname{EXP}(0.5973 *$ Average Illness Severity $)$ Units: Nurse/Patient

(14) Fatigue Accumulation= Units: 1/Hour

(15) Fatigue Index= $0.0018 * \operatorname{EXP}(2.7726 *$ Workload $)$

Units: $1 /$ Hour

(16) Fatigue Recovery= Fatigue*Recovery Index*(1-"Working or Not?")

Units: $1 /$ Hour

(17) Fractional Rate of Absence= 0.015

Units: $1 /$ Hour

(18) Fractional Rate of Burnout= $0.0002 * \operatorname{EXP}(6.0552 *$ Average Daily Fatigue $)$ Units: $1 /$ Hour

(19) Getting Burnt Out= Healthy*Fractional Rate of Burnout Units: Nurse/Hour

(20) Healthy= INTEG ( Recovering-Getting Burnt Out, 8)

Units: Nurse

(21) Hour of Day= INTEG (

Time Passing with Day Reset, 0)

Units: Hour

(22) Fatigue $=$ INTEG (

Fatigue Accumulation-Fatigue Recovery, $0.01)$

Units: Dmnl 
(23) INITIAL TIME $=0$

Units: Hour

The initial time for the simulation.

(24) NPR Limited by Budget=

$1 / 6$

Units: Nurse/Patient

(25) Medical Errors=

(13.373*"Fraction Burnt-Out") + 1.0947

Units: Errors

(26) Number of Working Days Per Week=

5

Units: Day

(27) Recovering=

Absent/Time Off Work

Units: Nurse/Hour

(28) Recovery Index= 0.03192

Units: $1 /$ Hour

(29) SAVEPER =

TIME STEP

Units: Hour [0,?]

The frequency with which output is stored.

(30) "Shift Length (Scheduled)"= 8

Units: Hour

(31) Taking Time Off=

"Burnt-Out"*Fractional Rate of Absence

Units: Nurse/Hour

(32) Time Off Work=

24

Units: Hour

(33) Time Passing with Day Reset=

IF THEN ELSE((MODULO(Time,(24))=0):AND:(Time>0),-((24)/TIME STEP)+1 , 1 ) Units: Hour/Hour

(34) Time Passing with Week Reset= IF THEN ELSE((MODULO(Time, $(7 * 24))=0)$ :AND:(Time>0),-((7*24)/TIME STEP)+1 , 1 )

Units: Hour/Hour 
(35) TIME STEP $=0.0625$

Units: Hour [0,?]

The time step for the simulation.

(36) Total Nurses on Duty= Absent+"Burnt-Out"+Healthy

Units: Nurse

(37) "Working or Not?"=

IF THEN ELSE((Hour of Day<=("Shift Length (Scheduled)"+"End-of-Shift Overtime"))

:AND:((Day of Week<=(Number of Working Days Per Week*24))), 1, 0 )

Units: Dmnl

(38) Workload=

"Expected NPR (Based on Severity)"/Actual NPR

Units: Dmnl 


\section{Appendix F: Results of Sensitivity Analysis for the Healthcare Model}

Tables A10-A5 list the results of the sensitivity analysis.

Table A10. Sensitivity Analysis results for NPR limited by budget

\begin{tabular}{|c|c|c|c|c|c|c|c|c|}
\hline & \multirow{2}{*}{$\begin{array}{c}\text { Time } \\
\text { (days) }\end{array}$} & \multirow[t]{2}{*}{$1: 6.00$} & \multirow[t]{2}{*}{ 1:5.17 } & \multirow[t]{2}{*}{$1: 4.34$} & \multirow[t]{2}{*}{$1: 3.51$} & \multirow[t]{2}{*}{$1: 2.68$} & $\begin{array}{l}\text { BASE } \\
\text { CASE } \\
\end{array}$ & \multirow[t]{2}{*}{ 1:1.00 } \\
\hline & & & & & & & $1: 2.00$ & \\
\hline \multirow{4}{*}{ 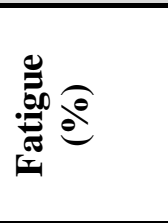 } & 1 Week & $99.9 \%$ & $97.6 \%$ & $85.8 \%$ & $64.1 \%$ & $64.1 \%$ & $64.1 \%$ & $64.1 \%$ \\
\hline & 2 Week & $99.9 \%$ & $97.6 \%$ & $85.8 \%$ & $64.3 \%$ & $64.3 \%$ & $64.3 \%$ & $64.3 \%$ \\
\hline & 3 Week & $99.9 \%$ & $97.6 \%$ & $85.8 \%$ & $64.3 \%$ & $64.3 \%$ & $64.3 \%$ & $64.3 \%$ \\
\hline & 4 Week & $99.9 \%$ & $97.6 \%$ & $85.8 \%$ & $64.3 \%$ & $64.3 \%$ & $64.3 \%$ & $64.3 \%$ \\
\hline \multirow{4}{*}{ 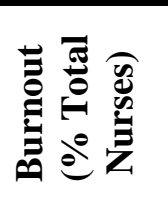 } & 1 Week & $56.8 \%$ & $52.8 \%$ & $37.9 \%$ & $16.3 \%$ & $16.3 \%$ & $16.3 \%$ & $16.3 \%$ \\
\hline & 2 Week & $56.2 \%$ & $52.5 \%$ & $38.9 \%$ & $18.1 \%$ & $18.1 \%$ & $18.1 \%$ & $18.1 \%$ \\
\hline & 3 Week & $56.2 \%$ & $52.5 \%$ & $38.9 \%$ & $18.1 \%$ & $18.1 \%$ & $18.1 \%$ & $18.1 \%$ \\
\hline & 4 Week & $56.2 \%$ & $52.5 \%$ & $38.9 \%$ & $18.1 \%$ & $18.1 \%$ & $18.1 \%$ & $18.1 \%$ \\
\hline \multirow{4}{*}{ 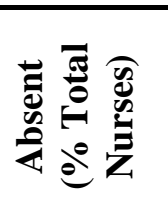 } & 1 Week & $19.4 \%$ & $17.8 \%$ & $12.4 \%$ & $5.3 \%$ & $5.3 \%$ & $5.3 \%$ & $5.3 \%$ \\
\hline & 2 Week & $19.6 \%$ & $18.2 \%$ & $13.2 \%$ & $6.1 \%$ & $6.1 \%$ & $6.1 \%$ & $6.1 \%$ \\
\hline & 3 Week & $19.6 \%$ & $18.2 \%$ & $13.2 \%$ & $6.1 \%$ & $6.1 \%$ & $6.1 \%$ & $6.1 \%$ \\
\hline & 4 Week & $19.6 \%$ & $18.2 \%$ & $13.2 \%$ & $6.1 \%$ & $6.1 \%$ & $6.1 \%$ & $6.1 \%$ \\
\hline \multirow{4}{*}{ 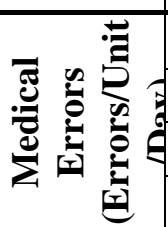 } & 1 Week & 8.7 & 8.2 & 6.2 & 3.3 & 3.3 & 3.3 & 3.3 \\
\hline & 2 Week & 8.6 & 8.1 & 6.3 & 3.5 & 3.5 & 3.5 & 3.5 \\
\hline & 3 Week & 8.6 & 8.1 & 6.3 & 3.5 & 3.5 & 3.5 & 3.5 \\
\hline & 4 Week & 8.6 & 8.1 & 6.3 & 3.5 & 3.5 & 3.5 & 3.5 \\
\hline
\end{tabular}


Table A10. Sensitivity Analysis results for varying Shift Length

\begin{tabular}{|c|c|c|c|c|c|c|c|c|}
\hline & $\begin{array}{c}\text { Time } \\
\text { (days) }\end{array}$ & $4.00 \mathrm{Hr}$ & $5.33 \mathrm{Hr}$ & $6.67 \mathrm{Hr}$ & $\begin{array}{c}\begin{array}{c}\text { BASE } \\
\text { CASE }\end{array} \\
\mathbf{8 . 0 0 ~ H r}\end{array}$ & $9.33 \mathrm{Hr}$ & $\begin{array}{c}10.67 \\
\mathrm{Hr}\end{array}$ & $\begin{array}{c}12.00 \\
\mathrm{Hr}\end{array}$ \\
\hline \multirow{4}{*}{ 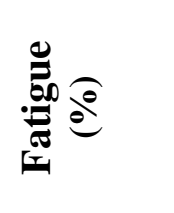 } & $1 \mathrm{Week}$ & $41.4 \%$ & $49.8 \%$ & $57.5 \%$ & $64.1 \%$ & $69.8 \%$ & $75.0 \%$ & $79.5 \%$ \\
\hline & 2 Week & $41.5 \%$ & $49.9 \%$ & $57.6 \%$ & $64.3 \%$ & $70.1 \%$ & $75.2 \%$ & $79.6 \%$ \\
\hline & 3 Week & $41.5 \%$ & $49.9 \%$ & $57.6 \%$ & $64.3 \%$ & $70.1 \%$ & $75.2 \%$ & $79.6 \%$ \\
\hline & 4 Week & $41.5 \%$ & $49.9 \%$ & $57.6 \%$ & $64.3 \%$ & $70.1 \%$ & $75.2 \%$ & $79.6 \%$ \\
\hline \multirow{4}{*}{ 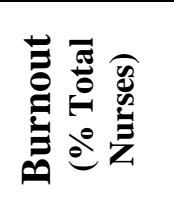 } & 1 Week & $5.8 \%$ & $8.4 \%$ & $12.0 \%$ & $16.3 \%$ & $21.5 \%$ & $27.6 \%$ & $34.1 \%$ \\
\hline & 2 Week & $6.5 \%$ & $9.4 \%$ & $13.3 \%$ & $18.1 \%$ & $23.4 \%$ & $29.4 \%$ & $35.7 \%$ \\
\hline & 3 Week & $6.6 \%$ & $9.5 \%$ & $13.4 \%$ & $18.1 \%$ & $23.5 \%$ & $29.5 \%$ & $35.7 \%$ \\
\hline & 4 Week & $6.6 \%$ & $9.5 \%$ & $13.4 \%$ & $18.1 \%$ & $23.5 \%$ & $29.5 \%$ & $35.7 \%$ \\
\hline \multirow{4}{*}{ 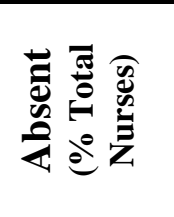 } & 1 Week & $1.9 \%$ & $2.8 \%$ & $3.9 \%$ & $5.3 \%$ & $7.0 \%$ & $8.9 \%$ & $11.0 \%$ \\
\hline & 2 Week & $2.2 \%$ & $3.2 \%$ & $4.5 \%$ & $6.1 \%$ & $7.8 \%$ & $9.8 \%$ & $12.0 \%$ \\
\hline & 3 Week & $2.2 \%$ & $3.2 \%$ & $4.5 \%$ & $6.1 \%$ & $7.9 \%$ & $9.9 \%$ & $12.0 \%$ \\
\hline & 4 Week & $2.2 \%$ & $3.2 \%$ & $4.5 \%$ & $6.1 \%$ & $7.9 \%$ & $9.9 \%$ & $12.0 \%$ \\
\hline \multirow{4}{*}{ 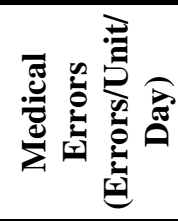 } & 1 Week & 1.9 & 2.2 & 2.7 & 3.3 & 4.0 & 4.8 & 5.6 \\
\hline & 2 Week & 2.0 & 2.4 & 2.9 & 3.5 & 4.2 & 5.0 & 5.9 \\
\hline & 3 Week & 2.0 & 2.4 & 2.9 & 3.5 & 4.2 & 5.0 & 5.9 \\
\hline & 4 Week & 2.0 & 2.4 & 2.9 & 3.5 & 4.2 & 5.0 & 5.9 \\
\hline
\end{tabular}

Table A10. Sensitivity Analysis results for varying Number of Working Days

\begin{tabular}{|c|c|c|c|c|c|c|c|c|}
\hline & $\begin{array}{c}\text { Time } \\
\text { (days) }\end{array}$ & $1 \mathrm{D}$ & $2 \mathrm{D}$ & $3 \mathrm{D}$ & $4 D$ & $\begin{array}{c}\begin{array}{c}\text { BASE } \\
\text { CASE }\end{array} \\
5 \mathrm{D}\end{array}$ & $6 \mathrm{D}$ & $7 \mathrm{D}$ \\
\hline \multirow{4}{*}{ 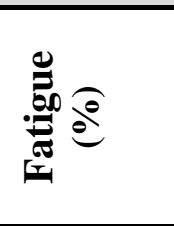 } & 1 Week & $41.8 \%$ & $56.2 \%$ & $61.4 \%$ & $63.3 \%$ & $64.1 \%$ & $64.4 \%$ & $64.6 \%$ \\
\hline & 2 Week & $41.3 \%$ & $56.1 \%$ & $61.5 \%$ & $63.5 \%$ & $64.3 \%$ & $64.6 \%$ & $64.6 \%$ \\
\hline & 3 Week & $41.3 \%$ & $56.1 \%$ & $61.5 \%$ & $63.5 \%$ & $64.3 \%$ & $64.6 \%$ & $64.6 \%$ \\
\hline & 4 Week & $41.3 \%$ & $56.1 \%$ & $61.5 \%$ & $63.5 \%$ & $64.3 \%$ & $64.6 \%$ & $64.6 \%$ \\
\hline \multirow{4}{*}{ 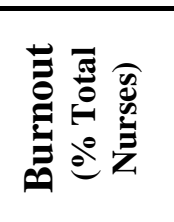 } & 1 Week & $2.6 \%$ & $5.8 \%$ & $9.8 \%$ & $13.5 \%$ & $16.3 \%$ & $18.4 \%$ & $20.6 \%$ \\
\hline & 2 Week & $3.1 \%$ & $6.6 \%$ & $10.9 \%$ & $14.8 \%$ & $18.1 \%$ & $20.2 \%$ & $21.8 \%$ \\
\hline & 3 Week & $3.1 \%$ & $6.6 \%$ & $11.0 \%$ & $14.9 \%$ & $18.1 \%$ & $20.3 \%$ & $21.9 \%$ \\
\hline & 4 Week & $3.1 \%$ & $6.6 \%$ & $11.0 \%$ & $14.9 \%$ & $18.1 \%$ & $20.3 \%$ & $21.9 \%$ \\
\hline \multirow{4}{*}{ 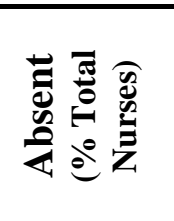 } & 1 Week & $0.8 \%$ & $1.8 \%$ & $3.1 \%$ & $4.3 \%$ & $5.3 \%$ & $6.1 \%$ & $7.0 \%$ \\
\hline & 2 Week & $1.0 \%$ & $2.1 \%$ & $3.5 \%$ & $4.8 \%$ & $6.1 \%$ & $7.0 \%$ & $7.8 \%$ \\
\hline & 3 Week & $1.0 \%$ & $2.1 \%$ & $3.5 \%$ & $4.9 \%$ & $6.1 \%$ & $7.0 \%$ & $7.8 \%$ \\
\hline & 4 Week & $1.0 \%$ & $2.1 \%$ & $3.5 \%$ & $4.9 \%$ & $6.1 \%$ & $7.0 \%$ & $7.8 \%$ \\
\hline \multirow{4}{*}{ 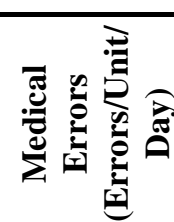 } & 1 Week & 1.4 & 1.9 & 2.4 & 2.9 & 3.3 & 3.6 & 3.8 \\
\hline & 2 Week & 1.5 & 2.0 & 2.6 & 3.1 & 3.5 & 3.8 & 4.0 \\
\hline & 3 Week & 1.5 & 2.0 & 2.6 & 3.1 & 3.5 & 3.8 & 4.0 \\
\hline & 4 Week & 1.5 & 2.0 & 2.6 & 3.1 & 3.5 & 3.8 & 4.0 \\
\hline
\end{tabular}


Table A10. Sensitivity Analysis results for varying Time Off Work

\begin{tabular}{|c|c|c|c|c|c|c|c|c|}
\hline & $\begin{array}{c}\text { Time } \\
\text { (days) }\end{array}$ & $\begin{array}{c}\begin{array}{l}\text { BASE } \\
\text { CASE }\end{array} \\
1 \mathrm{D}\end{array}$ & 4D & $8 \mathrm{D}$ & 12 D & $16 \mathrm{D}$ & $20 \mathrm{D}$ & 24 D \\
\hline \multirow{4}{*}{ 苟 } & 1 Week & $64.1 \%$ & $64.1 \%$ & $64.1 \%$ & $64.1 \%$ & $64.1 \%$ & $64.1 \%$ & $64.1 \%$ \\
\hline & 2 Week & $64.3 \%$ & $64.3 \%$ & $64.3 \%$ & $64.3 \%$ & $64.3 \%$ & $64.3 \%$ & $64.3 \%$ \\
\hline & 3 Week & $64.3 \%$ & $64.3 \%$ & $64.2 \%$ & $64.2 \%$ & $64.2 \%$ & $64.0 \%$ & $64.0 \%$ \\
\hline & 4 Week & $64.3 \%$ & $64.3 \%$ & $64.2 \%$ & $64.2 \%$ & $64.0 \%$ & $64.0 \%$ & $64.0 \%$ \\
\hline \multirow{4}{*}{ 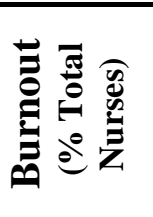 } & 1 Week & $16.3 \%$ & $15.9 \%$ & $15.8 \%$ & $15.7 \%$ & $15.7 \%$ & $15.7 \%$ & $15.7 \%$ \\
\hline & 2 Week & $18.1 \%$ & $16.1 \%$ & $14.9 \%$ & $14.2 \%$ & $13.9 \%$ & $13.6 \%$ & $13.5 \%$ \\
\hline & 3 Week & $18.1 \%$ & $15.8 \%$ & $13.8 \%$ & $12.6 \%$ & $11.8 \%$ & $11.2 \%$ & $10.8 \%$ \\
\hline & 4 Week & $18.1 \%$ & $15.8 \%$ & $13.5 \%$ & $11.9 \%$ & $10.9 \%$ & $10.1 \%$ & $9.5 \%$ \\
\hline \multirow{4}{*}{ 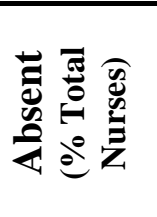 } & 1 Week & $5.3 \%$ & $13.6 \%$ & $18.3 \%$ & $20.4 \%$ & $21.6 \%$ & $22.3 \%$ & $22.8 \%$ \\
\hline & 2 Week & $6.1 \%$ & $18.1 \%$ & $27.3 \%$ & $32.7 \%$ & $36.3 \%$ & $38.8 \%$ & $40.6 \%$ \\
\hline & 3 Week & $6.1 \%$ & $18.7 \%$ & $30.0 \%$ & $37.3 \%$ & $42.3 \%$ & $46.0 \%$ & $48.9 \%$ \\
\hline & 4 Week & $6.1 \%$ & $18.7 \%$ & $30.6 \%$ & $38.9 \%$ & $44.8 \%$ & $49.3 \%$ & $52.7 \%$ \\
\hline \multirow{4}{*}{ 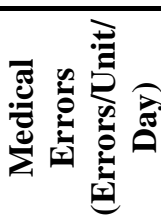 } & 1 Week & 3.3 & 3.2 & 3.2 & 3.2 & 3.2 & 3.2 & 3.2 \\
\hline & 2 Week & 3.5 & 3.2 & 3.1 & 3.0 & 2.9 & 2.9 & 2.9 \\
\hline & 3 Week & 3.5 & 3.2 & 2.9 & 2.8 & 2.7 & 2.6 & 2.5 \\
\hline & 4 Week & 3.5 & 3.2 & 2.9 & 2.7 & 2.5 & 2.4 & 2.4 \\
\hline
\end{tabular}

Table A10. Sensitivity Analysis results for varying Fractional Rate of Absence

\begin{tabular}{|c|c|c|c|c|c|c|c|c|}
\hline & \multirow{2}{*}{$\begin{array}{l}\text { Time } \\
\text { (days) }\end{array}$} & \multirow{2}{*}{$\begin{array}{c}\mathbf{0 . 0 5} \\
(\% / \mathbf{Y r})\end{array}$} & \multirow{2}{*}{$\begin{array}{c}\mathbf{0 . 8 8} \\
(\% / \mathrm{Yr})\end{array}$} & $\begin{array}{l}\text { BASE } \\
\text { CASE } \\
\end{array}$ & \multirow{2}{*}{$\begin{array}{c}2.53 \\
(\% / \mathbf{Y r})\end{array}$} & \multirow{2}{*}{$\begin{array}{c}3.35 \\
(\% / \mathrm{Yr})\end{array}$} & \multirow{2}{*}{$\begin{array}{c}4.18 \\
(\% / \mathbf{Y r})\end{array}$} & \multirow{2}{*}{$\begin{array}{c}5.00 \\
(\% / Y \mathbf{r})\end{array}$} \\
\hline & & & & $\begin{array}{c}1.50 \\
(\% / \mathrm{Yr})\end{array}$ & & & & \\
\hline \multirow{4}{*}{ 氙 } & 1 Week & $64.1 \%$ & $64.1 \%$ & $64.1 \%$ & $64.0 \%$ & $64.0 \%$ & $64.0 \%$ & $64.0 \%$ \\
\hline & 2 Week & $64.7 \%$ & $64.3 \%$ & $64.3 \%$ & $64.2 \%$ & $64.0 \%$ & $64.0 \%$ & $64.0 \%$ \\
\hline & 3 Week & $65.1 \%$ & $64.3 \%$ & $64.3 \%$ & $64.2 \%$ & $64.0 \%$ & $64.0 \%$ & $64.0 \%$ \\
\hline & 4 Week & $65.3 \%$ & $64.3 \%$ & $64.3 \%$ & $64.2 \%$ & $64.0 \%$ & $64.0 \%$ & $64.0 \%$ \\
\hline \multirow{4}{*}{ 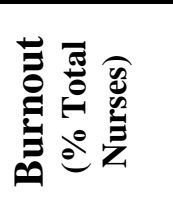 } & 1 Week & $32.9 \%$ & $20.6 \%$ & $16.3 \%$ & $12.0 \%$ & $9.9 \%$ & $8.3 \%$ & $7.2 \%$ \\
\hline & 2 Week & $53.7 \%$ & $25.1 \%$ & $18.1 \%$ & $12.5 \%$ & $10.1 \%$ & $8.4 \%$ & $7.3 \%$ \\
\hline & 3 Week & $66.0 \%$ & $25.7 \%$ & $18.1 \%$ & $12.5 \%$ & $10.1 \%$ & $8.4 \%$ & $7.3 \%$ \\
\hline & 4 Week & $73.6 \%$ & $25.8 \%$ & $18.1 \%$ & $12.5 \%$ & $10.1 \%$ & $8.4 \%$ & $7.3 \%$ \\
\hline \multirow{4}{*}{ 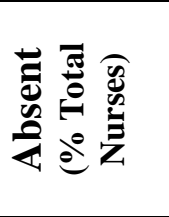 } & 1 Week & $0.4 \%$ & $4.0 \%$ & $5.3 \%$ & $6.5 \%$ & $7.1 \%$ & $7.4 \%$ & $7.7 \%$ \\
\hline & 2 Week & $0.6 \%$ & $5.0 \%$ & $6.1 \%$ & $6.9 \%$ & $7.4 \%$ & $7.7 \%$ & $7.9 \%$ \\
\hline & 3 Week & $0.8 \%$ & $5.1 \%$ & $6.1 \%$ & $6.9 \%$ & $7.4 \%$ & $7.7 \%$ & $7.9 \%$ \\
\hline & 4 Week & $0.9 \%$ & $5.2 \%$ & $6.1 \%$ & $6.9 \%$ & $7.4 \%$ & $7.7 \%$ & $7.9 \%$ \\
\hline \multirow{4}{*}{ 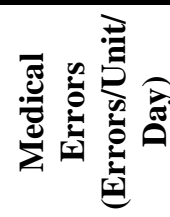 } & $1 \mathrm{Week}$ & 5.5 & 3.8 & 3.3 & 2.7 & 2.4 & 2.2 & 2.1 \\
\hline & 2 Week & 8.3 & 4.5 & 3.5 & 2.8 & 2.4 & 2.2 & 2.1 \\
\hline & 3 Week & 9.9 & 4.5 & 3.5 & 2.8 & 2.4 & 2.2 & 2.1 \\
\hline & 4 Week & 10.9 & 4.5 & 3.5 & 2.8 & 2.4 & 2.2 & 2.1 \\
\hline
\end{tabular}




\section{References}

Aiken, L. H., Clarke, S., Sloane, D., Sochalski, J., \& Silber, J. (2002). Hospital nurse staffing and patient mortality, nurse burnout, and job dissatisfaction. JAMA, 288(16), 1987-1993. http://doi.org/10.1001/jama.288.16.1987

Ajimotokan, H. A. (2011). Towards a rigorous equation-oriented technique for sustainable manufacturing safety programme. Journal of Manufacturing Technology Management, 23(1), 76-86. http://doi.org/10.1108/17410381211196294

AWCBC. (2014). 2014 Injury Statistics Across Canada.

Bae, S.-H. (2012). Nursing overtime: why, how much, and under what working conditions? Nursing Economic\$, 30(2), 60-71.

Baernholdt, M., Cox, K., \& Scully, K. (2010). Using Clinical Data to Capture Nurse Workload: Implications for Staffing and Safety. CIN: Computers, Informatics, Nursing, 28(4), 229234.

Báez, Y. A., Rodríguez, M. A., Limón, J., \& Tlapa, D. A. (2014). Model of human reliability for manual workers in assembly lines. 2014 IEEE International Conference on Industrial Engineering and Engineering Management. http://doi.org/10.1109/IEEM.2014.7058878

Barker, L. M., \& Nussbaum, M. A. (2011). Fatigue, performance and the work environment: A survey of registered nurses. Journal of Advanced Nursing, 67(6), 1370-1382. http://doi.org/10.1111/j.1365-2648.2010.05597.x

Bernard, B. P., \& Putz-Anderson, V. (1997). Musculoskeletal disorders and workplace factors: a critical review of epidemiologic evidence for work-related musculoskeletal disorders of the neck, upper extremity, and low back. U.S. Department of Health and Human Services, Public Health Service, Centers for Disease Control and Prevention, National Institute for Occupational Safety and Health U6 - ctx_ver=Z39.882004\&ctx_enc=info\%3Aofi\%2Fenc\%3AUTF-8\&rfr_id=info\%3Asid\%2Fsummon.s.

Berry, L., \& Curry, P. (2012). Nursing Workload and Patient Care - Understanding the Value of Nurses, the Effects of Excessive Workload, and How Nurse-Patient Ratios and Dynamic Staffing Models Can Help. The Canadian Federation of Nurses Unions.

Beswick, S., Hill, P. D., \& Anderson, M. A. (2010). Comparison of nurse workload approaches. Journal of Nursing Management, 18(5), 592-598. http://doi.org/10.1111/j.13652834.2010.01124.x

Blumenfeld, D. E., \& Inman, R. R. (2009). Impact of Absenteeism on Assembly Line Quality and Throughput. Production and Operations Management, 18(3), 333-343. http://doi.org/10.1111/j.1937-5956.2009.01019.x

Borshchev, A. (2013). The Big Book of Simulation Modeling.

Boyle, T. (2015, October). Nursing cuts hurting hospital care in Ontario, union says. TORONTO STAR. Toronto. Retrieved from https://www.thestar.com/news/queenspark/2015/10/22/nursing-cuts-hurting-hospital-carein-ontario-union-says.html

Bureau of Labor Statistics. (2014). TABLE R8. Incidence rates for nonfatal occupational injuries and illnesses involving days away from work per 10,000 full-time workers by industry and selected events or exposures leading to injury or illness, private industry, 2014. Retrieved from http://www.bls.gov/iif/oshwc/osh/case/ostb4374.pdf

Cañadas-De la Fuente, G. A., Vargas, C., San Luis, C., García, I., Cañadas, G. R., \& De la 
Fuente, E. I. (2015). Risk factors and prevalence of burnout syndrome in the nursing profession. International Journal of Nursing Studies, 52(1), 240-249.

http://doi.org/10.1016/j.ijnurstu.2014.07.001

Canadian Nurses Association. (2010). Nurse Fatigue and Patient Safety Research Report.

Canadian Nurses Association. (2013). Tested Solutions for Eliminating Canada's Registered Nurse Shortage. Retrieved from https://www.cna-aiic.ca/ /media/cna/page-content/pdfen/rn_highlights_e.pdf

Carayon, P., Wetterneck, T. B., Rivera-Rodriguez, A. J., Hundt, A. S., Hoonakker, P., Holden, R., \& Gurses, A. P. (2014). Human factors systems approach to healthcare quality and patient safety. Applied Ergonomics, 45(1), 14-25. http://doi.org/10.1016/j.apergo.2013.04.023

Cassidy, J. D., Côté, P., Carroll, L. J., \& Kristman, V. (2005). Incidence and course of low back pain episodes in the general population. Spine, 30(24), 2817-2823. http://doi.org/10.1097/01.brs.0000190448.69091.53

Chapman, R. J. (1998). The role of system dynamics in understanding the impact of changes to key project personnel on design production within construction projects. International Journal of Project Management, 16(4), 235-247. http://doi.org/10.1016/S02637863(97)00043-4

Chiu, Y.-S. P., Chen, K.-K., Cheng, F.-T., \& Wu, M.-F. (2010). Optimization of the finite production rate model with scrap, rework and stochastic machine breakdown. Computers and Mathematics with Applications. JOUR, Elsevier Ltd. http://doi.org/10.1016/j.camwa.2009.10.001

Cimiotti, J. P., Aiken, L. H., Sloane, D. M., \& Wu, E. S. (2012). Nurse staffing, burnout, and health care-associated infection. American Journal of Infection Control, 40(6), 486-490. http://doi.org/10.1016/j.ajic.2012.02.029

Cooke, D., Yang, H., Curry, G., Rogers, P., Rohleder, T., Lee, R., \& Strong, D. (2007). Introducing System Dynamics Modeling to Health Care in Alberta. Proceedings of the 2007 System Dynamics Conference, (July), 1-17.

Dabboussy, M., \& Uppal, S. (2012). Work absences in 2011. Statistics Canada.

Daniel, C. (1994). Factorial One-Factor-at-a-Time Experiments. The American Statistician, 48(2), 132-135. http://doi.org/10.1080/00031305.1994.10476042

Daynard, D., Yassi, A., Cooper, J. E., Tate, R., Norman, R. W., \& Wells, R. P. (2001). Biomechanical analysis of peak and cumulative spinal loads during simulated patienthandling activities: a substudy of a randomized controlled trial to prevent lift and transfer injury of health care workers. Applied Ergonomics, 32(3), 199-214. http://doi.org/10.1016/s0003-6870(00)00070-3

Di Pasquale, V., Miranda, S., Iannone, R., \& Riemma, S. (2015). A Simulator for Human Error Probability Analysis (SHERPA). Reliability Engineering \& System Safety, 139, 17-32. http://doi.org/10.1016/j.ress.2015.02.003

Dode, P., Greig, M., Zolfaghari, S., \& Neumann, W. P. (2016). Integrating human factors into discrete event simulation: a proactive approach to simultaneously design for system performance and employees' well being. International Journal of Production Research, 54(10), 3105. http://doi.org/10.1080/00207543.2016.1166287

Duffield, C., Diers, D., O’Brien-Pallas, L., Aisbett, C., Roche, M., King, M., \& Aisbett, K. (2011). Nursing staffing, nursing workload, the work environment and patient outcomes. Applied Nursing Research, 24(4), 244-255. http://doi.org/10.1016/j.apnr.2009.12.004 
Duffield, C., \& O'Brien-Pallas, L. (2003). The causes and consequences of nursing shortages: a helicopter view of the research. Australian Health Review : A Publication of the Australian Hospital Association, 26(1), 186-193. http://doi.org/10.1071/AH030186

Dul, J., Bruder, R., Buckle, P., Carayon, P., Falzon, P., Marras, W. S., ... van der Doelen, B. (2012). A strategy for human factors/ergonomics: developing the discipline and profession . Ergonomics . England : Taylor \& Francis . http://doi.org/10.1080/00140139.2012.661087

Dul, J., \& Neumann, W. P. (2009). Ergonomics contributions to company strategies. Applied Ergonomics, 40(4), 745-752. http://doi.org/10.1016/j.apergo.2008.07.001

Eklund, J. A. E. (1995). Relationships between ergonomics and quality in assembly work. Applied Ergonomics, 26(1), 15-20. http://doi.org/10.1016/0003-6870(95)95747-N

Eklund, J. A. E. (1997). Ergonomics, quality and continuous improvement--conceptual and empirical relationships in an industrial context. Ergonomics, 40(10), 982.

Elkosantini, S., \& Gien, D. (2009). Integration of human behavioural aspects in a dynamic model for a manufacturing system. International Journal of Production Research, 47(10), 26012623. http://doi.org/10.1080/00207540701663490

Faezipour, M., \& Ferreira, S. (2013). A System Dynamics Perspective of Patient Satisfaction in Healthcare. Procedia Computer Science, 16, 148-156. http://doi.org/10.1016/j.procs.2013.01.016

Falck, A. C., Örtengren, R., \& Högberg, D. (2010). The impact of poor assembly ergonomics on product quality: A cost-benefit analysis in car manufacturing. Human Factors and Ergonomics in Manufacturing, 20(1), 24.

Falck, A. C., \& Rosenqvist, M. (2014). A model for calculation of the costs of poor assembly ergonomics (part 1). International Journal of Industrial Ergonomics, 44(1), 140-147. http://doi.org/10.1016/j.ergon.2013.11.013

Garg, A., Boda, S., Hegmann, K., Moore, J., Kapellusch, J., Bhoyar, P., ... Malloy, E. (2014). The NIOSH Lifting Equation and Low-Back Pain, Part 1 Association With Low-Back Pain in the BackWorks Prospective Cohort Study. Human Factors: The Journal of the Human Factors and Ergonomics Society, 56(1), 6-28. http://doi.org/10.1177/0018720813491284

Garrett, C. (2008). The Effect of Nurse Staffing Patterns on Medical Errors and Nurse Burnout. AORN Journal, 87(6). http://doi.org/10.1016/j.aorn.2008.01.022

Givi, Z. S., Jaber, M. Y., \& Neumann, W. P. (2015). Modelling worker reliability with learning and fatigue. Applied Mathematical Modelling, 39(17), 5186-5199. http://doi.org/10.1016/j.apm.2015.03.038

Greenglass, E. R., Burke, R. J., \& Fiksenbaum, L. (2001). Workload and burnout in nurses. Journal of Community and Applied Social Psychology, 11(3), 211-215. http://doi.org/10.1002/casp.614

Grinspun, D., Harripaul-Yhap, A., Jarvi, K., \& Lenartowych, T. (2016). Mind the Safety Gap in Healthcare System Transformation: Reclaiming the Role of the RN. Retrieved from http://rnao.ca/sites/rnao-ca/files/HR_REPORT_May11.pdf

Grosse, E. H., \& Glock, C. H. (2015). The effect of worker learning on manual order picking processes. International Journal of Production Economics, 170, 882-890. http://doi.org/10.1016/j.ijpe.2014.12.018

Grosse, E. H., Glock, C. H., \& Jaber, M. Y. (2013). The effect of worker learning and forgetting on storage reassignment decisions in order picking systems. Computers and Industrial Engineering, 66(4), 653-662. http://doi.org/10.1016/j.cie.2013.09.013

Han, S., Saba, F., Lee, S., Mohamed, Y., \& Peña-Mora, F. (2014). Toward an understanding of 
the impact of production pressure on safety performance in construction operations. Accident; Analysis and Prevention, 68, 106-116. http://doi.org/10.1016/j.aap.2013.10.007

Hansson, G. Å., Balogh, I., Ohlsson, K., Granqvist, L., Nordander, C., Arvidsson, I., ... Skerfving, S. (2010). Physical workload in various types of work: Part II. Neck, shoulder and upper arm. International Journal of Industrial Ergonomics, 40(3), 267-281. http://doi.org/10.1016/j.ergon.2009.11.002

HealthForceOntario. (2016). Nursing Roles. Retrieved from http://www.healthforceontario.ca/en/Home/Nurses/Training_\%7C_Practising_In_Ontario/N ursing_Roles

Helander, M. (2006). A guide to human factors and ergonomics. CRC Taylor \& Francis.

Hirsch, G. B., \& Homer, J. (2004). Modeling the Dynamics of Health Care Services for Improved Chronic Illness Management. 22nd International Conference of the System Dynamics Society, 2004, 1-23.

Holden, R., Alper, S. J., Escoto, K. H., Kaushal, R., Murkowski, K., Patel, N., ... Karsh, B.-T. (2007). Nursing Workload and its Effect on Patient and Employee Safety. Proceedings of the Human Factors and Ergonomics Society Annual Meeting, 51(11), 760-764. http://doi.org/10.1177/154193120705101133

Hoy, D., Brooks, P., Blyth, F., \& Buchbinder, R. (2010). The Epidemiology of low back pain. Best Practice and Research: Clinical Rheumatology. http://doi.org/10.1016/j.berh.2010.10.002

IEA. (2016). Definition and Domains of Ergonomics. Retrieved August 17, 2016, from http://www.iea.cc/whats/index.html

Infrastructure Health and Safety Organization. (n.d.). Musculoskeletal Disorders \& Ergonomics. Retrieved August 18, 2016, from http://www.ihsa.ca/msd

Ingelgård, A., \& Norrgren, F. (2001). Effects of change strategy and top-management involvement on quality of working life and economic results. International Journal of Industrial Ergonomics, 27(2), 93-105. http://doi.org/10.1016/S0169-8141(00)00041-X

Inoue, G., Miyagi, M., Uchida, K., Ishikawa, T., Kamoda, H., Eguchi, Y., ... Ohtori, S. (2014). The prevalence and characteristics of low back pain among sitting workers in a Japanese manufacturing company. Journal of Orthopaedic Science, 20(1), 23-30. http://doi.org/10.1007/s00776-014-0644-X

Jaber, M. Y., Givi, Z. S., \& Neumann, W. P. (2013). Incorporating human fatigue and recovery into the learning-forgetting process. Applied Mathematical Modelling, 37(12-13), 72877299. http://doi.org/10.1016/j.apm.2013.02.028

Jacobson Consulting Inc. (2015). Trends in own illness or disability-related absenteeism and overtime among publicly-employed registered nurses: Quick facts. Canadian Federation of Nurses Unions.

Jensen, P. L. (2002). Human factors and ergonomics in the planning of production. International Journal of Industrial Ergonomics, 29(3), 121-131. http://doi.org/10.1016/S01698141(01)00056-7

Johns, G. (2010). Presenteeism in the workplace: A review and research agenda. Journal of Organizational Behavior, 31(4), 519-542. http://doi.org/10.1002/job.630

Kerr, M. S. (1998). A case-control study of biomechanical and psychosocial risk factors for low back pain reported in an occupational setting. ProQuest Dissertations and Theses. University of Toronto (Canada), Ann Arbor.

Khan, M., Jaber, M. Y., \& Ahmad, A.-R. (2014). An integrated supply chain model with errors 
in quality inspection and learning in production. Omega, 42(1), 16-24.

http://doi.org/10.1016/j.omega.2013.02.002

Kiekkas, P., Sakellaropoulos, G. C., Brokalaki, H., Manolis, E., Samios, A., Skartsani, C., \& Baltopoulos, G. I. (2008). Association Between Nursing Workload and Mortality of Intensive Care Unit Patients . Journal of Nursing Scholarship . Malden, USA : Blackwell Publishing Inc . http://doi.org/10.1111/j.1547-5069.2008.00254.x

Kolus, A., Wells, R. P., \& Neumann, W. P. (2014). A framework for describing the relationship between human factors and quality. In Conference: Association of Canadian Ergonomists (ACE) 45th Annual Conference. Montreal.

Konz, S. (1998). Work/rest: Part II - The scientific basis (knowledge base) for the guide. International Journal of Industrial Ergonomics, 22(1-2), 73-99. http://doi.org/10.1016/S0169-8141(97)00069-3

Kumar, S. (2001). Theories of musculoskeletal injury causation. Ergonomics, 44(1), 17-47. http://doi.org/10.1080/00140130120716

Landsbergis, P. A., Cahill, J., \& Schnall, P. (1999). The impact of lean production and related new systems of work organization on worker health. Journal of Occupational Health Psychology, 4(2), 108-130. http://doi.org/10.1037/1076-8998.4.2.108

Lane, D. C., Monefeldt, C., \& Rosenhead, J. (2000). Looking in the wrong place for healthcare improvements: a system dynamics study of an accident and emergency department. Journal of Operational Research Society, 51(5), 518-531. http://doi.org/10.1057/palgrave.jors.2600892

Leigh, J. P. (2011). Economic Burden of Occupational Injury and Illness in the United States. The Milbank Quarterly, 89(4), 728-772. http://doi.org/10.1111/j.1468-0009.2011.00648.x

Lötters, F., Meerding, W. J., \& Burdorf, A. (2005). Reduced productivity after sickness absence due to musculoskeletal disorders and its relation to health outcomes. Scandinavian Journal of Work, Environment and Health, 31(5), 367-374. http://doi.org/10.5271/sjweh.920

Marras, W. S., Ferguson, S. A., Burr, D., Schabo, P., \& Maronitis, A. (2007). Low back pain recurrence in occupational environments. Spine, 32(21), 2387-2397.

Marshall, D. A., Vanderby, S., Frank, C., Enns, E., Kulin, N., Wasylak, T., ... Carter, M. (2013). Simulation modeling with system dynamics (SD) to plan osteoarthritis care delivery in alberta. Osteoarthritis and Cartilage, 21, S167-S168. http://doi.org/10.1016/j.joca.2013.02.358

Martin, D. M. (2015). Nurse Fatigue and Shift Length: A Pilot Study. Nursing Economics, 33(2), $81-87$.

Maslach, C., Jackson, S. E., \& Leiter, M. P. (1997). Maslach Burnout Inventory. In Evaluating Stress: A Book of Resources (pp. 191-218). http://doi.org/10.1017/S0033291798257163

Mateo, R. (2008). The impact of absenteeism on the quality of assembly line production: The importance of a specialization requirement. Human Factors and Ergonomics in Manufacturing, 18(1), 49-69. http://doi.org/10.1002/hfm.20095

McDonald, M., DiBonaventura, M. daCosta, \& Ullman, S. (2011). Musculoskeletal Pain in the Workforce: The Effects of Back, Arthritis, and Fibromyalgia Pain on Quality of Life and Work Productivity. Journal of Occupational and Environmental Medicine, 53(7), 765-770. http://doi.org/10.1097/JOM.0b013e318222af81

Mealer, M., Burnham, E. L., Goode, C. J., Rothbaum, B. O., \& Moss, M. (2009). The prevalence and impact of post traumatic stress disorder and burnout syndrome in nurses. Depression and Anxiety, 26(12), 1118-1126. http://doi.org/10.1002/da.20631 
Michalos, G., Makris, S., \& Chryssolouris, G. (2013). The effect of job rotation during assembly on the quality of final product. CIRP Journal of Manufacturing Science and Technology, 6(3), 187-197.

Morris, A., Ross, W., \& Ulieru, M. (2010). A system dynamics view of stress: Towards humanfactor modeling with computer agents. In Conference Proceedings - IEEE International Conference on Systems, Man and Cybernetics (pp. 4369-4374).

http://doi.org/10.1109/ICSMC.2010.5642412

Myszewski, J. M. (2010). Mathematical model of the occurrence of human error in manufacturing processes. Quality and Reliability Engineering International, 26(8), 845851. http://doi.org/10.1002/qre.1162

Naidu, A. (2009). Factors affecting patient satisfaction and healthcare quality. International Journal of Health Care Quality Assurance, 22(4), 366-381. http://doi.org/10.1108/09526860910964834

National Research Council. (2001). Musculoskeletal disorders in the workplace - low back and upper extremities. Washington DC: National Academy Press.

Neumann, W. P., \& Dul, J. (2010). Human factors: spanning the gap between OM and HRM. International Journal of Operations \& Production Management, 30(9), 923-950. http://doi.org/10.1108/01443571011075056

Neumann, W. P., Ekman, M., \& Winkel, J. (2009). Integrating ergonomics into production system development - The Volvo Powertrain case. Applied Ergonomics, 40(3), 527-537. http://doi.org/10.1016/j.apergo.2008.09.010

Neumann, W. P., Greig, M., Village, J., \& Wells, R. P. (2013). Indicators For Managing Human Centred Manufacturing. In Proceedings of the 11th International Conference on Manufacturing Research (pp. 295-300).

Neumann, W. P., Kolus, A., \& Wells, R. P. (2016). Human Factors in Production System Design and Quality Performance - A Systematic Review. IFAC-PapersOnLine, 49(12), 17211724. http://doi.org/10.1016/j.ifacol.2016.07.830

Neumann, W. P., \& Medbo, P. (2009). Integrating human factors into discrete event simulations of parallel flow strategies. Production Planning \& Control, 20(1), 3-16. http://doi.org/10.1080/09537280802601444

Neumann, W. P., \& Medbo, P. (2016). Simulating operator learning during production ramp-up in parallel vs. serial flow production. International Journal of Production Research, 1-13. http://doi.org/10.1080/00207543.2016.1217362

Neumann, W. P., \& Village, J. (2012). Ergonomics action research II: a framework for integrating HF into work system design. Ergonomics, 55(10), 1140. http://doi.org/10.1080/00140139.2012.706714

Neumann, W. P., Wells, R. P., Norman, R. W., Frank, J., Shannon, H., \& Kerr, M. S. (2001). A posture and load sampling approach to determining low-back pain risk in occupational settings. International Journal of Industrial Ergonomics. JOUR, Elsevier B.V. http://doi.org/10.1016/S0169-8141(00)00038-X

Norman, R. W., Wells, R. P., Neumann, W. P., Frank, J., Shannon, H., \& Kerr, M. S. (1998). A comparison of peak vs cumulative physical work exposure risk factors for the reporting of low back pain in the automotive industry. Clinical Biomechanics, 13(8), 561-573.

OHSCO. (2006). PART 1: MSD Prevention Guideline for Ontario. Retrieved from http://www.wsps.ca/WSPS/media/Site/Resources/Downloads/msd_2006_guideline_ontario. pdf?ext=.pdf 
Oliva, R., \& Sterman, J. D. (2001). Cutting Corners and Working Overtime: Quality Erosion in the Service Industry. Management Science, 47(7), 894-914. http://doi.org/10.1287/mnsc.47.7.894.9807

Orchard, J. W., James, T., Portus, M., Kountouris, A., \& Dennis, R. (2009). Fast bowlers in cricket demonstrate up to 3- to 4-week delay between high workloads and increased risk of injury. The American Journal of Sports Medicine, 37(6), 1186-1192.

http://doi.org/10.1177/0363546509332430

Parker, P. A., \& Kulik, J. A. (1995). Burnout, self- and supervisor-rated job performance, and absenteeism among nurses. Journal of Behavioral Medicine, 18(6), 581-599. http://doi.org/10.1007/BF01857897

Pastrana, J., Marin, M., Helal, M., \& Mendizabal, C. (2010). Enterprise scheduling: Hybrid and hierarchical issues. In Proceedings - Winter Simulation Conference (pp. 3350-3362). http://doi.org/10.1109/WSC.2010.5679026

Perez, J. (2011). Virtual Human Factors Tools for Proactive Ergonomics - Qualitative Exploration and Method Development. Ryerson University.

Perez, J., de Looze, M. P., Bosch, T., \& Neumann, W. P. (2014). Discrete event simulation as an ergonomic tool to predict workload exposures during systems design. International Journal of Industrial Ergonomics, 44(2), 298-306. http://doi.org/10.1016/j.ergon.2013.04.007

Repenning, N. P., \& Sterman, J. D. (2002). Nobody ever gets credit for fixing problems that never happened: Creating and sustaining process improvement. IEEE Engineering Management Review. http://doi.org/10.1109/EMR.2002.1167285

Ribeiro, V. F., Filho, C., Valenti, V. E., Ferreira, M., de Abreu, L., de Carvalho, T., ... Ferreira, C. (2014). Prevalence of burnout syndrome in clinical nurses at a hospital of excellence. International Archives of Medicine, 7(1), 22. http://doi.org/10.1186/1755-7682-7-22

Roelen, C. A. M., Bültmann, U., Groothoff, J., van Rhenen, W., Magerøy, N., Moen, B. E., ... Bjorvatn, B. (2013). Physical and mental fatigue as predictors of sickness absence among Norwegian nurses. Research in Nursing and Health, 36(5), 453-465. http://doi.org/10.1002/nur.21558

Rogers, A., Hwang, W., Scott, L. D., Aiken, L. H., \& Dinges, D. F. (2004). The Working Hours Of Hospital Staff Nurses And Patient Safety. Health Affairs, 23(4), 202-212. http://doi.org/10.1377/hlthaff.23.4.202

Rogers, B., Buckheit, K., \& Ostendorf, J. (2013). Ergonomics and Nursing in Hospital Environments. Workplace Health \& Safety, 61(10), 429-439. http://doi.org/10.3928/21650799-20130916-09

Rose, L. M., Ericsson, M., Glimskar, B., Nordgren, B., \& Ortengren, R. (1992). Computer Applications in Ergonomics, Occupational Safety and Health. (M. Mattila \& W. Karwowski, Eds.). North-Holland: Elsevier Science Publishers.

Rose, L. M., Orrenius, U. E., \& Neumann, W. P. (2013). Work Environment and the Bottom Line: Survey of Tools Relating Work Environment to Business Results. Human Factors and Ergonomics in Manufacturing \& Service Industries, 23(5), 368-381. http://doi.org/10.1002/hfm.20324

Rudolph, J. W., \& Repenning, N. P. (2002). Disaster Dynamics: Understanding the Role of Quantity in Organizational Collapse. Administrative Science Quarterly, 47(1), 1-30. http://doi.org/10.2307/3094889

Schaufeli, W. B., \& Greenglass, E. R. (2001). Introduction to special issue on burnout and health. Psychology \& Health, 16(5), 501-510. http://doi.org/10.1080/08870440108405523 
Scott, L. D., Hofmeister, N., Rogness, N., \& Rogers, A. E. (2010). An interventional approach for patient and nurse safety: a fatigue countermeasures feasibility study. Nurs Res, 59(4), 250-258. http://doi.org/10.1097/NNR.0b013e3181de9116

Seago, J. A. (2002). The California experiment - Alternatives for minimum nurse-to-patient ratios. Journal of Nursing Administration, 32(1), 48-58. http://doi.org/10.1097/00005110200201000-00012

Shanafelt, T. D., Balch, C. M., Bechamps, G., Russell, T., Dyrbye, L., Satele, D., ... Freischlag, J. (2010). Burnout and medical errors among American surgeons. Annals of Surgery, 251(6), 995-1000. http://doi.org/10.1097/SLA.0b013e3181bfdab3

Shields, M., \& Wilkins, K. (2006). Findings from the 2005 National Survey of the Work and Health of Nurses. Statistics.

Shin, M., Lee, H.-S., Park, M., Moon, M., \& Han, S. (2014). A system dynamics approach for modeling construction workers' safety attitudes and behaviors. Accident; Analysis and Prevention, 68, 95-105. http://doi.org/10.1016/j.aap.2013.09.019

Smith-Miller, C. A., Shaw-Kokot, J., Curro, B., \& Jones, C. B. (2014). An Integrative Review: Fatigue Among Nurses in Acute Care Settings. Journal of Nursing Administration, 44(9), 487-494. http://doi.org/10.1097/NNA.0000000000000104

Sobhani, A. (2014). Integrating human factors aspects into performance optimization models of a serial assembly system. Ryerson University.

Statistics Canada. (2015). Injuries at work, 2013. Retrieved August 17, 2016, from http://www.statcan.gc.ca/pub/82-625-x/2015001/article/14148-eng.htm

Sterman, J. D. (2000). Business Dynamics: Systems Thinking and Modeling for a Complex World. http://doi.org/10.1057/palgrave.jors.2601336

Sterman, J. D., Repenning, N. P., \& Kofman, F. (1997). Unanticipated Side Effects of Successful Quality Programs: Exploring a Paradox of Organizational Improvement. Management Science, 43(4), 503-521. http://doi.org/10.1287/mnsc.43.4.503

Tan, K. C., Kannan, V. R., Handfield, R. B., \& Ghosh, S. (2000). Quality, manufacturing strategy, and global competition: An empirical analysis. Benchmarking: An International Journal. http://doi.org/10.1108/14635770010331333

Taylor, E., Hignett, S., \& Joseph, A. (2014). The environment of safe care : considering building design as one facet of safety. Proceedings of the International Conference on Applied Human Factors and Ergonomics, 3(June), 123-127. http://doi.org/10.1177/2327857914031020

Trinkoff, A., Geiger-Brown, J., Brady, B., Lipscomb, J., \& Muntaner, C. (2006). How long and how much are nurses now working? The American Journal of Nursing.

Tucker, A. L., \& Spear, S. J. (2006). Operational failures and interruptions in hospital nursing. Health Services Research, 41(3 I), 643-662. http://doi.org/10.1111/j.14756773.2006.00502.x

Unruh, L., Joseph, L., \& Strickland, M. (2007). Nurse absenteeism and workload: Negative effect on restraint use, incident reports and mortality. Journal of Advanced Nursing, 60(6), 673-681. http://doi.org/10.1111/j.1365-2648.2007.04459.x

Van Bogaert, P., Clarke, S., Willems, R., \& Mondelaers, M. (2013). Nurse practice environment, workload, burnout, job outcomes, and quality of care in psychiatric hospitals: A structural equation model approach. Journal of Advanced Nursing, 69(7), 1515-1524. http://doi.org/10.1111/jan.12010

Vensim PLE Plus. (n.d.). Retrieved from http://vensim.com/ 
Vézina, M., Cloutier, E., Stock, S., Lippel, K., Fortin, É., Delisle, A., ... Prud'homme, P. (2011). Québec Survey on Working and Employment Conditions and Occupational Health and Safety (EQCOTESST).

Vicente, K. (2004). The Human Factor. Random House of Canada.

Wallace, J. E., Lemaire, J. B., \& Ghali, W. A. (2009). Physician wellness: a missing quality indicator. The Lancet. http://doi.org/10.1016/S0140-6736(09)61424-0

Wasiak, R., Kim, J. Y., \& Pransky, G. (2006). Work disability and costs caused by recurrence of low back pain: Longer and more costly than in first episodes. Spine, 31(2), 219-225. http://doi.org/10.1097/01.brs.0000194774.85971.df

Welton, J. M., Zone-Smith, L., \& Bandyopadhyay, D. (2009). Estimating nursing intensity and direct cost using the nurse-patient assignment. Journal of Nursing Administration, 39(6), 276-284. http://doi.org/10.1097/NNA.0b013e3181a72911

Winterton, J. (2004). A conceptual model of labour turnover and retention. Human Resource Development International, 7(3), 371-390. http://doi.org/10.1080/1367886042000201967

Winwood, P. C., Winefield, A. H., \& Lushington, K. (2006). Work-related fatigue and recovery: the contribution of age, domestic responsibilities and shiftwork. Journal of Advanced Nursing, 56(4), 438-49. http://doi.org/10.1111/j.1365-2648.2006.04011.x

Wolf, Z. R., \& Hughes, R. G. (2008). Error Reporting and Disclosure. In Patient Safety and Quality: An Evidence-Based Handbook for Nurses (pp. 333-379).

WorkSafeBC. (2001). Understanding the Risks of Musculoskeletal Injury (MSI): An educational guide for workers on sprains, strains, and other MSIs.

WSIB. (2015). By the Numbers: 2015 WSIB Statistical Report. Retrieved from http://www.wsibstatistics.ca/

Wynne-Jones, G., Cowen, J., Jordan, J. L., Uthman, O., Main, C. J., Glozier, N., \& van der Windt, D. (2014). Absence from work and return to work in people with back pain: a systematic review and meta-analysis. Occupational and Environmental Medicine, 71(6), 448-56. http://doi.org/10.1136/oemed-2013-101571

Zare, M., Croq, M., Hossein- Arabi, F., Brunet, R., \& Roquelaure, Y. (2016). Does Ergonomics Improve Product Quality and Reduce Costs? A Review Article. Human Factors and Ergonomics in Manufacturing \& Service Industries, 26(2), 205-223. http://doi.org/10.1002/hfm.20623

Zboril-Benson, L. R. (2001). Why nurses are calling in sick: the impact of health-care restructuring. Canadian Journal of Nursing Research, 33(4), 89-107. 